\title{
Tocopherols as antioxidants in lipid-based systems: The combination of chemical and physicochemical interactions determines their efficiency
}

\author{
Nathalie Barouh ${ }^{1,2}$ \\ Claire Bourlieu-Lacanal ${ }^{3}$ \\ Maria Cruz Figueroa-Espinoza ${ }^{2}$ \\ Erwann Durand ${ }^{1,2}$ \\ Pierre Villeneuve ${ }^{1,2}$ (D)
}

${ }^{1}$ CIRAD, UMR QUALISUD, Montpellier, France

${ }^{2}$ Qualisud, Univ Montpellier, Avignon

Université, CIRAD, Institut Agro,

Université de La Réunion, Montpellier,

France

${ }^{3}$ INRAE, UMR IATE, Montpellier, France

\begin{abstract}
Lipid oxidation is a major concern in the food, cosmetic, and pharmaceutical sectors. The degradation of unsaturated lipids affects the nutritional, physicochemi$\mathrm{cal}$, and organoleptic properties of products and can lead to off-flavors and to the formation of potentially harmful oxidation compounds. To prevent or slow down lipid oxidation, different antioxidant additives are used alone or in combination to achieve the best possible efficiency with the minimum possible quantities. In manufactured products, that is, heterogeneous systems containing lipids as emulsions or bulk phase, the efficiency of an antioxidant is determined not only by its chemical reactivity, but also by its physical properties and its interaction with other compounds present in the products. The antioxidants most widely used on the industrial scale are probably tocopherols, either as natural extracts or pure synthetic molecules. Considerable research has been conducted on their antioxidant activity, but results regarding their efficiency are contradictory. Here, we review the known mechanisms behind the antioxidant activity of tocopherols and discuss the chemical and physical features that determine their efficacy. We first describe their chemical reactivity linked with the main factors that modulate it between efficient antioxidant capacity and potential prooxidant effects. We then describe their chemical interactions with other molecules (phenolic compounds, metals, vitamin $\mathrm{C}$, carotenes, proteins, and phospholipids) that have potential additive, synergistic, or antagonist effects. Finally, we discuss other physical parameters that influence their activity in complex systems including their specific interactions with surfactants in emulsions and their behavior in the presence of association colloids in bulk oils.
\end{abstract}

\footnotetext{
Nomenclature: AA, Ascorbic acid; $a_{\mathrm{w}}$, Water activity; BDE, Bond dissociation energy; CC, Critical concentration; CI, Criegee intermediate; CMC, Critical micelle concentration; DMPC, Dimyristoylphosphatidylcholine; DOPC, Dioleoylphosphatidylcholine; DOPE,

Dioleoylphosphatidylethanolamine; IP, Inhibition of formation of hydroperoxide; LH, Lipid; LO•, Lipo alkoxyl radical; LOO•, Lipo peroxyl radical; PC, Phosphatidylcholine; PCA, Principal component analysis; PE, Phosphatidylethanolamine; PI, Phosphatidylinositol; PLPC,

1-Palmitoyl-2-lauroyl-sn-glycero-3-phosphocholine; PUFA, Polyunsaturated fatty acid; PV, Peroxide value; RH, Relative humidity; T3, Tocotrienols; TocOH, Tocopherols and tocotrienols; TOH, Tocopherols.
} 


\section{1 | INTRODUCTION}

Preventing lipid oxidation in unsaturated fat-based products is a huge challenge for the agricultural, food, and cosmetics sectors. Lipid deterioration affects the overall quality of products by modifying the nutritional, physicochemical, organoleptic, and sanitary properties of products, causing loss of liposoluble vitamins and unsaturated fatty acids, off-flavors and the formation of harmful chemicals, and so on (Budilarto \& Kamal-Eldin, 2015b).

Lipid oxidation is a multifactorial reaction that is influenced by several physicochemical parameters such as the physical structure of the system (i.e., bulk oil/ homogeneous system vs. emulsion, liposome/ heterogeneous system) such as the partition of molecules within the complex system (location, diffusion in each phase, the presence of others molecules and either activities (antioxidant oxidizable substrates, surfactant, prooxidant) and the physicochemical properties of the global media, $\mathrm{pH}$, ionic strength, and temperature (Decker et al., 2017).

Different techniques can be used to prevent or slow down lipid oxidation. Such techniques act at different levels, for example, during storage and distribution (from raw material to the final product), each step in the transformation process (e.g., the unit operation, intensity, and physicochemical conditions), and formulation with antioxidant additives. Lipid oxidation is caused by oxygen in the presence of initiators (e.g., heat, UV, photosensitizers, transition metal ions, free radicals). It is generally accepted that lipid oxidation takes place via three reaction pathways: (i) nonenzymatic, free radical chain autoxidation, (ii) nonenzymatic and nonradical photooxidation, and (iii) enzymatic oxidation by lipoxygenases. In this review, we focus on autoxidation, which occurs as a free radical mechanism reaction that releases different volatile and nonvolatile molecules (Figure 1). Many studies aim to obtain a deeper knowledge of the complexity of the chemistry of lipid oxidation. For example, Schaich and co-workers (Schaich, 2012, 2020; Schaich et al., 2017) questioned the standard three-stage free radical chain reaction assumed for lipid oxidation (i.e., initiated by $\mathrm{H}$ abstraction and propagated by peroxy radicals) and proposed an integrated alternative pathway. According to these authors, many reactions by peroxyl and alkoxyl radicals can compete with $\mathrm{H}$ abstraction making lipid oxidation a complex interconnected series of competing reaction pathways and not just a simple free radical chain reaction, as it does not always go through the same pathways and produce the same products (radicals $\rightarrow$ hydroperoxides $\rightarrow$ products). The oversimplified free radical chain reaction scheme does not reveal the numerous and complex competing side reactions that occur during lipid oxidation, as a wide range of products are produced simultaneously or at least overlap, rather than a sequence of single reactions or compounds (Schaich et al., 2017).

Similarly, Zeng et al. (2020) proposed an additional pathway where lipid autoxidation is triggered by $\bullet \mathrm{OH}$ addition to the $\mathrm{C}=\mathrm{C}$ bond of the lipid, followed by addition of $\mathrm{O}_{2}$ to produce a $\beta$-hydroxyl peroxyl radical (Figure 1). C-C bond scission of the $\beta$-hydroxyl peroxyl radical produces a Criegee intermediate (CI) and an $\alpha$-hydroxyl alkyl radical, which is then propagated by chain reactions involving CI.

Considerable work has been carried out to identify the best antioxidants or combinations of antioxidants to delay or prevent lipid oxidation and to ensure optimal efficiency using the minimum possible quantities of the antioxidants concerned. The use of synthetic antioxidants such as butylated hydroxyanisole and butylated hydroxytoluene in food and nonfood products dates back to the 1940s. Today, due to the consumer concerns about synthetic molecules as additives that are suspected of having adverse health effects, interest has been growing in natural molecules or extracts with demonstrable antioxidant properties (Ghorbani Gorji et al., 2019; Moure et al., 2001; Shahidi \& Ambigaipalan, 2015).

Many parameters play crucial roles in the behaviors and efficiencies of antioxidants used to combat lipid oxidation. Porter et al. (1989) were among the first authors to show that trying to compare antioxidant behavior either in bulk oils or heterogeneous systems is irrelevant (Porter et al., 1989). They introduced the polar paradox concept, which states that polar antioxidants work best in bulk oils (by placing them at the oil-air interface), whereas nonpolar antioxidants work best in lipid dispersions (by placing them at the oil-water interface) (Figure 2a). To be effective against lipid oxidation, nonpolar antioxidants should be surface active to locate themselves at the lipiddroplet interface, where both lipid hydroperoxides and transition metals can accumulate and come into close proximity (Frankel et al., 1994; Laguerre et al., 2015; Porter et al., 1989; Waraho et al., 2011). However, the polar paradox concept has been the subject of criticism, for example, Zhong and Shahidi (2012) suggested that the polar 

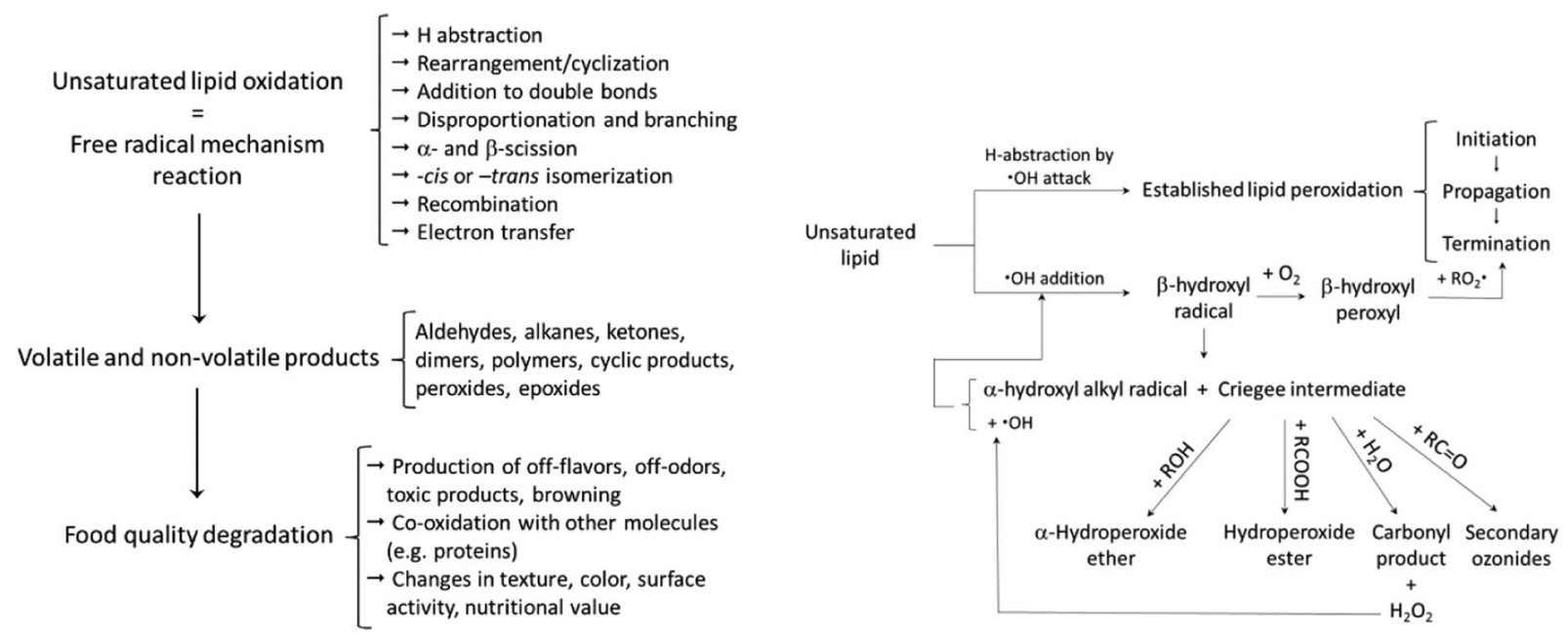

F I G U R E 1 Unsaturated lipid autoxidation (adapted from Schaich, 2012) (left) and Criegee intermediate-driven lipid autoxidation (adapted from Zeng et al., 2020) (right). $\bullet \mathrm{OH}$, hydroxyl, $\mathrm{RO}_{2} \bullet$, peroxy radical; $\mathrm{ROH}$, alcohol; $\mathrm{RCOOH}$, carboxylic acid; $\mathrm{RC}=\mathrm{O}$, aldehyde

paradox is only applicable within specific concentration ranges (Figure 2b) (Zhong \& Shahidi, 2012). The validity of the concept depends on both the polarity and the concentration of the antioxidant, meaning that the most efficient antioxidants are the nonpolar ones at concentrations below their critical concentration (CC) and the polar ones at concentrations above this CC (where the polar paradox is valid). The model proposed by Porter et al., with an oil/air interface in the case of bulk oils, has also been contested. Bulk oils are no longer considered to be a homogeneous liquid but rather a water-in-oil nano-emulsion (Figure 2c), because even when refined, bulk oils can contain very small quantities of water and/or surfactant molecules (mono- and diacylglycerols, phospholipids, sterols, etc.) (Chaiyasit et al., 2007; Chen et al., 2013). These molecules organize themselves into reverse micelles named "association colloids," which, depending on their size, morphology, and chemical composition and the potential partitioning of hydrophilic antioxidants and oxidation products within association colloids, have a significant impact on lipid oxidation (Laguerre et al., 2015). As air is less polar than oil, polar antioxidants tend not to migrate to the air-oil interface more than hydrophobic antioxidants (as suggested by the polar paradox). Thus, to be efficient in bulk oil, hydrophilic antioxidants need to be surface active and to get adsorbed in high amount at the interface of the colloid association, where oxidative reactions may be more prevalent.

Moreover, other studies of emulsified systems showed that the polar paradox theory is probably not entirely valid and that more complex phenomena than only their polarity may occur and influence the behavior of antioxidants.
For example, when testing homologous series of phenolipids (alkyl esters of phenolic acids), Laguerre et al. (2009) showed that hydrophobicity and antioxidant activity in oil-in-water emulsions increase to a certain extent (corresponding to the critical alkyl chain length) beyond which any lengthening of the alkyl chain led to the collapse of antioxidant activity (Figure 2d) (Laguerre et al., 2009). This phenomenon, which the authors called the "cutoff effect," has also been observed in more complex systems (e.g., liposomes, living cells) (Bayrasy et al., 2013) and reported in a wide range of other studies (Berton-Carabin et al., 2014; Budilarto \& Kamal-Eldin, 2015b; Laguerre et al., 2009, 2010).

The results described above underline the major impact of the system itself on lipid oxidation. Autoxidation in heterogeneous lipid dispersions is more complex than autoxidation in bulk oil. In such heterogeneous systems, several factors can influence the oxidation kinetics and behaviors of antioxidants as summarized in Figure 3 (Berton-Carabin et al., 2014; Chaiyasit et al., 2007; Decker et al., 2017; Frankel, 1996; Laguerre et al., 2015, 2017, 2020). These factors include (i) the characteristics of the lipid substrate (class of lipids and degree of unsaturation of the oil), (ii) the presence of other molecules and their water/oil partitioning properties, (iii) the environmental conditions (temperature, oxygen concentration, ultraviolet, potential presence of catalysts (e.g., photosensitizers, metal ions), and (iv) the nature of the emulsion (size, concentration, and physical state of the droplets, the thickness, electrical charge, and composition of the interface layer) (Berton-Carabin et al., 2018). 
(a) Polar paradox
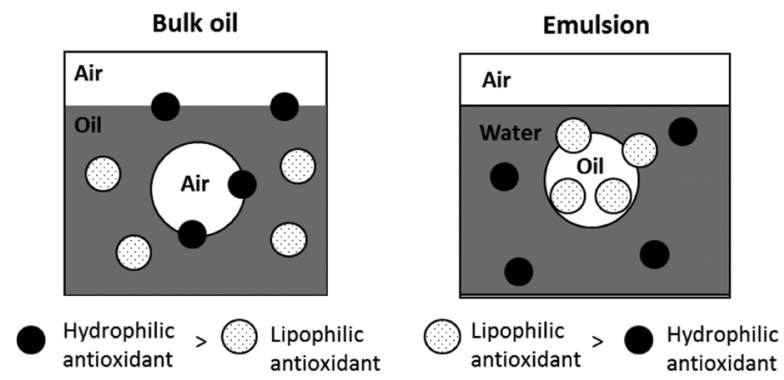

(c) Bulk oil

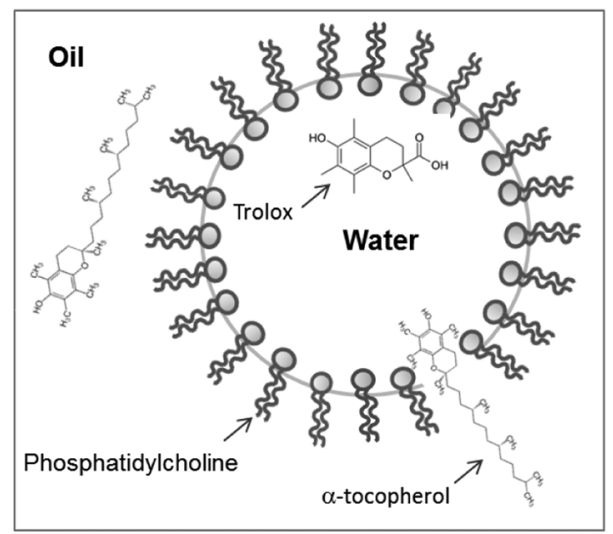

(b) In bulk oil (polarity and concentration effect)

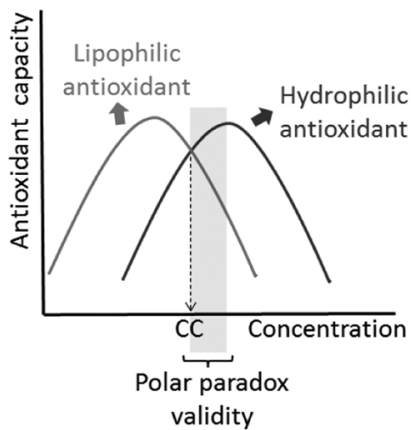

(d) In emulsion (cut-off effect)

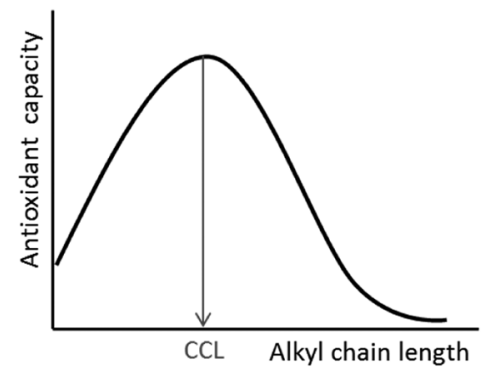

F I G U R E 2 Antioxidant activity and interphase distribution of hydrophilic and lipophilic antioxidants according to (a) Porter et al. (1989) and Frankel (1996), (b) Zhong and Shahidi (2012) (CC, critical concentration), and (c) Chen et al. (2013) and of amphiphilic antioxidants (e.g., phenolipids) according to (d) Laguerre et al. (2009, 2010) and Sørensen et al. (2014) (CCL, critical alkyl chain length). All the figures were adapted from the originals

In the context of combating lipid oxidation in food and cosmetic products, and the difficulty caused by the many chemical and physicochemical parameters involved, the most widely used antioxidants on the industrial scale are probably tocopherols $(\mathrm{TOH})$. Indeed, since their discovery in the last century, $\mathrm{TOH}$ (and their unsaturated derivatives, tocotrienols [T3]) have attracted strong interest among the scientific community. TOH, particularly $\alpha-\mathrm{TOH}$, are regularly used as food additives, either as extracts or pure synthetic molecules in formulae to protect unsaturated lipids. Although considerable research has been conducted on the antioxidant activity of these molecules to elucidate their mechanisms of action, results regarding their efficiencies are contradictory and some authors have even described them as molecules with potential prooxidant activity (Bakır et al., 2013; Frankel et al., 1959; MartinRubio, Sopelana, Ibargoitia, et al., 2018). Here, we review the mechanisms known to be involved in the antioxidant activity of $\mathrm{TOH}$ and $\mathrm{T} 3$ in lipid oxidation and discuss the chemical and physicochemical factors and interactions that determine their efficacy as antioxidants in multiphase systems.

\section{2 | CHEMICAL BEHAVIOR OF TOCOPHEROLS WITH RESPECT TO LIPID OXIDATION (MECHANISMS AND PRODUCTS)}

\section{1 | Tocopherols and tocotrienols: Structure and nomenclature}

In 1922, Evans and Bishops set light on a new molecule while conducting an interventional nutritional assay on animal model (Evans \& Bishop, 1922). They showed that the molecule, which is found in natural foods, was required for reproduction but not for growth. In 1924, similar results were obtained by Sure who named the molecule vitamin $\mathrm{E}$ (Sure, 1924). Later, in 1936, Evans et al. gave vitamin E the scientific name of tocopherol (Evans et al., 1936). The name comes from the Greek tokos and phero meaning "childbirth" and "give birth," respectively, with the ending "-ol" to link it with the presence of the alcohol chemical group. Different forms of tocopherol- $\beta, \gamma$, and $\delta$ tocopherolswere identified in 1938 (Emerson, 1938) and 1947 (Stern et al., 1947) and $\zeta$ tocopherol in 1955 (Green et al., 1955). 


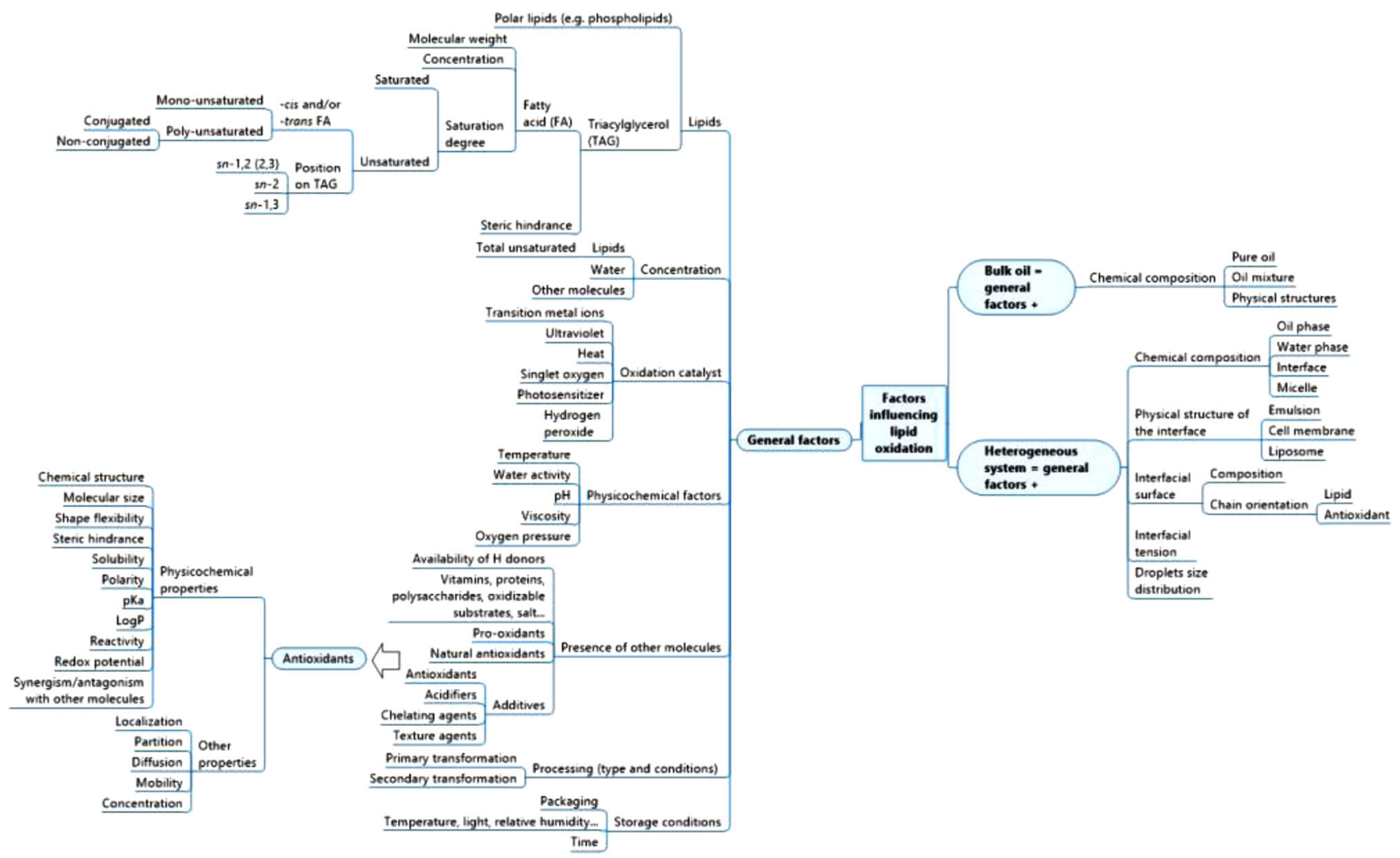

F I G U R E 3 Principal factors influencing lipid oxidation in bulk oil and heterogeneous systems

In 1964, $\zeta$ tocopherol was renamed "tocotrienol" by the team of Pennock who isolated a new "vitamin E compound" from Hevea brasiliensis (Pennock et al., 1964). Since tocopherols and tocotrienols ( $\mathrm{TocOH}$ ) were discovered in the last century, they have continually been subject to the curiosity of the scientific community.

Structurally, TOH and T3 are made of a chromane moiety based on two rings-one phenolic and one heterocyclic-and a phytyl tail (Figure 4). The four tocopherols $(\alpha, \beta, \gamma$, and $\delta)$ have saturated tails and vary only in the positions and number of methyl groups on their phenolic ring: $\alpha, \beta / \gamma$, and $\delta$ forms have three, two, and one methyl groups on the chromanol ring, respectively. The four tocotrienols $(\alpha, \beta, \gamma$, and $\delta$ ) only differ from tocopherols by three double bonds in their phytyl tails. TOH and $\mathrm{T} 3$ are liposoluble compounds. T3 are found in nature under its esterified forms contrary to $\mathrm{TOH}$ that are found as free phenols. The natural forms of TOH have RRR stereochemistry on the three asymmetric carbon atoms of the phytyl chain connected to the chromanol ring. They are synthesized and stored in plant leaves (Mallet et al., 1994; Soll et al., 1980), latex of Hevea brasiliensis (Chow \& Draper, 1970; Whittle et al., 1966), seeds, and fruits (Górnaś et al., 2015; Horvath et al., 2006). Biosynthesis of TocOH forms is triggered by prenylation of homogentisate. $\mathrm{TOH}$ are synthetized from phytyl diphosphate (PDP) as prenyl donor, whereas $\mathrm{T}$ are synthesized from geranylgeranyl diphosphate (DellaPenna, 2005; Mène-Saffrané, 2018; Yang et al., 2010). Originally, the name vitamin E was limited to TOH (mostly dl- $\alpha-\mathrm{TOH}$ ) because of their biological activity, but T3 were later added to this generic term (Sen et al., 2006). However, recently, Azzi (2018) assumed that only $\alpha$-TOH should be considered as vitamin E, because it was the only one to produce significant results in the prevention and the treatment of diseases associated with vitamin E deficiency.

\section{2 | Tocopherol reactivity (antioxidant vs. prooxidant effect)}

As mentioned above, lipid (LH) oxidation is a complex chemical reaction (Figures 1 and 3) involving the formation and propagation of lipid radicals, the uptake of oxygen, and the production of miscellaneous breakdown products, including alcohols, ketones, alkanes, aldehydes, epoxides, and ethers (Frankel, 2005; Schaich, 2005). Its mechanisms have been extensively studied, but are still the subject of debate (Schaich, 2020). The multitude of possible reaction pathways and the large number of products that can be generated oblige us to view this reaction in a simplified way based on free radical chemistry, in which lipid peroxyl (LOO•) and alkoxyl (LO•) radicals undergo a number of 


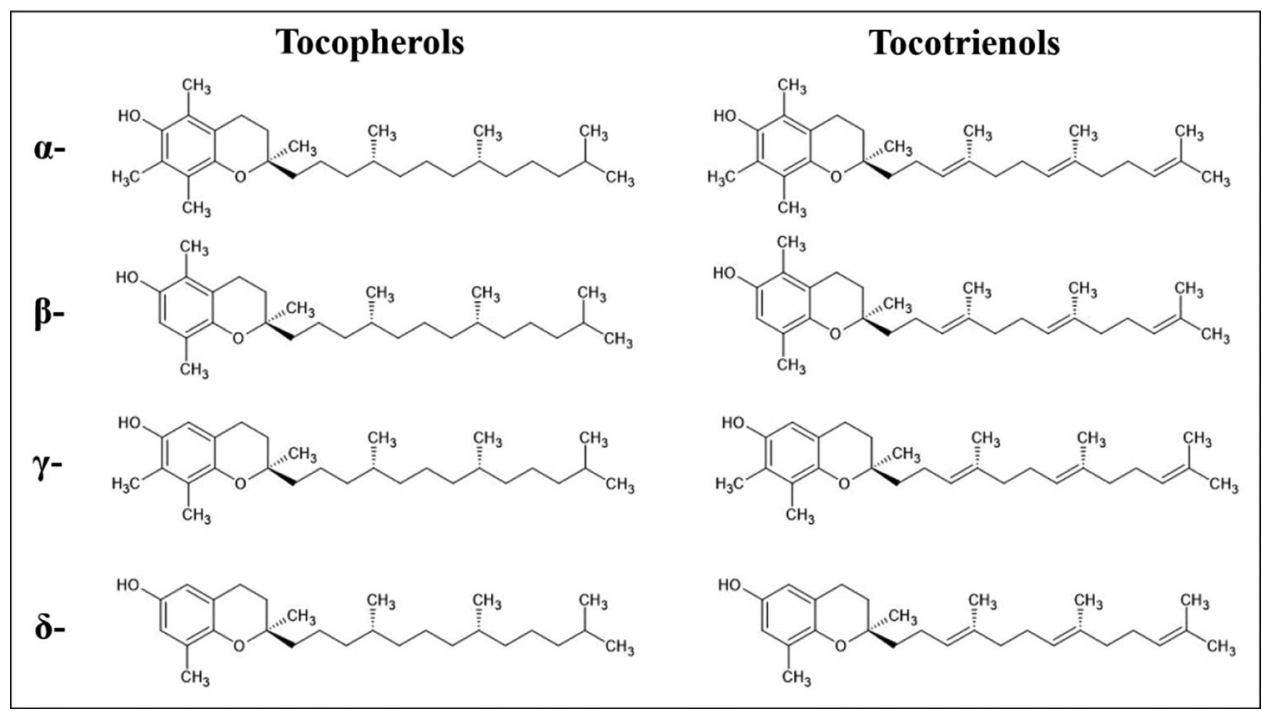

F I G U R E 4 The structure of $\alpha, \beta, \gamma$, and $\delta$ tocopherols and tocotrienols

alternate reactions in addition to and in competition with hydrogen abstraction. In this context, the antioxidant activity of $\mathrm{TocOH}$ is principally due to their ability to donate their phenolic hydrogen. This capacity is closely linked to the bond dissociation energy (BDE) of the phenolic $\mathrm{O}-\mathrm{H}$ bond. The lower the BDE, the stronger the $\mathrm{H}$-atom donor character, and the reaction with free radicals. In chemical structure, the hydrogen-donating power follows the order $\alpha>\beta=\gamma>\delta(+0.273,+0.343,+0.348$, and +0.405 volts) (Kamal-Eldin \& Appelqvist, 1996). Indeed, electronreleasing moieties in ortho- and/or para positions facilitate the homolytic fission of the $\mathrm{O}-\mathrm{H}$ bond, extending the radical lifetime $(\mathrm{O} \bullet)$ and increasing reactivity with other radicals (Lucarini et al., 1994). Accordingly, in terms of pure chemical reactivity, $\alpha$-TocOH (with two ortho-methyl substituents) is generally considered as the most effective antioxidant, followed by $\beta$ - and $\gamma$-TocOH (with one orthomethyl substituent) and $\delta$-TocOH (with no ortho-methyl substituent). The architecture of the chromane moiety thus appears to be the principal parameter that determines the relative antioxidant efficacy of tocopherols. In contrast, the phytyl tail interferes either very little or even not at all in this chemical reactivity. That is why TOH and T3 have been reported to have largely the same reactivity with free radicals in homogeneous systems (Yoshida et al., 2007). Yet, the results of published studies on in vitro antioxidant activities do not necessarily follow these antioxidant rules and ranking. In particular, the effectiveness of the eight $\mathrm{TocOH}$ in lipid dispersion systems or in bulk oil may be unpredictable and rather variable, causing doubts regarding their relative in vitro efficacy (Table 1). Although it is difficult to clearly elucidate the reason for this change in efficacy, we can say that the activity of TocOH as antioxidants is influenced by both its chemical reactivity and its ability to limit other side reactions. Overall, the activity of $\mathrm{TocOH}$ as antioxidants not only depends on their absolute chemical reactivities with free radicals, but also on many other side reactions that are governed by chemical and physical interactions with neighboring molecules. In this section, we focus on how the chemical behavior of $\mathrm{TocOH}$ with respect to lipid oxidation may be affected.

\subsubsection{Interactions of $\mathrm{TocOH}$ in lipid oxidation}

$\mathrm{TocOH}$ can inhibit lipid oxidation in different ways (Figure 5). For instance, they may chelate transition metal ions, thus forming a complex that will prevent the prooxidant activity catalyzed by metals $\left(\mathrm{A}_{1}\right)$ or through physical or chemical quenching reactions with singlet oxygen $\left({ }^{1} \mathrm{O}_{2}\right)$. Physical quenching deactivates the excited state of singlet oxygen $\left({ }^{1} \mathrm{O}_{2}\right)$ into ground state triplet oxygen $\left({ }^{3} \mathrm{O}_{2}\right)$ after energy or charge transfer, for example, the electron transfer mechanism $\left(\mathrm{A}_{2}\right)$ (Thomas \& Foote, 1978; Yamauchi \& Matsushita, 1977). In this case, no consumption of oxygen nor formation of products is observed. The rates of physical quenching of ${ }^{1} \mathrm{O}_{2}$ by TOH were reported to be in the magnitude of $10^{7}$ to $10^{8} \mathrm{M}^{-1} \mathrm{~s}^{-1}$, and in the order $\alpha>\beta>\gamma>\delta$ (Kaiser et al., 1990; Neely et al., 1988). Oxidation of a quencher rather than quenching is observed during the chemical quenching of singlet oxygen. Therefore, this chemical quenching leads rather to the formation of degradation or oxidation products of a quencher than to termination products. TocOH may react irreversibly with ${ }^{1} \mathrm{O}_{2}$ to form a hydroperoxide adduct (TocO-OOH) that decomposes to form secondary products such as hydroperoxy dienone, tocopherol quinone, or tocopherol quinone-epoxide $\left(\mathrm{A}_{3}\right)$ 


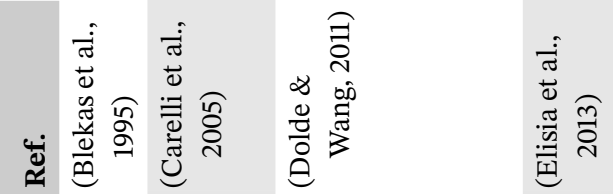

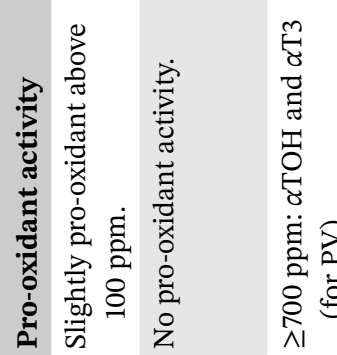

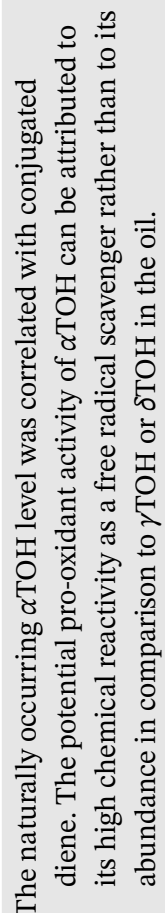

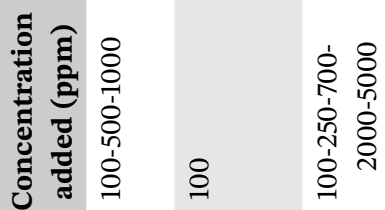

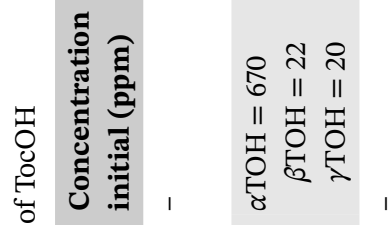

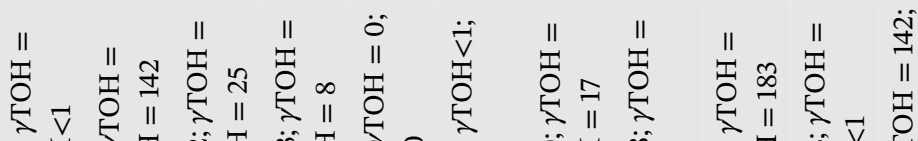

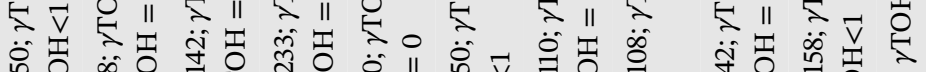

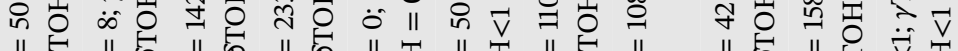

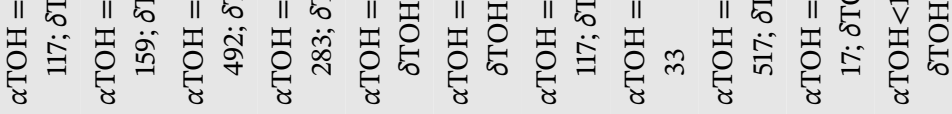

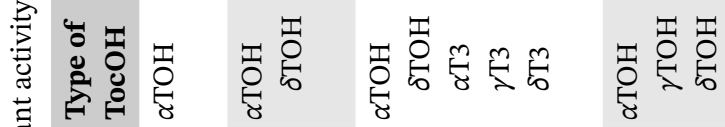

.

要

है

घ추

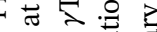

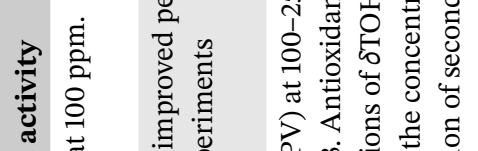

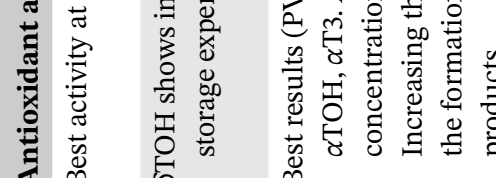

范 


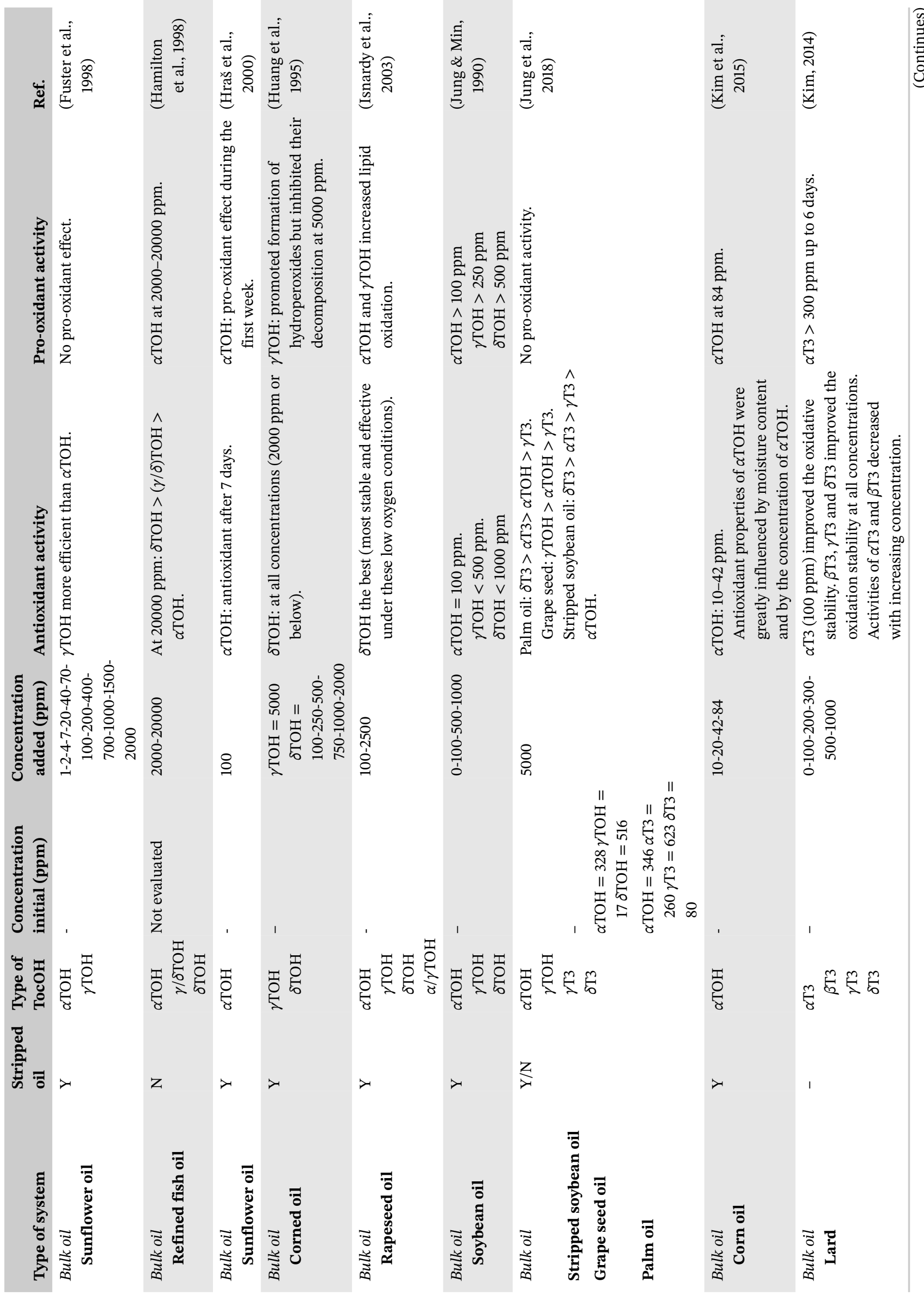




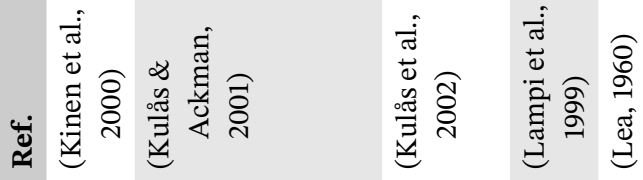
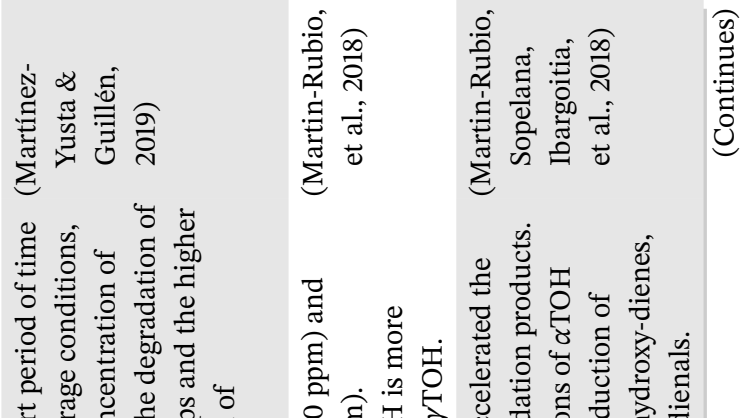

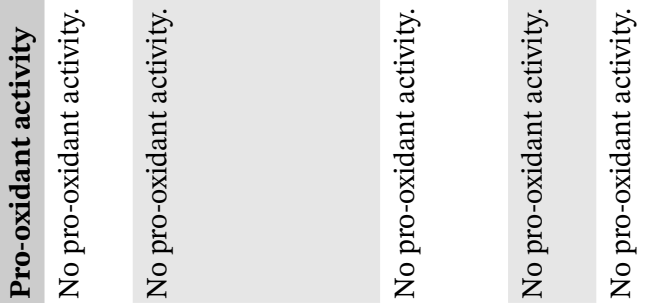
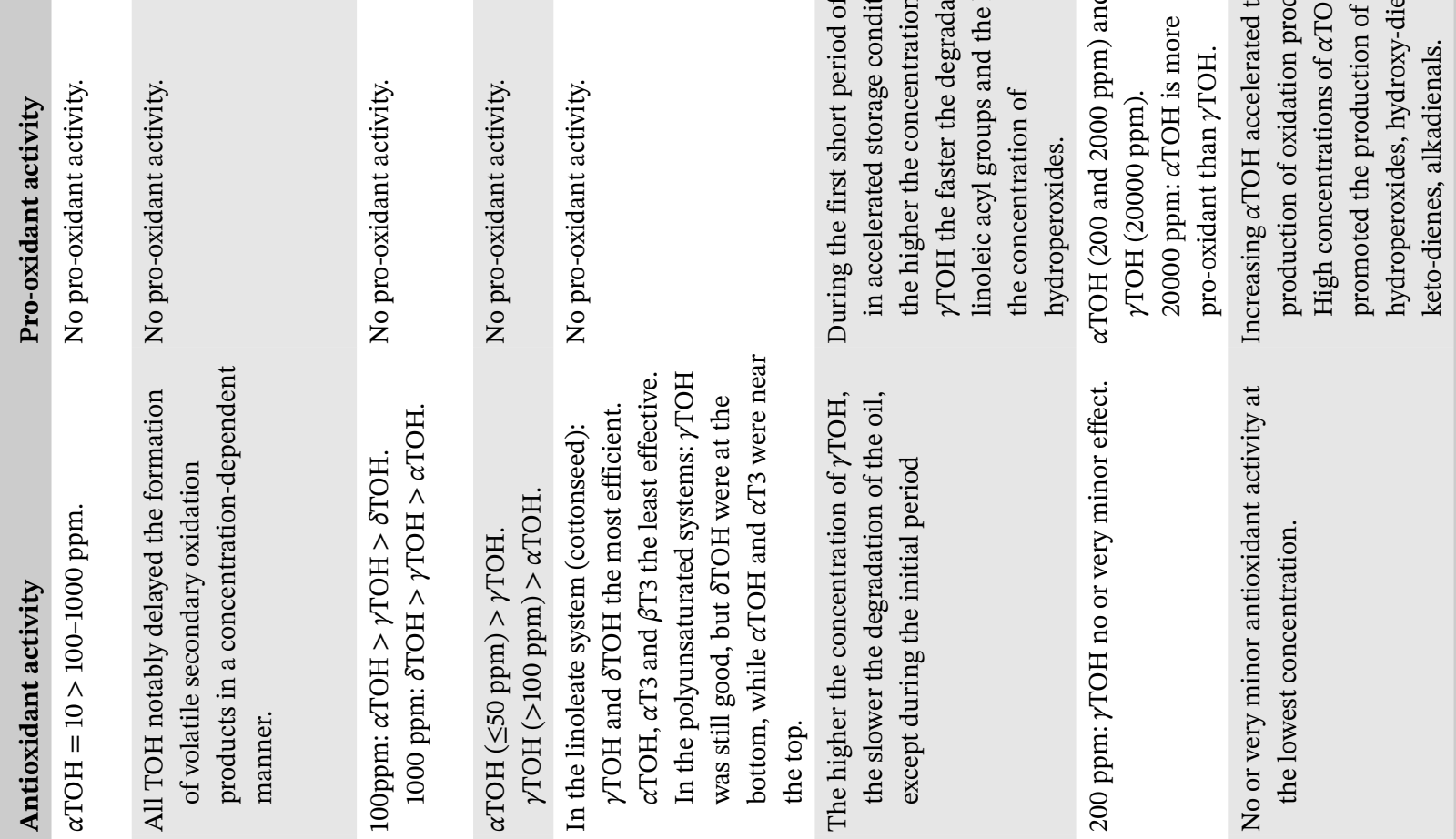

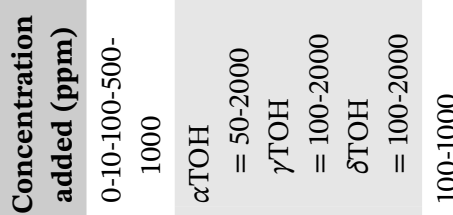

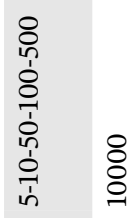

:
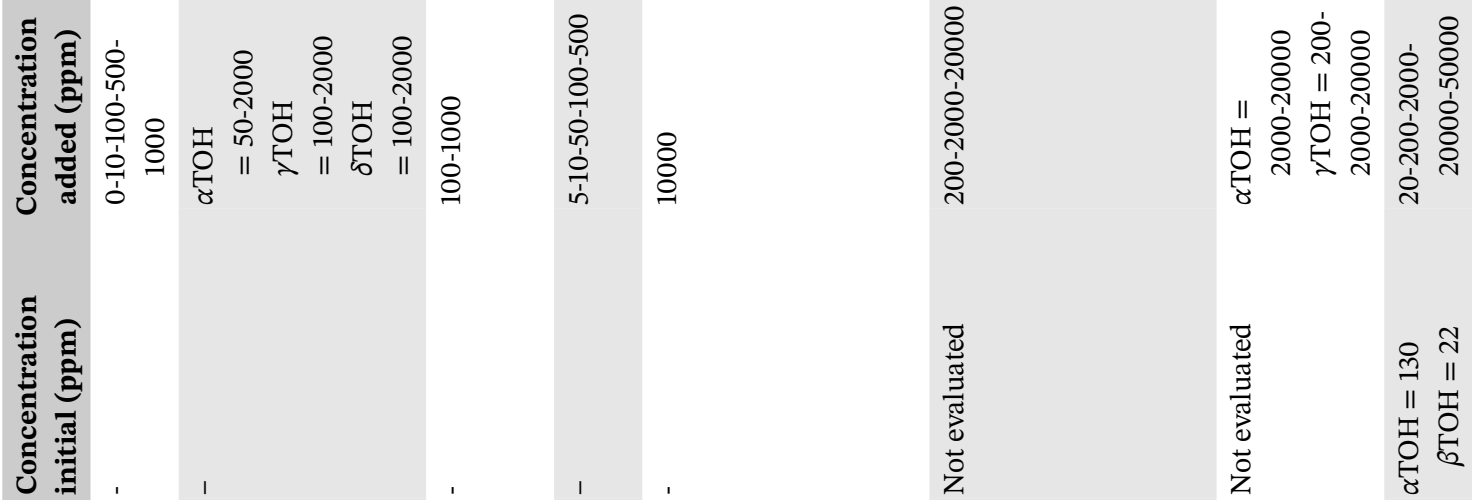

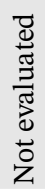

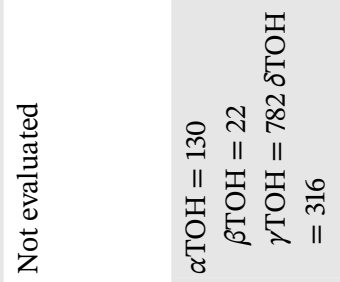

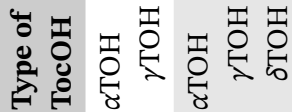

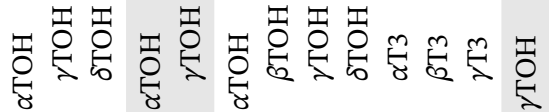
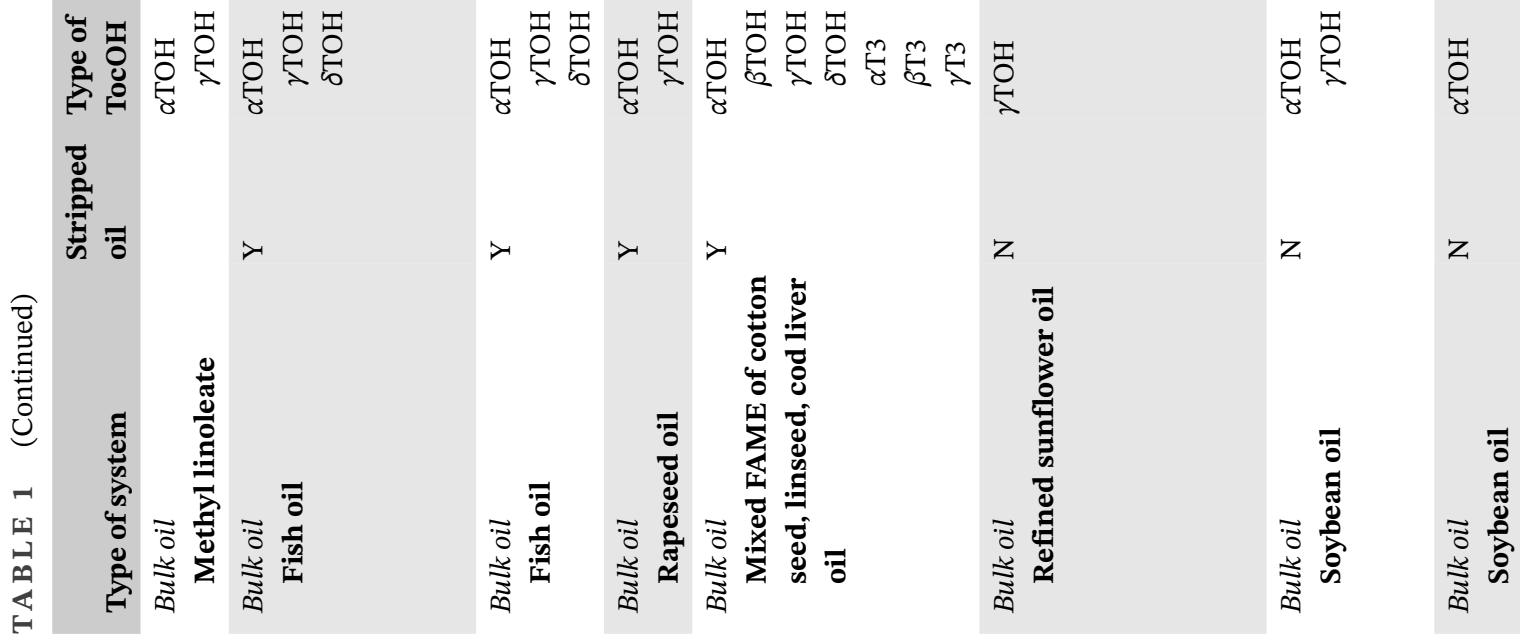
๕ั in

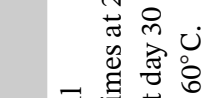

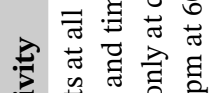

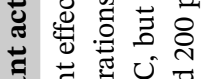

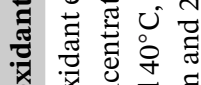

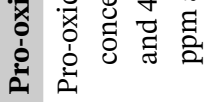
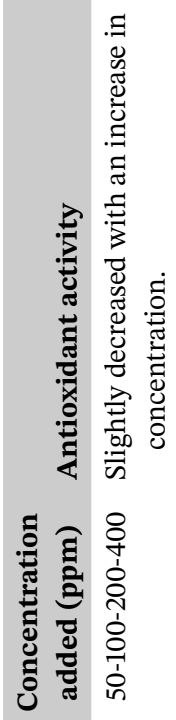
究
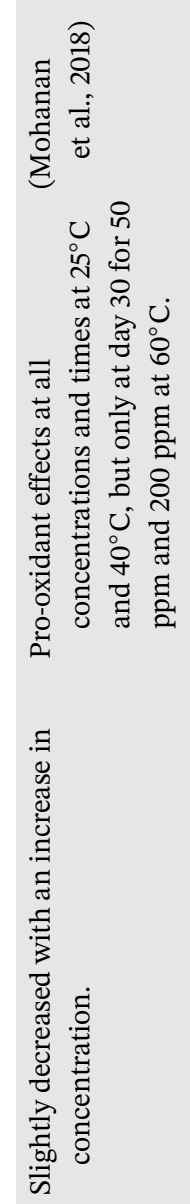

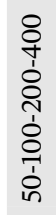

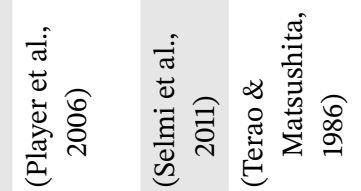

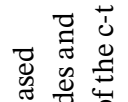

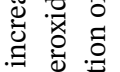

.
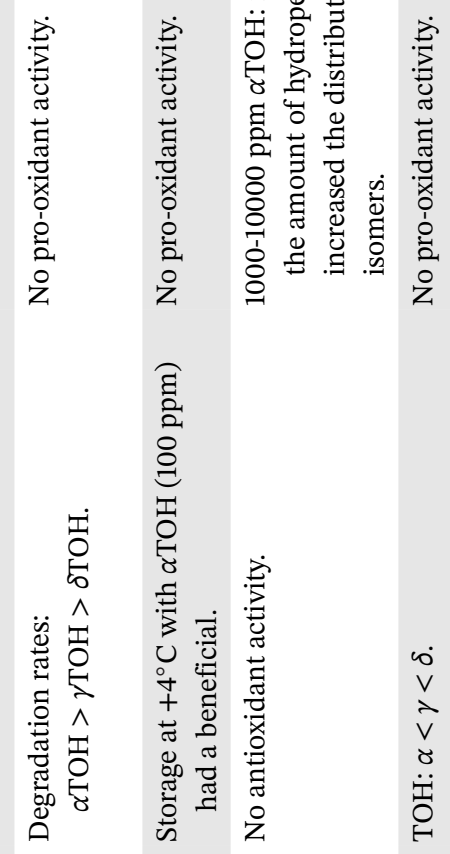

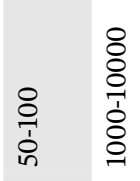

تِ

II

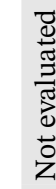

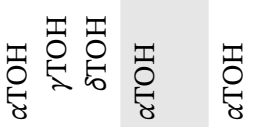

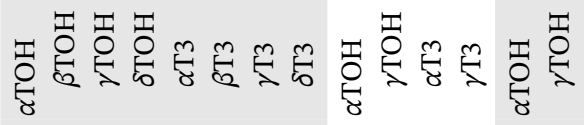
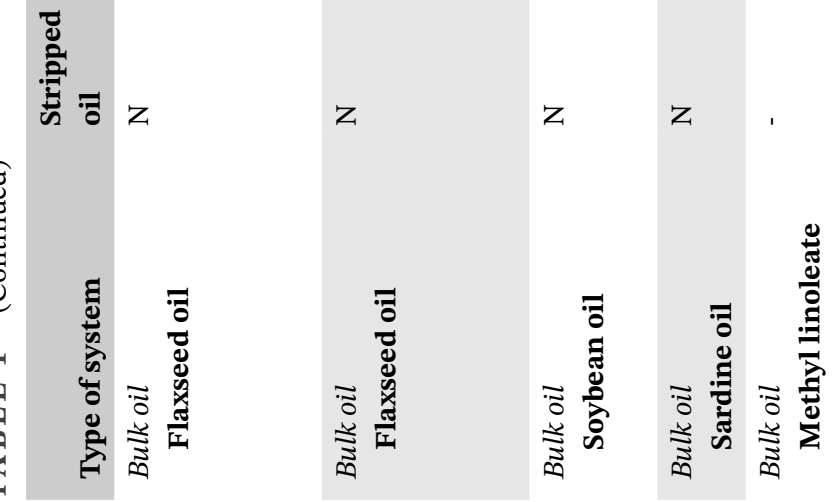

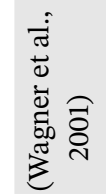

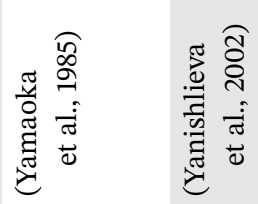

商

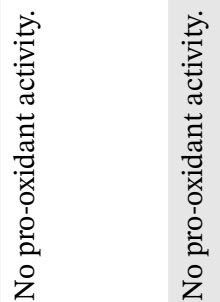

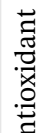

:

氛

के चี

究

宅

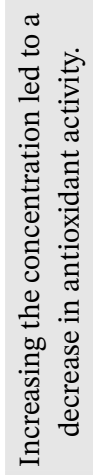

$\circ 8$

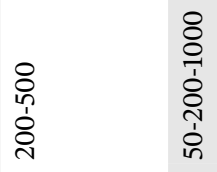

离

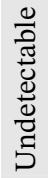

:

z
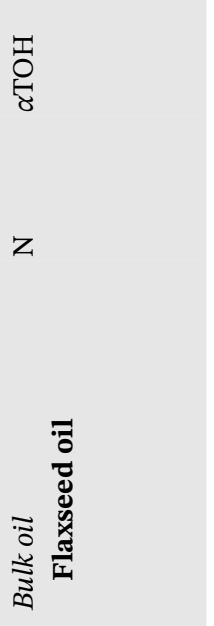

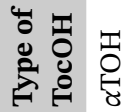

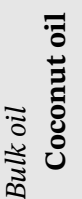

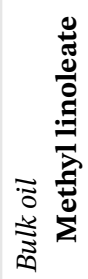

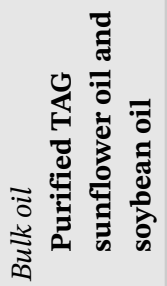




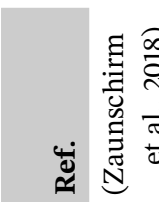

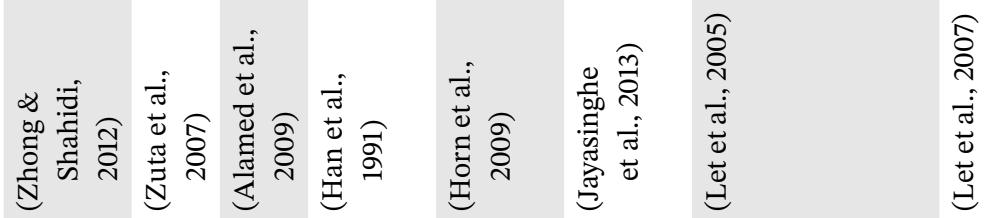
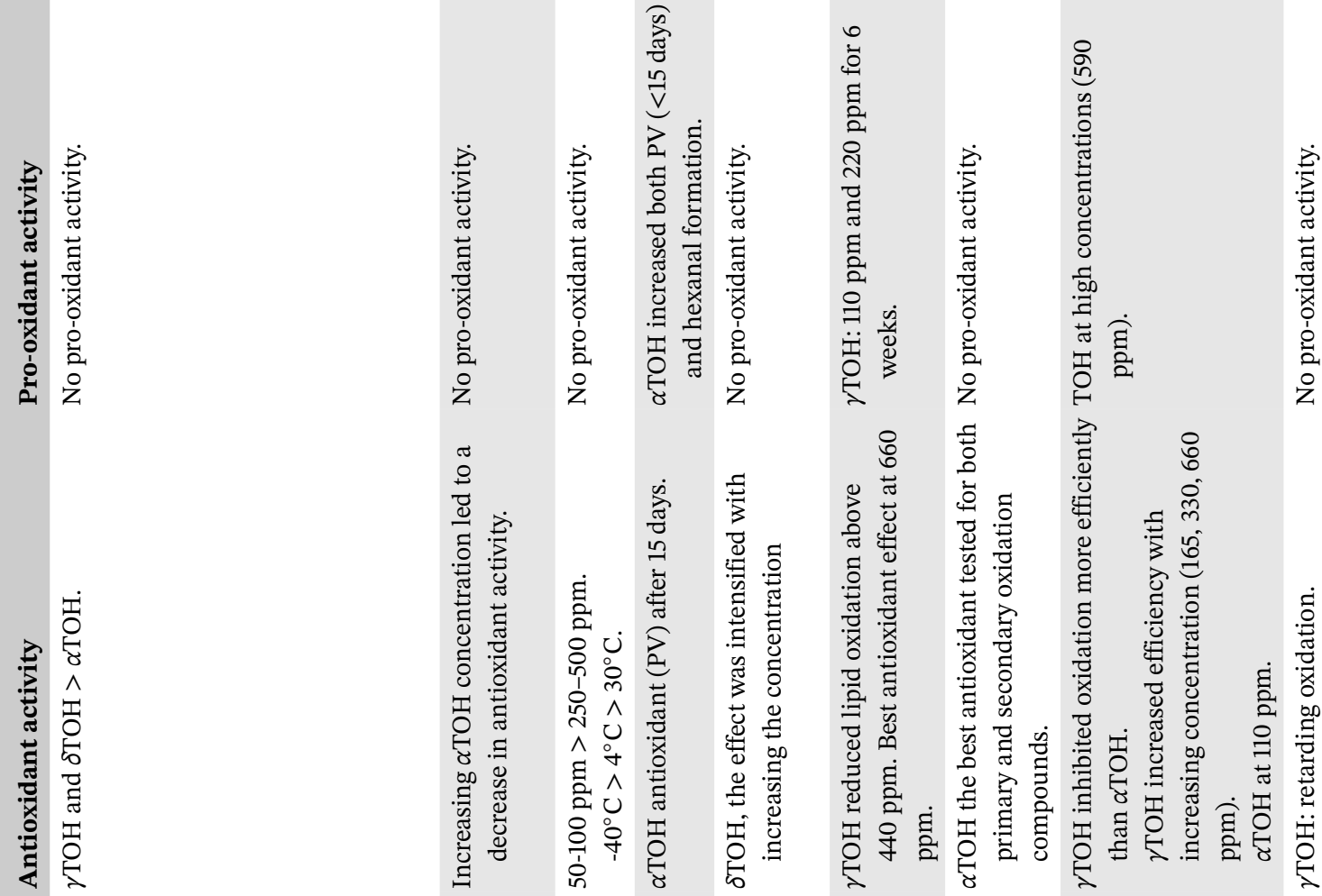

\section{(1)}
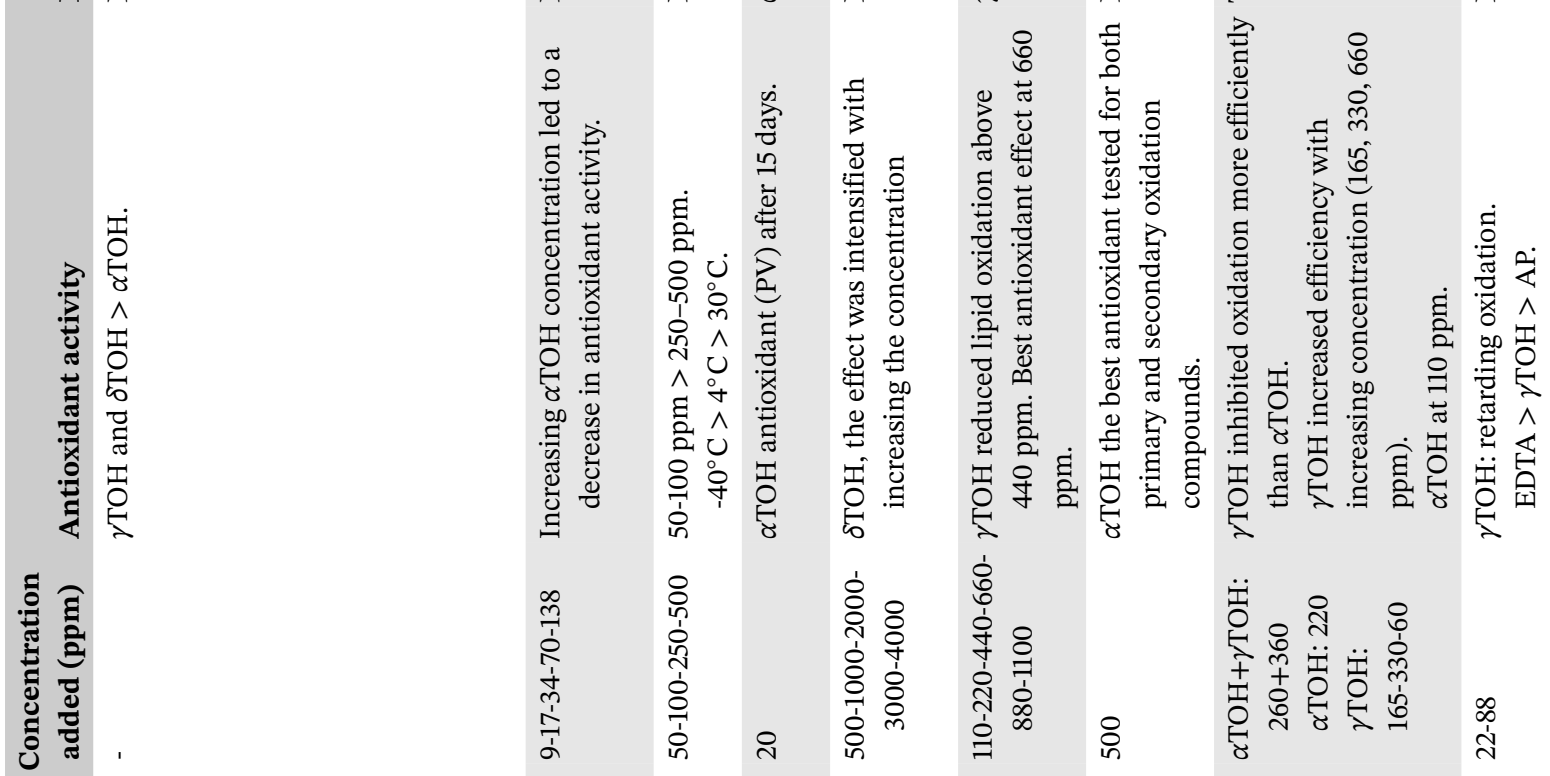

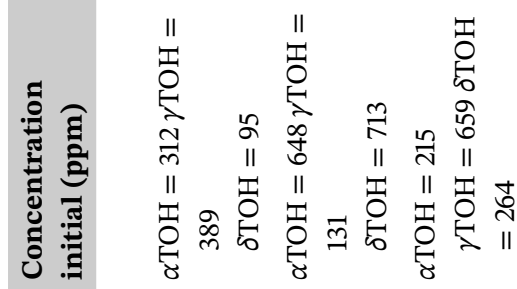

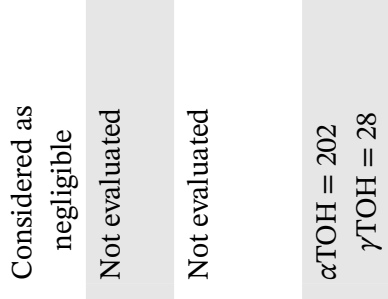

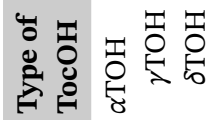

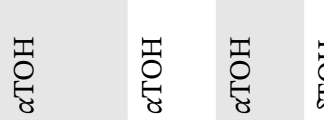

高

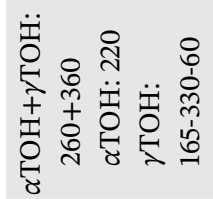

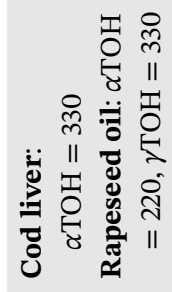

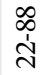

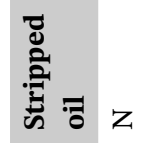

㗊
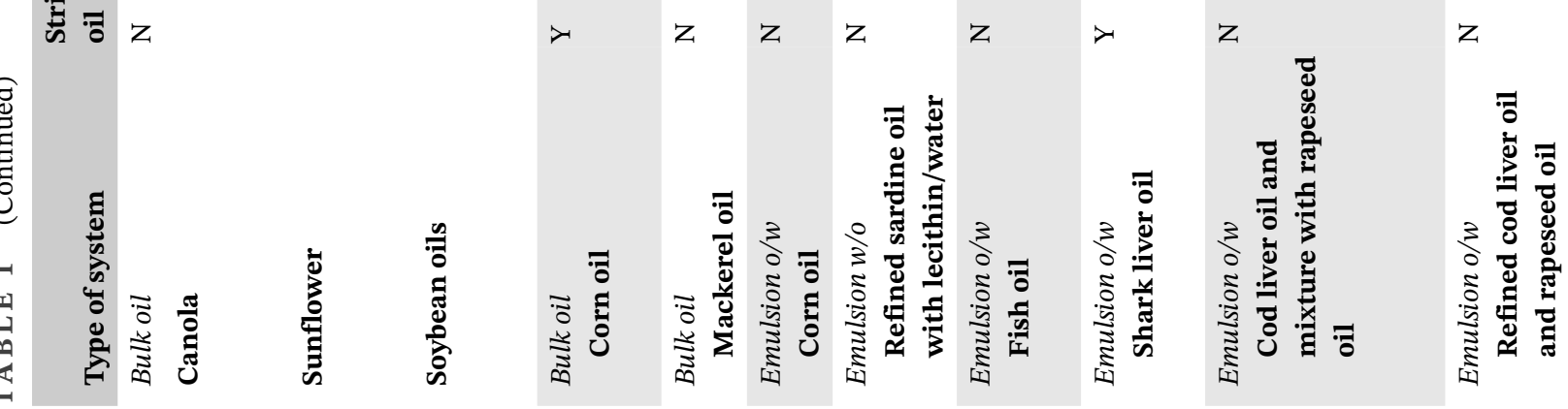


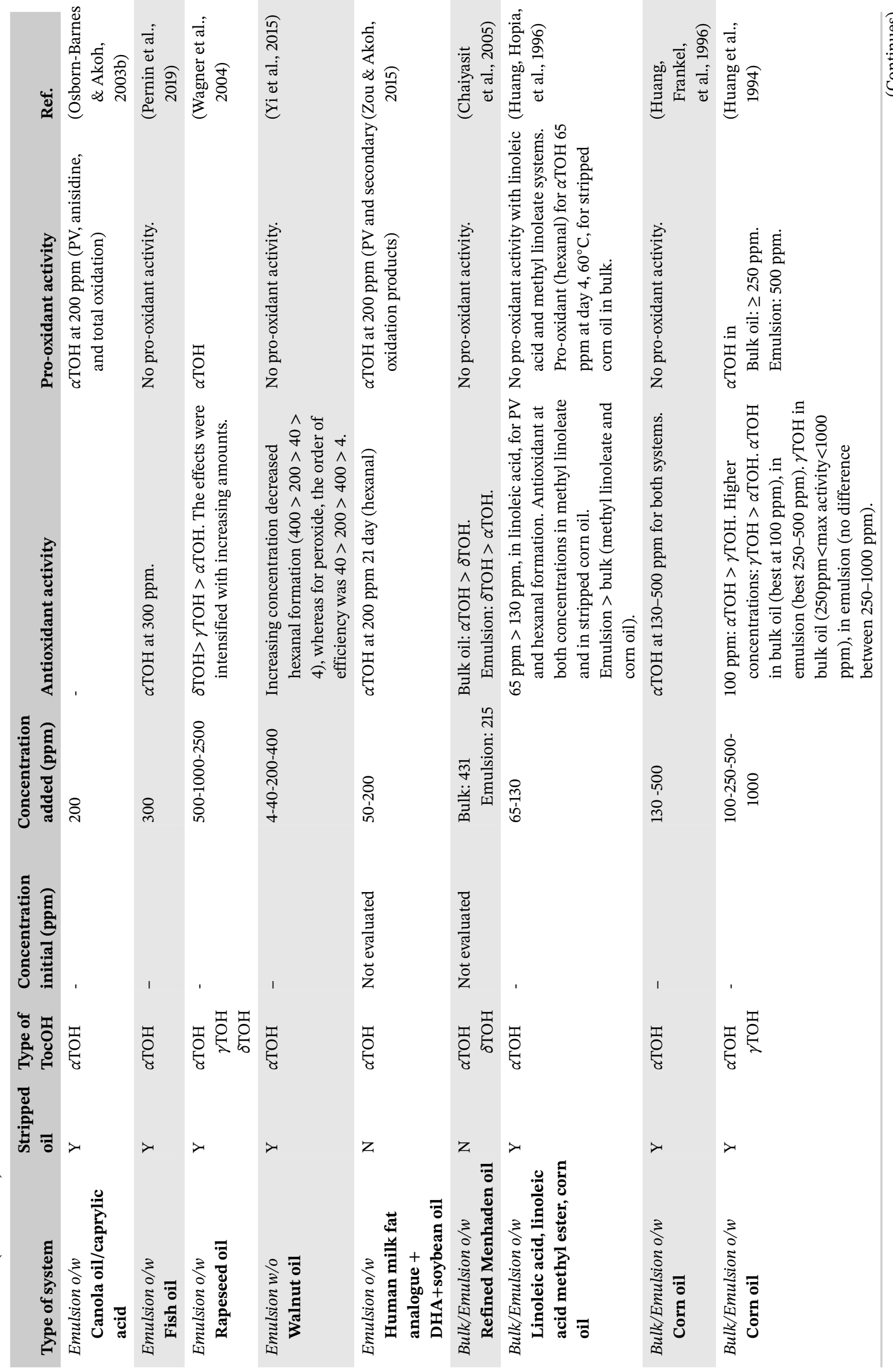




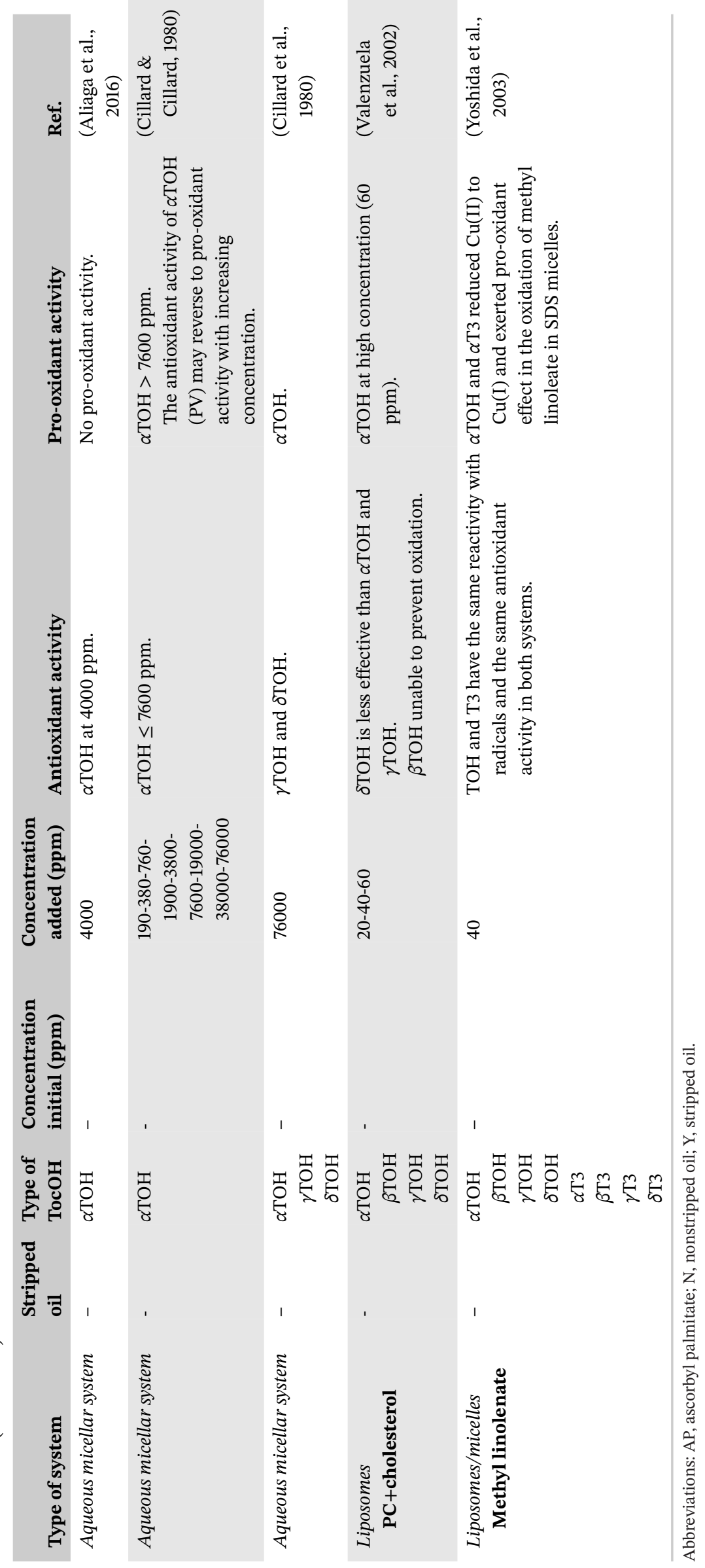




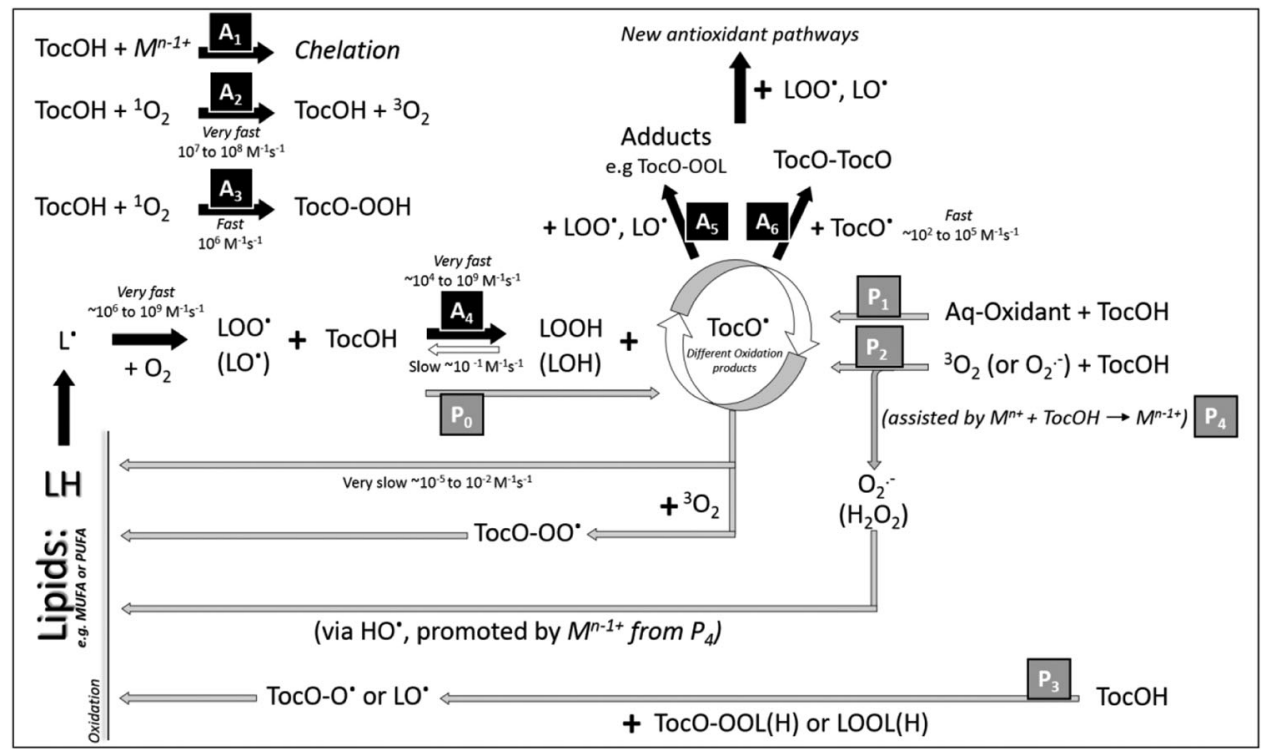

F I G U R E 5 Chemical behavior of tocopherols and tocotrienols (TocOH) with respect to the lipid (LH) oxidation pathway ( $\rightarrow$ antioxidant pathway $[\mathrm{A}]$ and $\leftarrow$ prooxidant pathway $[\mathrm{P}])$

(Clough et al., 1979; Neely et al., 1988; Yamauchi \& Matsushita, 1977). Such reactivity will consume TocOH. Moreover, TocO-OOH hydroperoxides formed in reactions with ${ }^{1} \mathrm{O}_{2}$ (Clough et al., 1979; Terao \& Matsushita, 1980), along with $\alpha$-tocopherol quinone, $\alpha$-tocopherol hydroquinone, and tocopherol quinone-epoxide, were shown to promote LH autoxidation (Chapman et al., 2009; Jung \& Min, 1992; Kim et al., 2007). The chemical reaction rates of TOH with ${ }^{1} \mathrm{O}_{2}$ were in the order of magnitude of $10^{6} \mathrm{M}^{-1} \mathrm{~s}^{-1}$ and followed the same order among isomers (Mukai et al., 1991). Subsequently, because the physical quenching kinetic rate is much faster, the quenching process was almost entirely "physical" and TOH deactivated about $120{ }^{1} \mathrm{O}_{2}$ molecules before being destroyed by chemical reaction (Mukai et al., 1991). Obviously, TocOH can also be strongly involved as a free radical scavenger. Most of the time, TocOH quickly transfers a phenolic hydrogen to a lipid radical. Such transfer results in a resonance-stabilized chroman-6-oxyl radical ( $\mathrm{TocO} \cdot)$ due to the donation of the $\mathrm{TocOH}$ phenolic hydrogen to a lipid radical $\left(\mathrm{A}_{4}\right)$.

In the induction period of lipid oxidation, TocOH mainly react with peroxy radicals ( $\mathrm{LOO} \bullet$ ), and later with alkoxy radicals ( $\mathrm{LO} \bullet$ ) that have appeared during the propagation period. The intensity of the oxidation parameters, the presence of other molecules nearby, the delocalization of the unpaired electrons that produce radical sites at different positions (ortho- and para-), and the different possible rearrangements modify the fate of TocO $\bullet$. For instance, the oxidation of $\mathrm{TocOH}$ in presence of water may form many oxidation products by different pathways because electron mobility is enhanced compared to that observed in the lipid phase. In bulk oil, when TocO $\bullet$ are present with other lipid radicals (e.g., LOO• or $\mathrm{LO} \bullet$ ), the latter are mainly involved in radical-radical coupling $\left(\mathrm{A}_{5}\right)$; such coupling results in the formation of different adducts such as TocOOOL. TocO - tend to react mainly by radical-radical selfcoupling $\left(\mathrm{A}_{6}\right)$, and dimeric tocopherol products (TocO$\mathrm{TocO}$ ) are formed when any other lipid radicals are present. Moreover, $\alpha$-analog was found to have a low rate constant in the dimerization process $\left(\sim 10^{2} \mathrm{M}^{-1} \mathrm{~s}^{-1}\right)$ that is presumably due to the steric hindrance of the chromane moiety (two ortho-methyl substituents) to the approach of two TocO • to form the dimer (Lucarini et al., 1994). An important consequence of this slow rate of dimerization is that $\alpha$-TO • or $\alpha$-T3O•, which are formed at very low concentrations, will live long enough to trap a second peroxyl radical $\left(\mathrm{A}_{5}\right)$. Regardless of the antioxidant pathways, the oxidized tocopherol adducts that are formed may react again with new lipid radicals. This would, in addition, explain the higher activity of $\gamma$ - or $\delta$-analogs compared to $\alpha$ - and $\beta$ - in many in vitro systems (Chaiyasit et al., 2005; Fuster et al., 1998; Huang et al., 1995; Wagner et al., 2004), because the former can be dimerized into compounds that may still be effective antioxidants (Kamal-Eldin \& Appelqvist, 1996).

Like all antioxidants involved in slow lipid oxidation, $\mathrm{TocOH}$ are mainly involved to reduce lipid radicals, and therefore to be oxidized. When this action is limited due to lipids radicals or radical-radical coupling that catches hydrogen(s) or electron(s), this mainly yields an antioxidant response. Yet, antioxidants and/or their oxidized forms may be exposed to other side reactions and react with relatively stable molecules (e.g., molecular oxygen, lipid molecules, and lipid hydroperoxides), which may lead 
to a prooxidant response. Generally, a molecule is categorized as prooxidant when its presence triggers an increase in the total radical yield in the system under study. In vitro, this usually happens when the concentrations of primary (hydroperoxide: $\mathrm{LOOH}$ ) or secondary (aldehydes, ketones, epoxides, etc.) lipid oxidation products increase. In addition, the production of reactive oxygen species such as superoxide anion, hydrogen peroxide, and hydroxyl radicals often also increases. This usually happens after the rate of lipid peroxidation is stimulated chemically or parallel antioxidant reactions are inhibited. The degree of such reactions is mostly determined by the structure of the antioxidant, its concentration, and the nature of neighboring molecules. There is no doubt that $\mathrm{TocOH}$ play a predominant role in the protection of lipids. However, they may also be involved in oxidation routes and, in this case, cause oxidative damage. It is generally accepted that the prooxidant effect of $\mathrm{TocOH}$ occurs when $\mathrm{TocOH}$ are present at high concentrations associated with the capacity of $\mathrm{TocO}$ - to promote or participate in a number of undesirable side reactions (Martin-Rubio, Sopelana, Ibargoitia, et al., 2018). Below are the five reaction mechanisms hypothesized to be behind the prooxidant effects of TocOH:

1. From the reactions of TocO- with lipid hydroperoxides (LOOH) or nonperoxidized LHs: At high concentrations of $\mathrm{TocOH}$, it is unlikely that the reverse reactions $\left(\mathrm{A}_{4}\right)$ of $\mathrm{TocO}$. with $\mathrm{LOOH}$ have a prooxidant effect because of (i) the higher concentration of unoxidized $\mathrm{TocOH}$ compared to TocO $\bullet$, which shifts the reaction toward $\mathrm{A}_{4}$, and (ii) the much slower rate of the prooxidant effect compared to $\mathrm{A}_{4}, \mathrm{~A}_{5}$, and $\mathrm{A}_{6}$ (Becker et al., 2004; Burton \& Ingold, 1981; Mukai et al., 1993). However, under certain conditions, $\mathrm{TocO} \bullet$ could trigger propagation chains upon $\mathrm{H}$ abstraction from $\mathrm{LH}$, leading to an increase in peroxides ( $\mathrm{LOO} \cdot$ ) in the system after competitive and rapid reaction with triplet oxygen $\left(\mathrm{P}_{0}\right)$. As the rate is very slow $\left(\sim 10^{-5}\right.$ to $10^{-2} \mathrm{M}^{-1}$ $\mathrm{s}^{-1}$ ) (Mukai et al., 1993), the ability of TocO to give off the radical chain thanks to a reaction with LH in the vicinity has to be combined with its inability to escape and to react with other radicals (e.g., TocO•, LOO•, LO•). Therefore, LH oxidation could also be initiated by $\mathrm{TocO} \cdot$ after oxidation reactions of $\mathrm{TocOH}$ with attacking aqueous radicals $\left(\mathrm{P}_{1}\right)$, residing at, or near, the surface of association colloids in bulk oil, or at the interface of micelles and oil droplets in emulsions. Yet TocOH-mediated peroxidation would not display significant prooxidative behavior in the presence of water-soluble antioxidants such as ascorbic acid (AA), because AA would quickly reduce $\mathrm{TocO}$ - to $\mathrm{TocOH}$ (Bowry \& Stocker, 1993).
2. From the generation of superoxide radical anions $\left(\mathrm{O}_{2}{ }^{-}\right)$or radical coupling, after reaction of $\mathrm{TocOH}$ with triplet molecular oxygen $\left({ }^{3} \mathrm{O}_{2}\right)$ : Like most organic compounds, the direct reaction of TocOH with ${ }^{3} \mathrm{O}_{2}$ is spin-forbidden. Therefore, this way is much less often followed than the way involving hydroperoxides. ${ }^{3} \mathrm{O}_{2}$ can, however, react with radicals released from $\mathrm{TocOH}$, thereby explaining the prooxidant effect of $\mathrm{TocOH}$. Although very slow, this effect may arise after radical coupling of TocO $\bullet$ with ${ }^{3} \mathrm{O}_{2}$, leading to TocO-OO• (from $\mathrm{P}_{0}, \mathrm{P}_{1}, \mathrm{P}_{2}, \mathrm{P}_{4}$ ). Another prooxidant activity of tocopherols is based on a sum of reactions involving the reduction of ${ }^{3} \mathrm{O}_{2}\left(\mathrm{P}_{2}\right)$. The first step of autoxidation is the one-electron oxidation forming the radical intermediate and the superoxide radical $\left(\mathrm{O}_{2} \bullet^{-}\right)$(or $\mathrm{HO}_{2} \bullet$ under acidic $\mathrm{pH}, \mathrm{p} K_{\mathrm{a}}=4.88$ ). This reaction is endothermic and kinetically unfavorable, with a very slow kinetic rate likely due to the low redox potential of the $\mathrm{O}_{2} / \mathrm{O}_{2}{ }^{-}{ }^{-}$couple $\left(-0.33 \mathrm{~V}\right.$ at pH $7,10^{5} \mathrm{~Pa}$ ) (Wood, 1988) and the spin restriction between the reactants. However, in presence of transition metals (such as $\mathrm{M}^{n+}=\mathrm{Cu}^{2+}, \mathrm{Fe}^{2+}$ ) the one-electron oxidation of $\mathrm{TocOH}$ may be substantially enhanced $\left(\mathrm{P}_{4}\right)$. Indeed, transition metals, which exist in several spin states, may reduce the spin restriction issue and thus act as catalysts in this process. According to the redox potential involving one-electron transfer $(0.89 \mathrm{~V}$, $\mathrm{pH} 7$ ), the superoxide radical generated $\left(\mathrm{O}_{2} \bullet^{-}\right)$becomes a stronger oxidant. Thus, tocopherols can more easily be involved as electron donors to $\mathrm{O}_{2} \bullet^{-}\left(\mathbf{P}_{2}\right)$ leading to the production of hydrogen peroxide $\left(\mathrm{H}_{2} \mathrm{O}_{2}\right)$, which is one of the active oxygen species and a precursor of the strongest known oxidizing agent (HO•). The harmful activity of $\mathrm{H}_{2} \mathrm{O}_{2}$ is not really due to its intrinsic reactivity, but to the subsequent formation of $\mathrm{HO} \cdot$ under the action of energetically favored metal reduction.

3. From the decomposition of $\mathrm{LOOL}(\mathrm{H})$ or TocO-OOL $(\mathrm{H})$ after reactivity with $\mathrm{TocOH}\left(\mathbf{P}_{\mathbf{3}}\right)$ : The diffusion of autooxidation reactions by the peroxide is due to the decomposition of $\mathrm{LOOH}$ via unimolecular or bimolecular mechanisms. At low to moderate temperatures $\left(<40^{\circ} \mathrm{C}\right)$ that favor hydrogen bonding, lipid peroxides can catch hydrogen atom of $\mathrm{TocOH}$, along with the TocO-OOL (or TocO-OOH) adducts, leading to stable lipid alkoxides ( $\mathrm{LOH}$ ) and alkoxy $\mathrm{LO}$ • or TocO-O• radicals. In addition to the competing reactions of scission and internal rearrangement that are also fast, these unstable radicals are rapidly prone to abstract a hydrogen atom from LH. Still, these radicals would be neutralized in presence of large amounts of $\mathrm{TocOH}$, and should thus not have a significant prooxidative effect in the early stage of autoxidation. However, the prooxidant effect of $\mathrm{TocOH}$ may be enhanced at $40^{\circ} \mathrm{C}$ by the presence of high levels of hydroperoxides (between 0.45 and 
$1.43 \mathrm{~mol} \%$ of peroxide) (Hicks \& Gebicki, 1981). Moreover, if the conditions are fulfilled, the decomposition of $\mathrm{LOOH}$ from $\alpha-\mathrm{TocOH}$ is predicted to be the fastest due to its ability to give its phenolic hydrogen.

4. From the reduction of metal transition $\left(\mathrm{P}_{4}\right)$ : TocOH and $\mathrm{TocO}$ - radicals may also cause the reduction of transition metal ions into low-valent species (e.g., $\mathrm{Fe}^{3+}$ to $\mathrm{Fe}^{2+}$ ) liable to increase the overall yield of radicals through the Fenton reaction ( $\mathrm{HO} \bullet$ ) from $\mathrm{H}_{2} \mathrm{O}_{2}$ or Fenton-like reactions ( $\mathrm{LO} \bullet$ ) from $\mathrm{LOOH}$ or $\mathrm{TocO}-$ LOO adducts or to assist the generation of superoxide radical anions $\left(\mathrm{O}_{2} \bullet^{-}\right)$. Theoretically, $\gamma$ - and $\delta$-TOH and $\mathrm{T} 3$ should have weaker prooxidant effects than other analogs because of their lower reduction effects on metal transitions, lower reactivity with $\mathrm{O}_{2} \bullet^{-}$, and the formation of dimerizable compounds that are still active antioxidants, along with the formation of lipid hydroperoxide adducts (e.g., 5-(peroxy)- $\gamma$-tocopherone) that will dissociate to become quinone and alkyl alcohol (LOH) (Jung \& Min, 1992; Kamal-Eldin \& Appelqvist, 1996). Furthermore, the reason for the contradiction between the effectiveness of $\mathrm{TocOH}$ and the balance between antioxidant and prooxidant pathways in different experiments cannot only be the presence and the proportion of $\mathrm{TocO} \bullet$ radicals. These chemical pathways are most probably significantly affected by dissimilarities in the physical parameters of the system and/or different chemical factors.

\section{3 | Major factors affecting tocopherol reactivity}

Several intrinsic factors (fatty acid composition and quality of oils, presence of co-antioxidants vs. prooxidants, etc.) and external factors (duration of storage, temperature, etc.) may influence the antioxidant effect of TocOH. We examined 15 studies to evaluate and compare the antioxidant and prooxidant effects of $\mathrm{TocOH}$ in bulk oils.

PCA (principal component analysis) provided an overview of all the results obtained by different authors for all $\mathrm{TocOH}$ (data not shown). The selected articles listed in Table 1 met the following criteria and had the most common parameters as variables, temperature, and length of storage, concentration of $\mathrm{TocOH}$, and analysis of primary and secondary oxidation products. Restrictions were applied to limit the area of analysis, that is, the maximum added concentration for isoforms was $2000 \mathrm{ppm}$ and the maximum peroxide value (PV) was $100 \mathrm{meq}$ $\mathrm{O}_{2} / \mathrm{kg}$.

The model was based on PV, inhibition of formation of hydroperoxide (IP), the concentration of added isoforms, the length and temperature of storage, and the presence of polyunsaturated fatty acids (PUFA) in oils. As additional variables, we also considered the inhibition of both the $p$-anisidine and hexanal value and the presence of saturated fatty acids, monounsaturated fatty acids, and PUFA in oil. Four components were necessary to describe variations in the model. The first two principal components (PC1 and $\mathrm{PC} 2$ ) explained approximately $63 \%$ of the variance in the dataset for the TocOH models in both stripped and unstripped oil.

First, $\mathrm{PC} 1$ and $\mathrm{PC} 2$ explained $32.87 \%$ and $30.37 \%$ of variance, respectively. The PCA loadings plot showed that the concentration, the temperature, and PV were correlated and were located in the positive direction of PC1. Conversely, IP was inversely correlated with the others and was located in the negative direction of PC1. IP was also inversely correlated with storage and was located in the positive direction of $\mathrm{PC} 2$. The loading plot revealed no isoform clusters. However, this analysis is difficult to interpret, as most authors only treated $\alpha-\mathrm{TOH}$, not all TocOH. Last but not the least, the standard radical chain reaction of lipid oxidation put pressure on the scientific community to examine and evaluate antioxidant efficiency in bulk oils or in emulsions almost only by evaluating $\mathrm{LOOH}$ and/or secondary oxidation products (mostly aldehydes). Standard nonspecific methods such as headspace oxygen content, conjugated dienes, or $p$-anisidine value were also used. In addition, a competition between the hydrogen abstraction and many other reactions for $\mathrm{LOO} \bullet$ and $\mathrm{LO}$ • radicals exists. These radicals, along with $\mathrm{LOOH}$, undergo reactions in parallel and at rates competitive with $\mathrm{H}$ atom abstractions that need to be integrated to fully account for the extent of lipid oxidation and hence, to more accurately estimate the efficiency of the antioxidant (Schaich, 2020). A very restrictive analysis of oxidation products could thus introduce a bias in the results because the mechanism pathways and the different classes of oxidation products are not affected by the addition of an antioxidant (e.g., TocOH) in the same way (Huang, Hopia, et al., 1996; Martin-Rubio, Sopelana, \& Guillen, 2018; Martin-Rubio, Sopelana, Ibargoitia, et al., 2018). For instance, in addition to its ability to influence the mechanism of autoxidation at high concentrations (Terao \& Matsushita, 1986), $\alpha$-TocOH was found to accelerate the formation of $\mathrm{LOOH}$ at higher concentrations in the early stages of oxidation in both bulk and emulsion systems, although on the contrary, it inhibited hexanal formation more strongly (Huang et al., 1994). This ambiguity underlines the importance of using more than one method to determine antioxidant activity. PV, in addition to volatiles such as aldehydes, is still the most convenient approach to roughly estimate oxidative stability, but a systemic approach including monitoring the different types of oxidation compounds would provide more precise data to determine the effect and compare antioxidants with respect to the lipid oxidation mechanisms. 

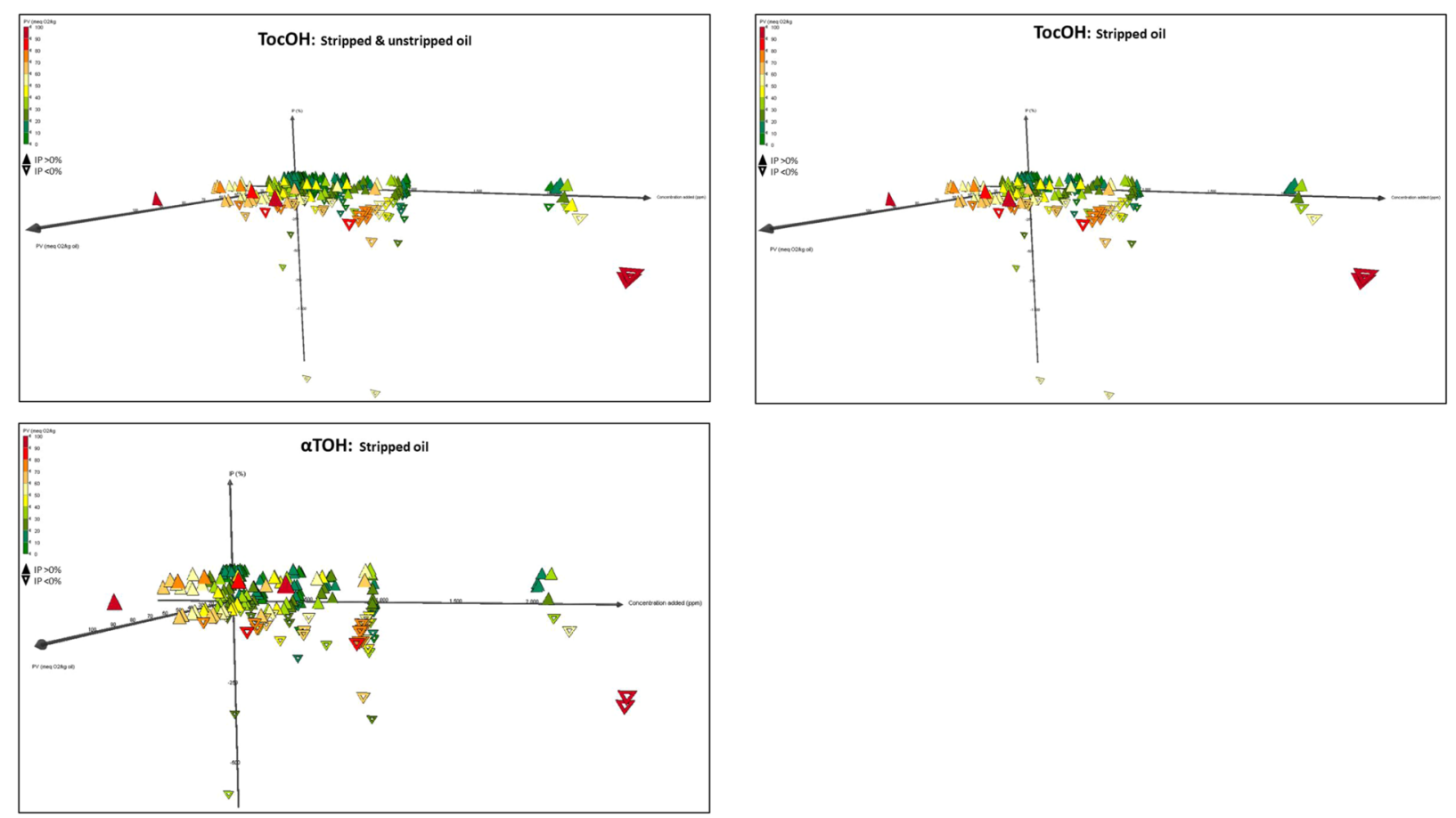

F I G U R E 6 Inhibition of hydroperoxide (\%) according to the added concentration of TocOH or $\alpha-\mathrm{TOH}(\mathrm{ppm})$ and $\mathrm{PV}$ (meq $\mathrm{O}_{2} / \mathrm{kg}$ oil) in bulk oil. $\Delta$ IP $>0 \%$; V IP $<0 \%$ IP $=$ [(hydroperoxide formed in control - hydroperoxide formed in the sample)/hydroperoxide formed in the control] $\times 100$

As mentioned above, the prooxidant effects of TocOH (particularly $\alpha$ isoforms) are known to predominate when high concentrations of $\mathrm{TocOH}$ are present in oils. Thus, concentration is a critical parameter. However, the most effective dose of $\mathrm{TocOH}$ beyond which their antioxidant activity will switch to prooxidant remains unclear. For example, Jung and Min (1990) reported that the maximum concentration for $\mathrm{TocOH}$ to be an antioxidant depends on the nature of the isoform, that is, 100, 500, and $1000 \mathrm{ppm}$ for $\alpha, \gamma$, and $\delta$, respectively. Thus, the $\mathrm{CC}$ of each $\mathrm{TocOH}$ needed for maximum stability depends on the system. To investigate the effect of the concentration in more detail, we produced a three-dimensional representation from data collected with the PCA from 13 representative articles that dealt with antioxidant and prooxidant activity of $\mathrm{TocOH}$ in bulk oils (Figure 6). We represent the antioxidant response (normalized in \% IP) according to the added concentration of $\mathrm{TocOH}$ (normalized in ppm) at different stages of oxidation (normalized with PV). A positive $y$-axis value (\% IP) indicated antioxidant activity of $\mathrm{TocOH}$, whereas a negative value indicated prooxidant activity. The first graph shows the response of all isoforms (A), the second, all stripped isoforms, and the last one (C), only the stripped $\alpha$-TOH.

As shown, most of the experiments analyzed were performed at a concentration ranging from 0 to $1000 \mathrm{ppm}$, and at all the concentrations tested (up to $2000 \mathrm{ppm}$ ), $\mathrm{TocOH}$ showed both antioxidant and prooxidant activities. Nev- ertheless, no clear consensus emerged on a threshold, or on a clear decrease in antioxidant capacity only based on the increasing concentration parameter. A similar interpretation was made of the data collected with stripped oils, for which the representation of $\mathrm{TocOH}$ concentrations was more precise, along with concentrations obtained with only $\alpha-\mathrm{TOH}$, which represented $75 \%$ of the data. Indeed, the presence of endogenous $\mathrm{TocOH}$ in unstripped oils may lead to errors in interpreting the results. For example, adding $200 \mathrm{ppm}$ of $\alpha$-TOH in bulk and emulsified rapeseed oil that already contained $669 \mathrm{ppm}$ of native tocopherols did not improve the antioxidant effect. In contrast, adding the same quantity (200 ppm) in the same stripped rapeseed oil produced an effective antioxidant effect (Samotyja \& Małecka, 2007). Similarly, $\alpha$-TOH had no prooxidant effect when added at very high concentrations (e.g., 2000 ppm) for the protection of sunflower or rapeseed oils that were previously purified in order to remove native TOH and traces of metals and pigments (Kamal-Eldin \& Appelqvist, 1996).

Yet, by analyzing the data with the third dimension (PV), we identified a zone where antioxidant activity of TocOH strongly predominates, whereas beyond this zone, the prooxidant effect prevails (Figure 7). Indeed, up to a value of about $200 \mathrm{ppm}$, TocOH exhibited almost exclusive antioxidant activity; beyond that, their activity very often switched to prooxidant, except very low levels of oil oxidation $(\mathrm{PV}<10)$. 


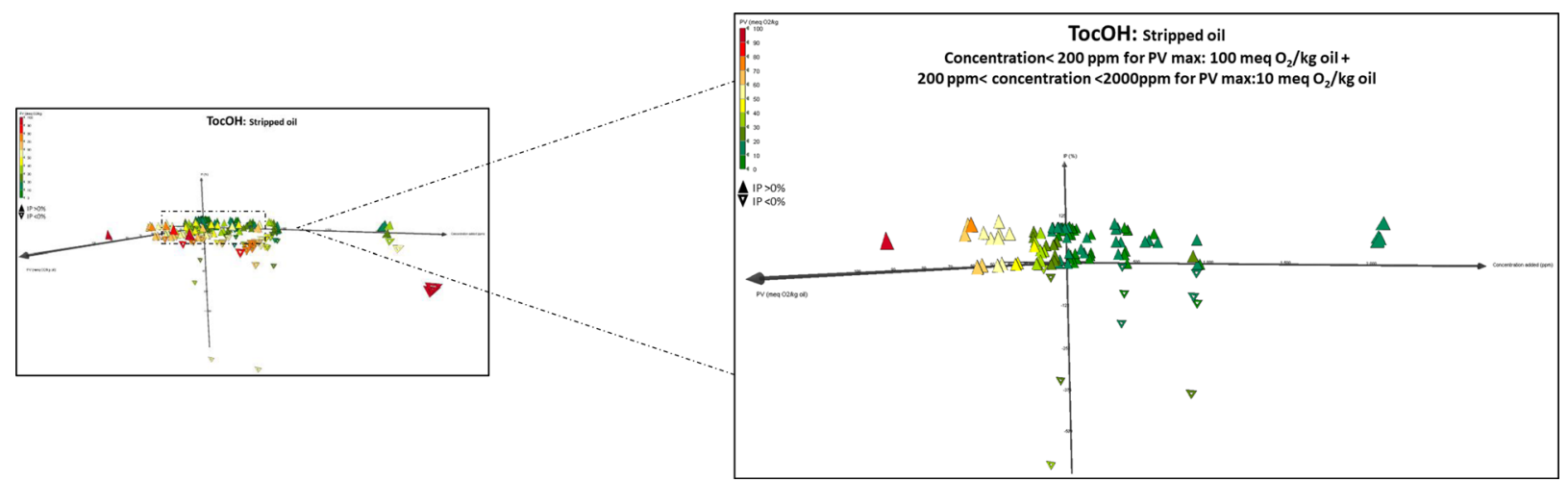

F I G U R E 7 Inhibition of hydroperoxide (\%) as a function of the added concentration (ppm) of TocOH and PV (meq $\mathrm{O}_{2} / \mathrm{kg}$ oil). For a maximum concentration of $200 \mathrm{ppm}, \mathrm{PV} \max =100 \mathrm{meq} \mathrm{O}_{2} / \mathrm{kg}$ and for concentrations between 200 and $2000 \mathrm{ppm}, \mathrm{PV}$ max $=10 \mathrm{meq} \mathrm{O}_{2} / \mathrm{kg}$ oil. $\Delta$ IP $>0 \%$; V IP $<0 \%$ IP $=[$ (hydroperoxide formed in control - hydroperoxide formed in sample $) /$ hydroperoxide formed in control $] \times 100$

Thus, below a concentration of around $200 \mathrm{ppm}$, the chances of obtaining antioxidant activity regardless of the oxidation state are extremely high. In this region, the antioxidant variation and intensity between experiments and isoforms varies with the internal $(\mathrm{pH}$, water activity $\left[a_{\mathrm{w}}\right]$, etc.) and external physicochemical factors (light, temperature, etc.). For example, Kim et al. (2015) showed that for the same concentration (84 ppm), the antioxidant capacity of TOH depended on the water content (Kim et al., 2015). Because water contains prooxidant molecules such as metals, it is involved in the chemistry of lipid oxidation. Indeed, water-soluble prooxidants such as metals are key actors of the oxidation pathways (Barden \& Decker, 2016). High $a_{\mathrm{w}}$ increases the mobility of the transition metal, and consequently its probability of being in contact with and reduced by TocOH. On the other hand, water may promote the interaction and possible regeneration of lipophilic TocOH at the interface with water-soluble antioxidants, or protect against hydroperoxide decomposition. The protection process relies on the solvation of the hydroperoxides and on the hydration of metal catalysts (Chen et al., 1992). Temperature was also reported to influence lipid oxidation pathways and $\mathrm{TocOH}$ efficiency. $\alpha>\beta>\gamma>\delta$ TocOH was reported to be the order of antioxidant efficiency under low to mild temperatures. At high temperatures $\left(>60^{\circ} \mathrm{C}\right)$, however, a reverse order was obtained $\alpha<\beta<\gamma<\delta$ (Lea \& Ward, 1959; Rao \& Achaya, 1967). Temperature is assumed to affect the reaction kinetics (e.g., radical reactions between the antioxidant and the lipids) because it can reduce the viscosity of the medium, increase the mobility of the molecules (e.g., $T^{\circ} \mathrm{C}>T_{\text {fusion }}{ }^{\circ} \mathrm{C}$ of lipids), break hydrogen bonds, and promote the formation of hydrophobic bonds. In addition, the stability and solubilization of molecules (e.g., antioxidants and hydroperoxides) along with the organization and stability of colloidal structures can be modified. In general, increasing the temperature has a negative effect on lipid oxidation by reducing the stability of the antioxidant, and accelerating the decomposition rate of hydroperoxides and reactivity with metal transitions (O’Brien, 1969). However, some authors found that temperature positively affected $\alpha$ TOH efficiency (Marinova \& Yanishlieva, 1992). One possible explanation is that increasing the temperature reduced the solubility of oxygen in oils, resulting in a lower formation rate of the autoxidative peroxide (prooxidant effects of $\mathrm{P}_{0}, \mathrm{P}_{1}, \mathrm{P}_{2}, \mathrm{P}_{4}$; Figure 5) that is slowly replaced by other antioxidant reactions (e.g., $\mathrm{A}_{4}, \mathrm{~A}_{5}, \mathrm{~A}_{6}$, Figure 5). The inversed response (from antioxidant to prooxidant) is assumed to be related to the redox potential of $\mathrm{TocOH}$. The redox potential can theoretically be linked to the capacity of the $\mathrm{O}-\mathrm{H}$ bond to dissociate (homolytic fission). As previously explained, it is dependent on the structure of $\mathrm{TocOH}$, and it is suspected that $\delta$ isomers with higher reduction potential will show inversion of activity at higher concentrations than those with lower reduction potentials $(\gamma, \beta$, $\alpha$ ). So, experiments conducted in the same condition and with the equal concentrations of $\mathrm{TocOH}$ may show that the concentrations of the TocO $\mathrm{O}$ should follow the same order, $\alpha$ - being the earliest prooxidant. To cite one example, Jung and Min (1990) observed that $\alpha$-TOH (500 ppm in soybean oil) showed a prooxidant capacity, whereas $\gamma$ $\mathrm{TOH}$ had no noticeable effect, but $\delta$-TOH had an antioxidant effect. Yet, when TocOH are added to bulk oils or lipid dispersions at the best concentrations to obtain the best efficiency of antioxidants, the order of antioxidant ability should be as follows: $\alpha>\beta>\gamma>\delta$. Thus, each TocOH has a CC for maximum stability that is system dependent. Moreover, the switch in TocOH activity also depends on the presence of compounds such as transition metal ions or other oxidizing agents that are needed to assist the prooxidant response. Thus, regarding the $\mathrm{TocOH}$ chemical pathways (Figure 5), a systematic increase in $\mathrm{TocOH}$ concentration up to thousands of ppm is not required, rather its concentration needs to be optimized. In our opinion, 
TocOH (particularly $\alpha$-TocOH) should be added at the lowest concentration possible so that the probability to form TocO $\bullet$ radical from $\mathrm{P}_{1}, \mathrm{P}_{2}, \mathrm{P}_{3}$, and $\mathrm{P}_{4}$ (Figure 5) is reduced. Interestingly, among the pool of publications we analyzed, we noticed that, beyond $200 \mathrm{ppm}$ the antioxidant activity of TocOH was strongly preserved at low PVs $(<10$ $\mathrm{PV})$. Therefore, it is difficult to imagine that the involvement of TocO radicals is the main explanation for this change in the response. Another possible explanation is the capacity of oxidizing agents (e.g., LOOH) to assist the prooxidant activity of TocOH through physical $\left(\mathrm{P}_{1}, \mathrm{P}_{2}, \mathrm{P}_{4}\right)$ or physicochemical interactions $\left(\mathrm{P}_{3}\right)$. This underlines the need to understand the distribution of antioxidants and their interaction with oxidant species in complex systems such as emulsions. Indeed, in emulsions, different phases coexist, and the physical organization of the environment becomes more important than the reactivity of the various molecular species involved in the lipid oxidation reaction. Porter (1993) with "the polar paradox theory" set the quite counter intuitive hypothesis that nonpolar antioxidants are better antioxidants in system presenting high interfacial surface (e.g., emulsion), whereas polar or hydrophilic antioxidants have better efficacy in bulk oil system presenting low surface-to-volume ratios of lipids (Figure 2). The study of Frankel et al. (1994) supports this paradoxical hypothesis by demonstrating that hydrophilic antioxidants (in their study: Trolox and AA) stabilized better bulk oil system than oil-in-water emulsion. The same study also demonstrated the opposite tendency for lipophilic derivatives ( $\alpha$-TOH and ascorbyl palmitate). This paradox can be mainly explained by the opposite distribution behavior of polar or nonpolar antioxidants in multiphasic systems. Indeed, in such systems, their partition, diffusion into the interphase, and putative vicinity with anti- or prooxidants differ. Castle and Perkins (1986) suggested that the antioxidant capacity of $\alpha$-TOH in micellar systems is restricted because its inter-micellar diffusion, that is, its capacity to visit each micelle, is slower than the lifetime of peroxy radicals to circulate from one micelle to another. In this continuum of interphase diffusion, micelles could take part in lipid oxidation process, by conveying some important actors of the process such as surface-active molecules, antioxidants, and lipid oxidation products (such as hydroperoxides) (Li et al., 2020). In the same way, it is very likely that $\mathrm{TocOH}$ efficiency is modulated by its putative interaction with the micellar phase of the system. Furthermore, this micellar phase may be influenced by the concentration of $\mathrm{TocOH}$, because the number of ortho methyl substituents in the phenolic rings $(2,1$, and 0 in $\alpha-, \gamma$-, and $\delta$-tocopherol, respectively) takes part in the formation of co-micelles with other surfactant molecules. In addition, unlike the chromanol moiety that is similar among $\mathrm{TocOH}$ and is responsible for the chemical reactivity, the phytyl tail could result in greater dissimilarity between $\mathrm{TOH}$ and $\mathrm{T} 3$, as has been observed, for example, with T3, which appeared to be more readily incorporated into liposomal membranes (Yoshida et al., 2007). In addition to its physical structure, the polarity of the medium can also influence the antioxidant/prooxidant reactivity of $\mathrm{TocOH}$ via the electrostatic interaction effect. For example, hydrogen bonding with the phenolic group may reduce their antioxidant capacity in protic environments (Iwatsuki et al., 1994), resulting in higher prooxidant effect of $\alpha-\mathrm{TOH}$ in aqueous media than in aprotic and nonpolar solvents such as hexane (Cillard \& Cillard, 1980; Cillard et al., 1980; Sumarno et al., 1987).

\section{3 | CHEMICAL INTERACTION OF TOCOPHEROLS WITH OTHER MOLECULES}

The presence of other molecules (e.g., phenolic compounds, vitamin C, carotenes, proteins and peptides, phospholipids, etc.) that interact with $\mathrm{TocOH}$ either directly or indirectly may influence their effectiveness with respect to lipid oxidation (Figure 3).

\section{1 | Interactions with other antioxidant molecules (from antagonism to additive and synergistic effects)}

When several antioxidant molecules are present in an oxidizing lipid media, the total antioxidant capacity may be lower (antagonism), equal (additive), or higher than the sum of their individual effects (the so-called synergistic effect). Antagonism has been shown between $\alpha$-TOH and phenolic compounds such as rosmarinic acid and caffeic acid (Peyrat-Maillard et al., 2003; Samotyja \& Małecka, 2007), as well as with plant extracts rich in polyphenols (Banias et al., 1992; Hraš et al., 2000). Antagonism can be the result of (i) the regeneration of the less effective antioxidant by the more effective antioxidant, (ii) the oxidation of the more effective antioxidant by the radicals of the less effective antioxidant, (iii) competition between the formation of antioxidant radical adducts and regeneration of the antioxidant, and (iv) alteration of the microenvironment of one antioxidant by another antioxidant (Mortensen \& Skibsted, 1997a, 1997b; Peyrat-Maillard et al., 2003). However, antagonism mechanisms are not frequently documented, because co-addition of antioxidants usually yields additivity, and even synergism, with respect to lipid oxidation (Table 2). Three main mechanisms could explain the transition from an additive to a synergetic effect with TocOH: 


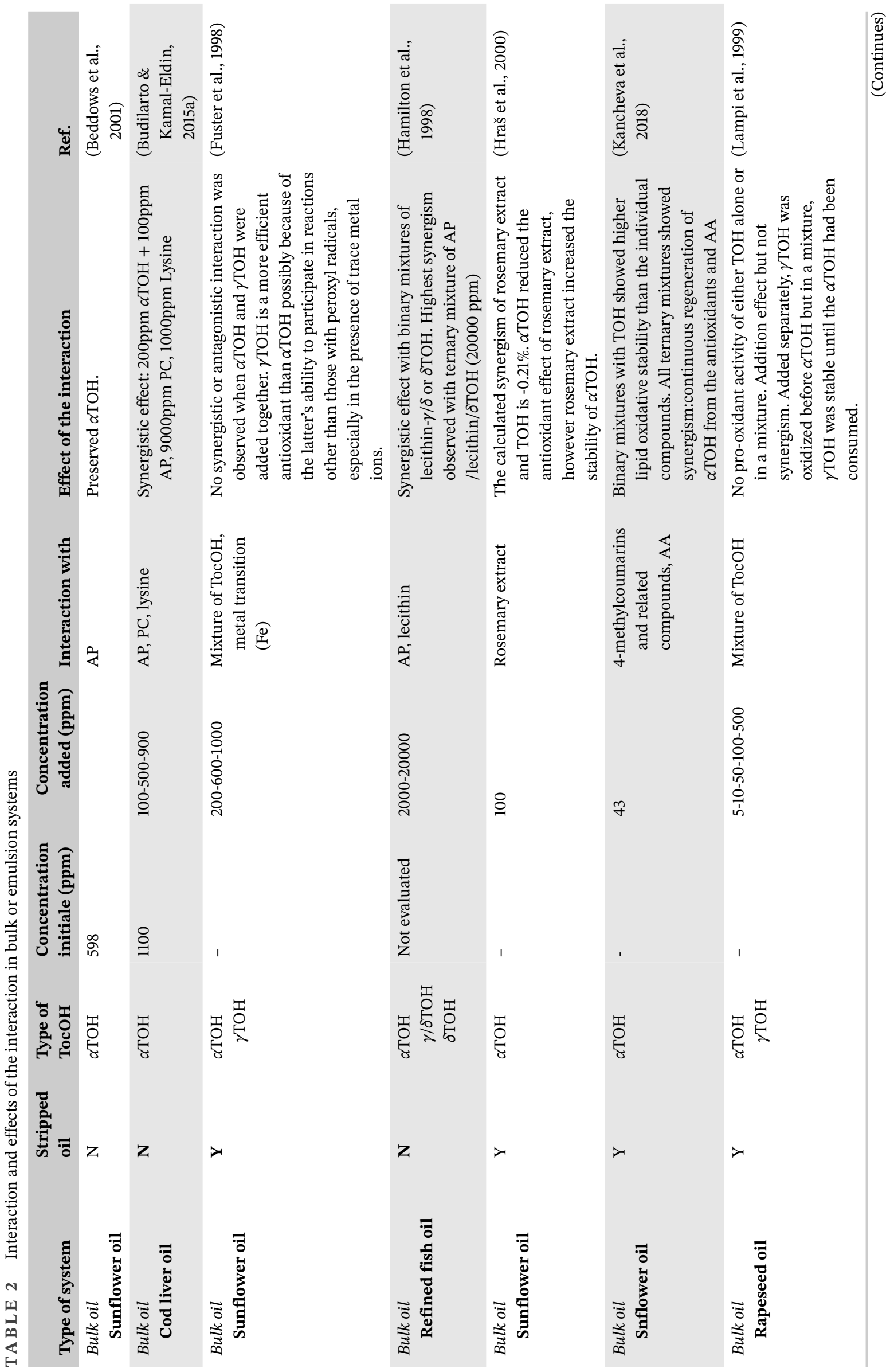




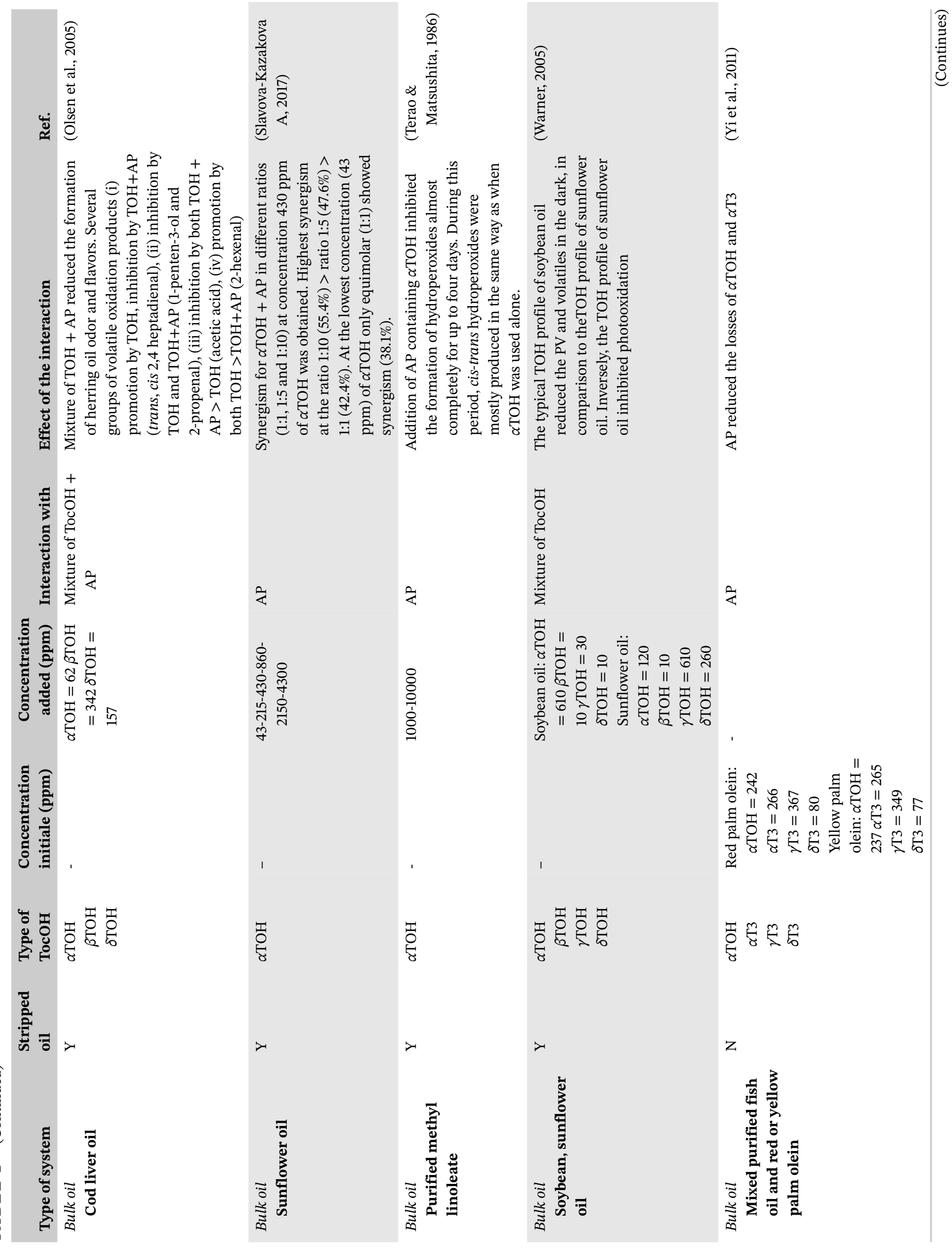




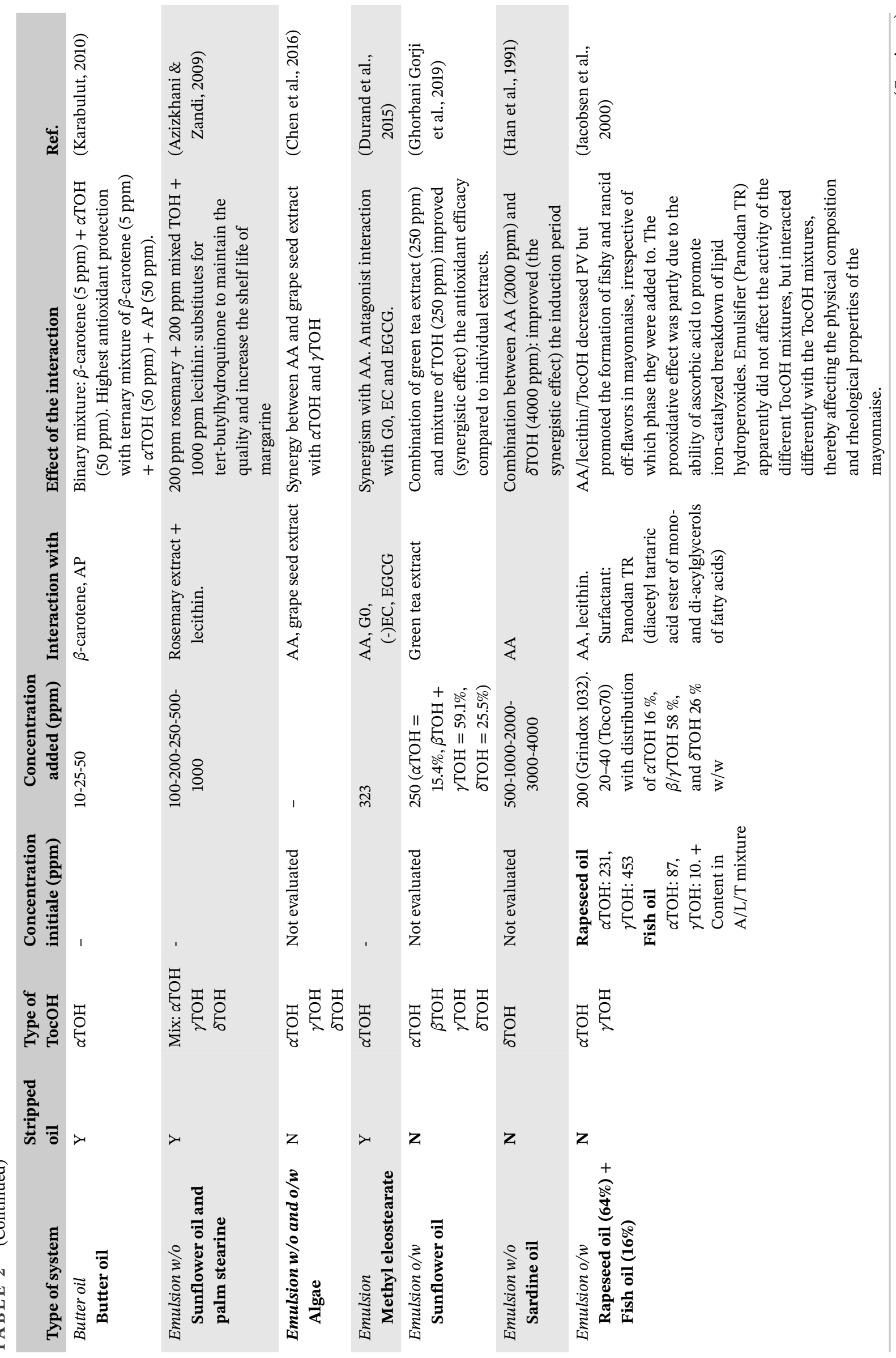




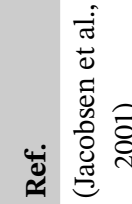

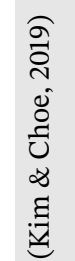
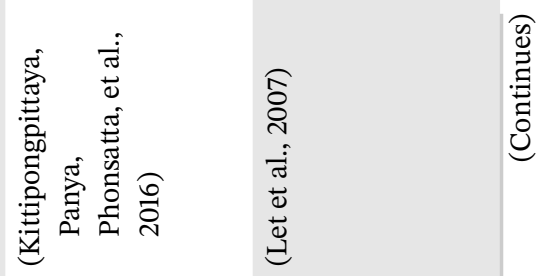

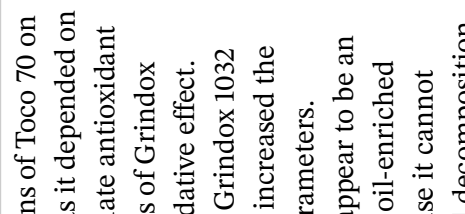

ప 0

菏

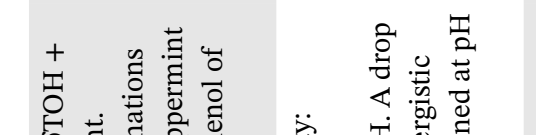

选

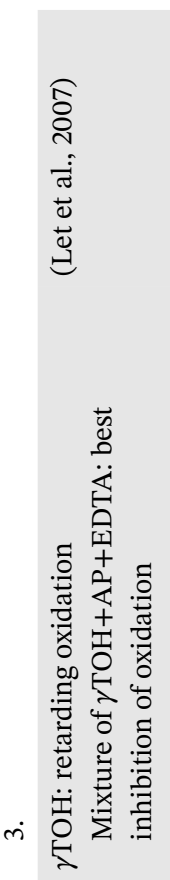

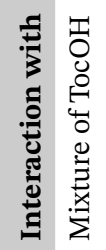

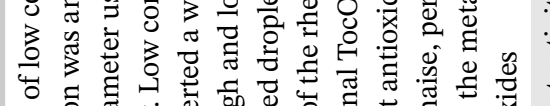

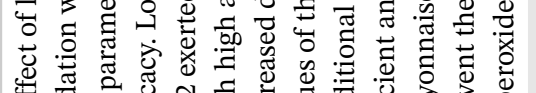

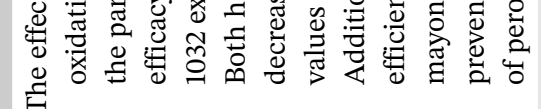

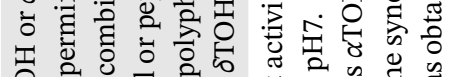

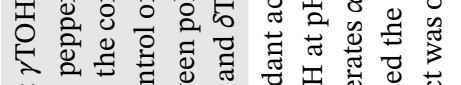

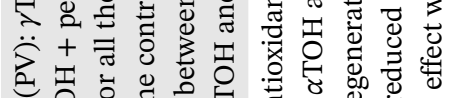

ह

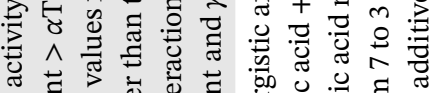

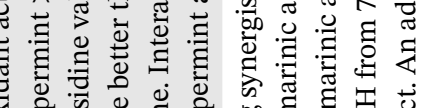

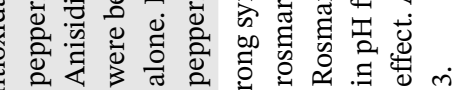

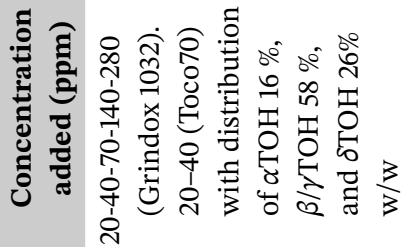

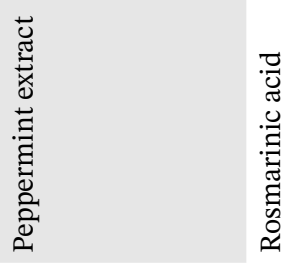

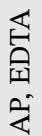

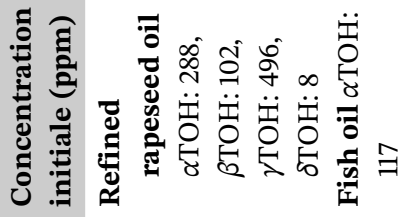

8

בิ

$\infty$
$\stackrel{\sim}{1}$
$\stackrel{1}{1}$

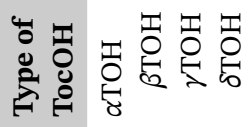

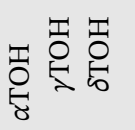

녕
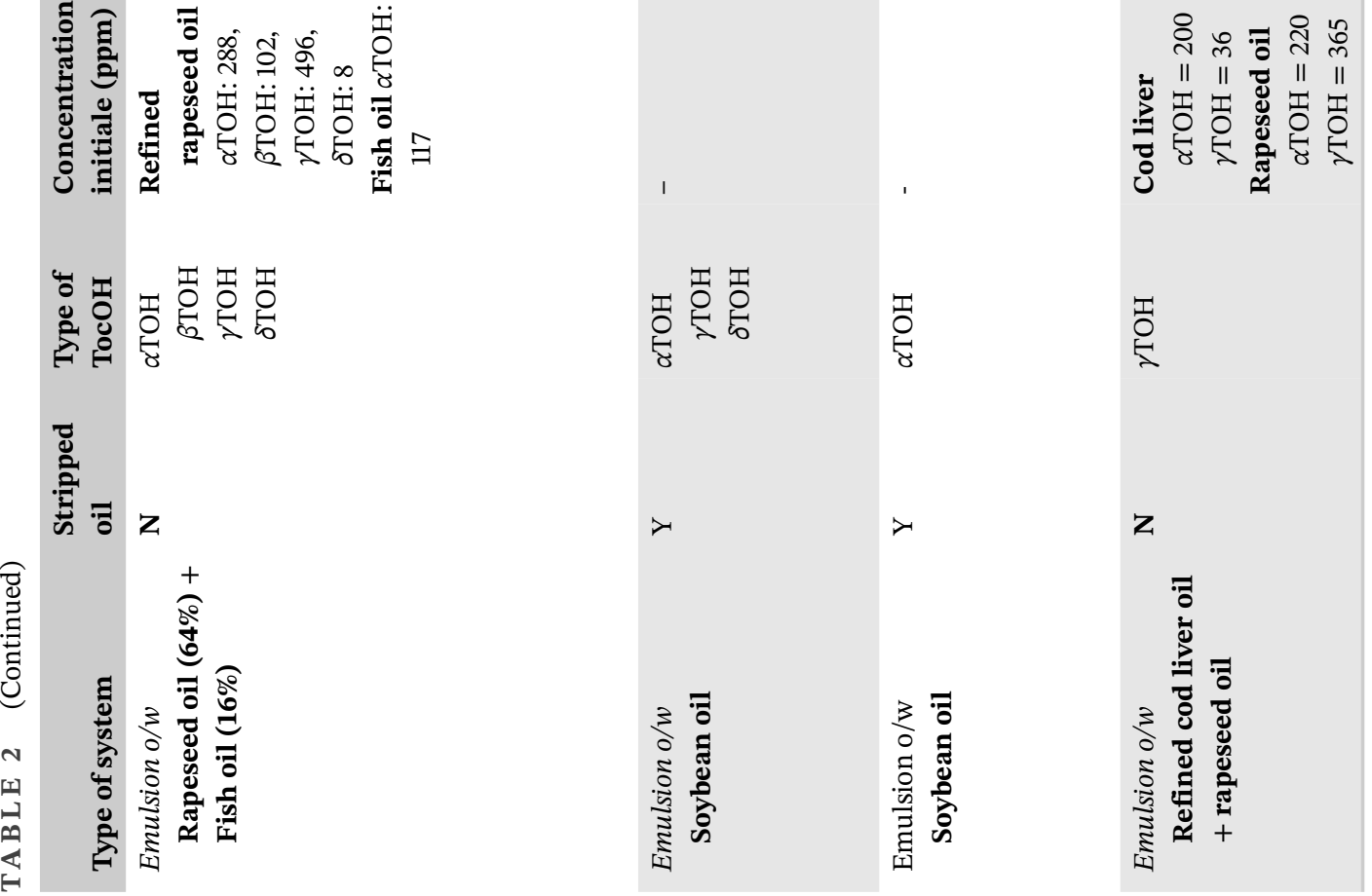

퐁

z

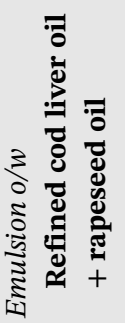




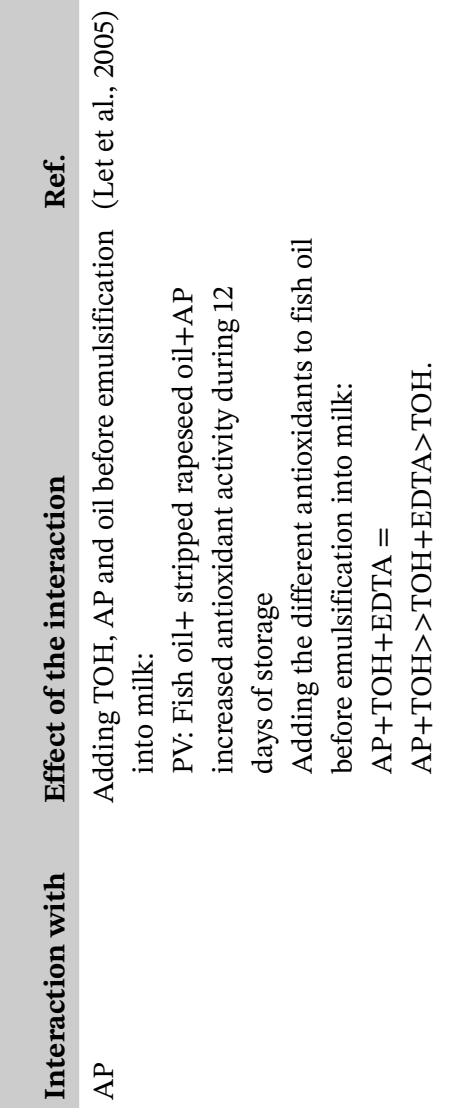

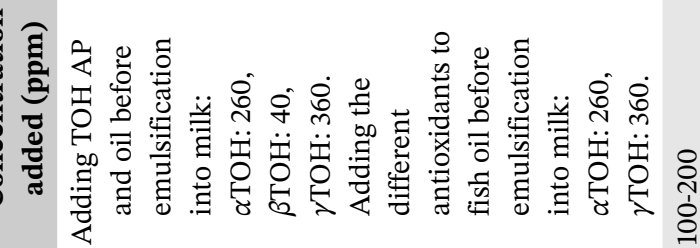

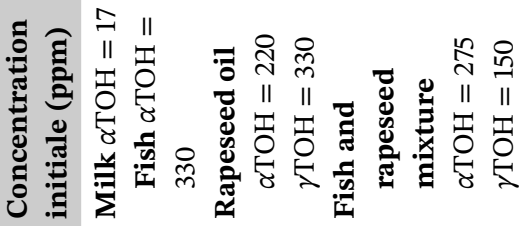

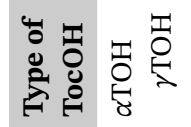
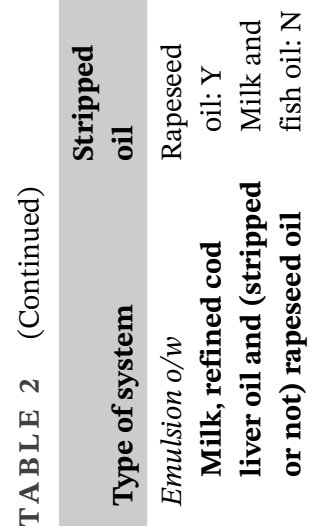

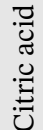
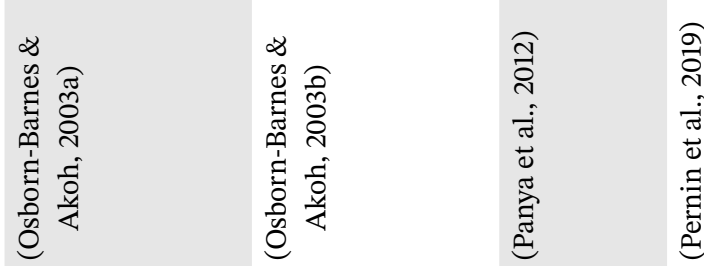

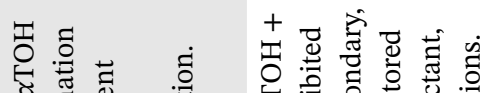

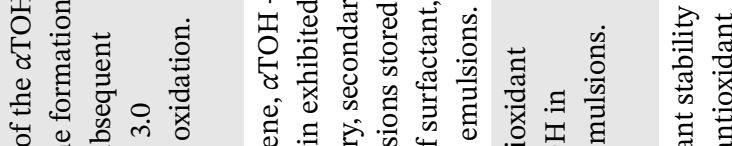

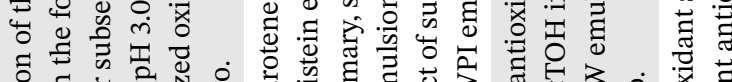

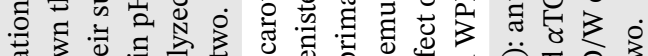

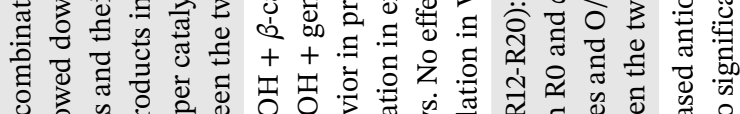

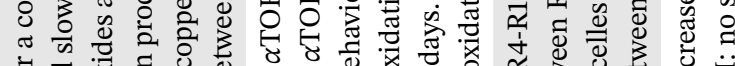

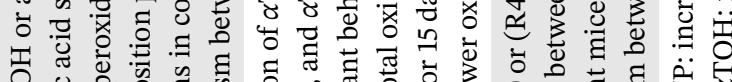

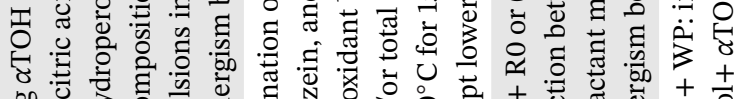
on

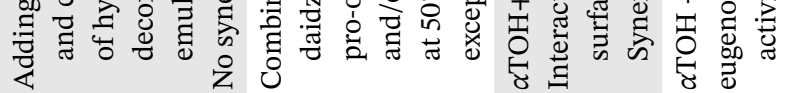

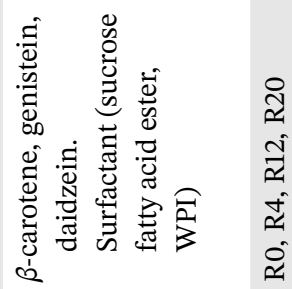

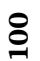

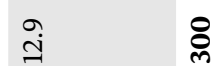

\&్ల
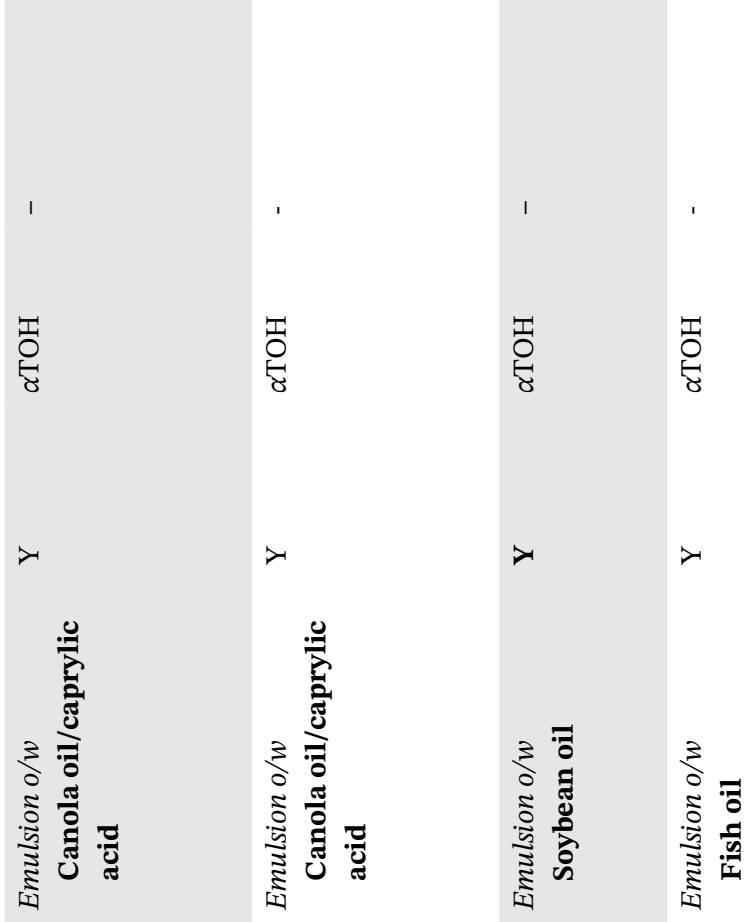


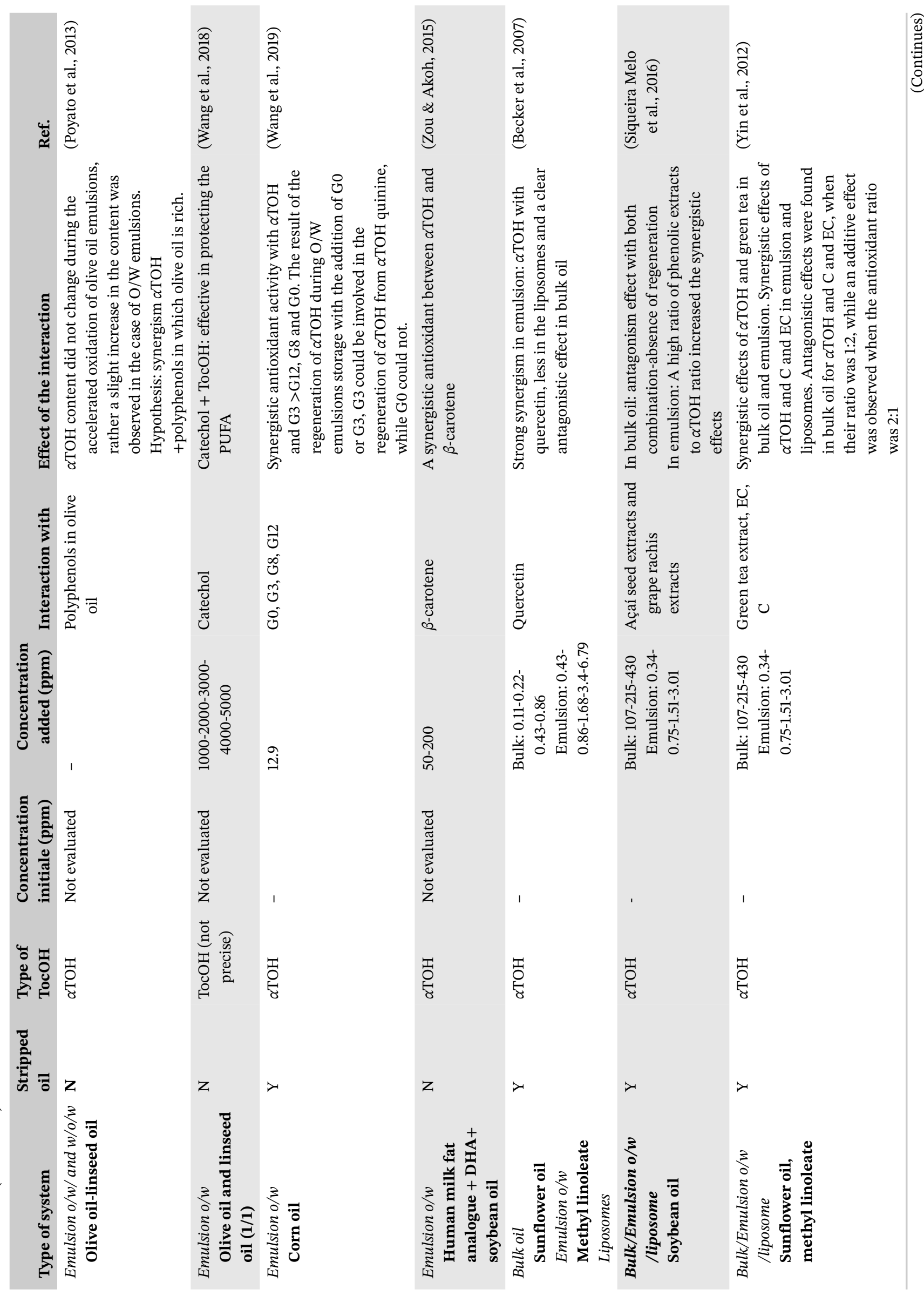




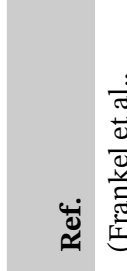

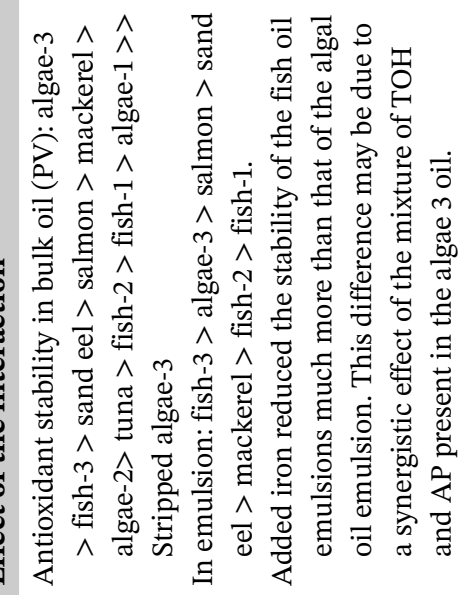

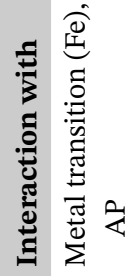

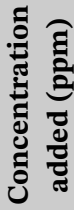

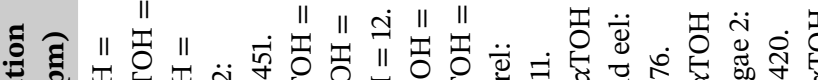

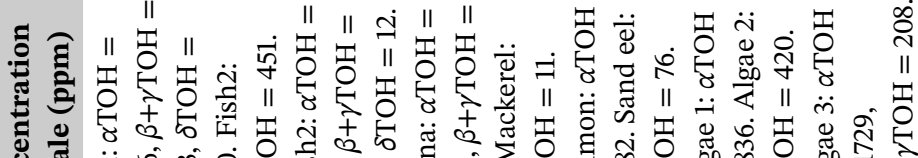

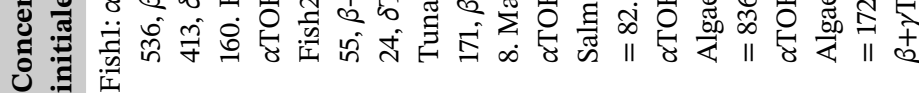

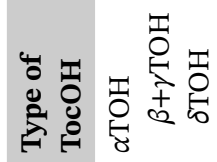

离

ठิ

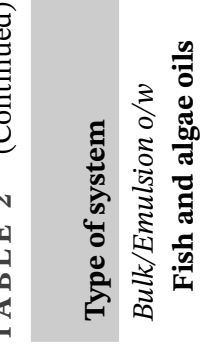

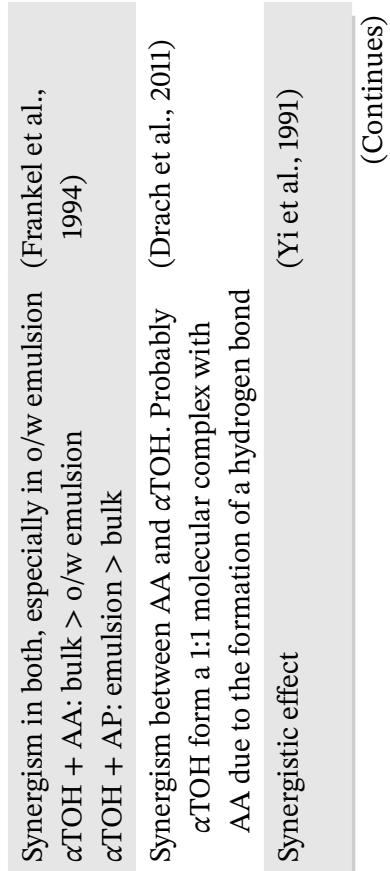

$\underset{4}{\&}$

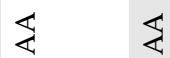

8
in
\&

in

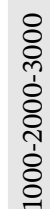

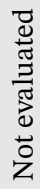

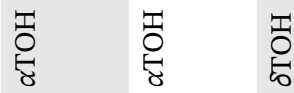

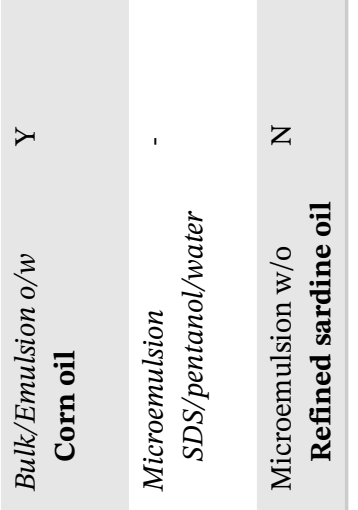




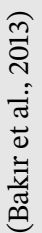
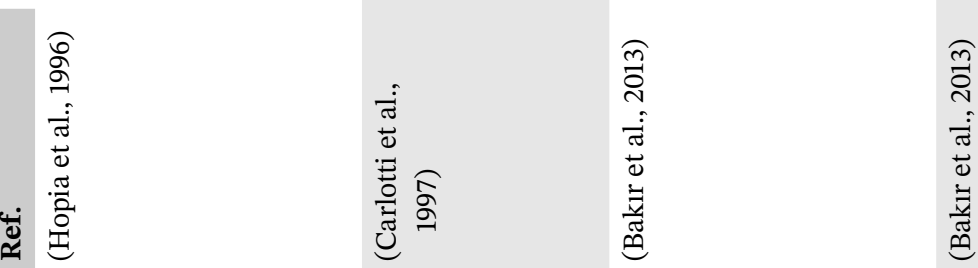

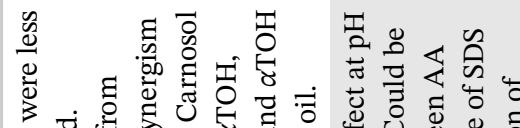

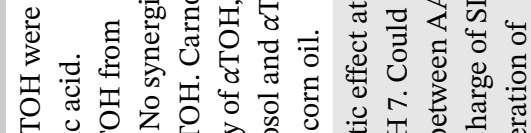

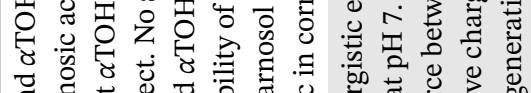
चี

₹

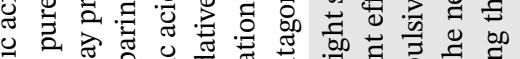

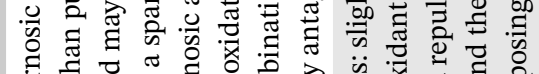

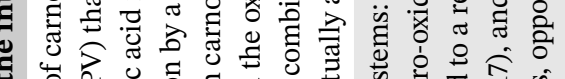

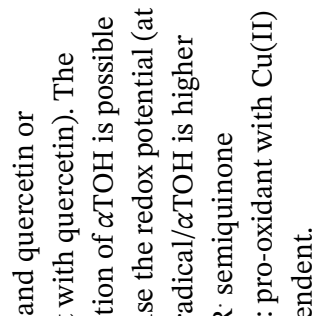
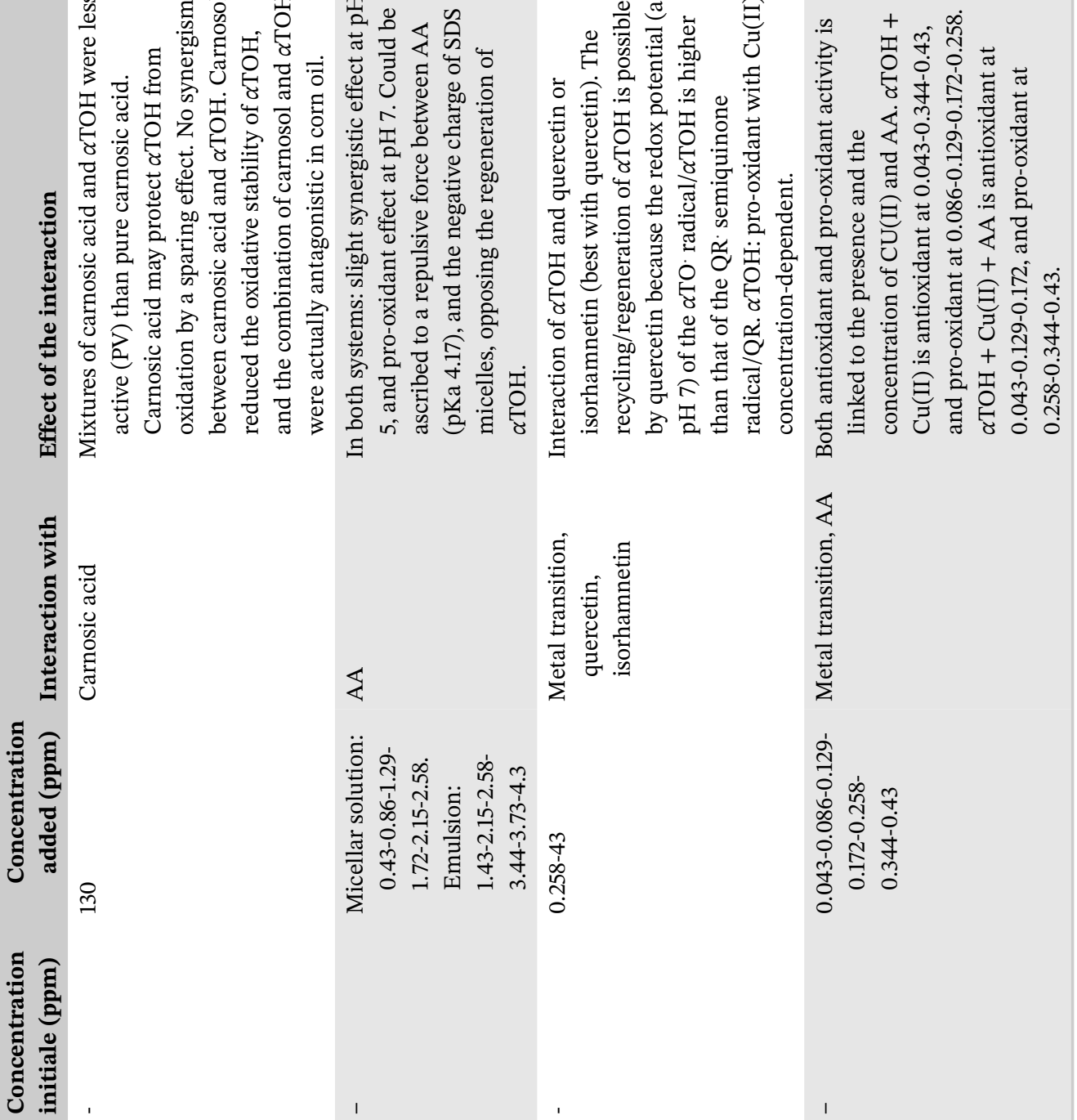

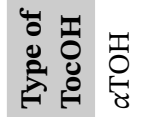

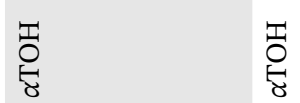

㞼
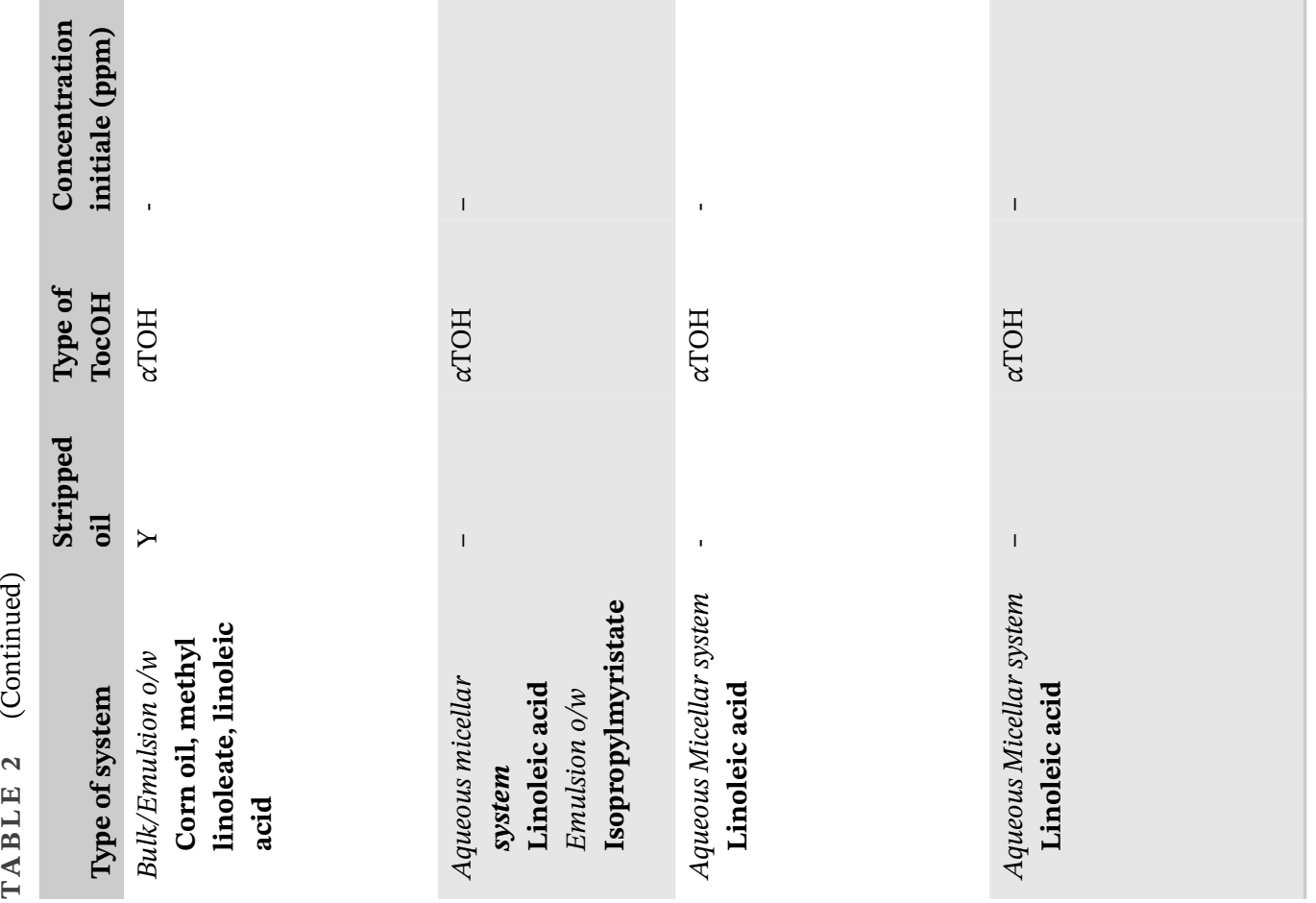


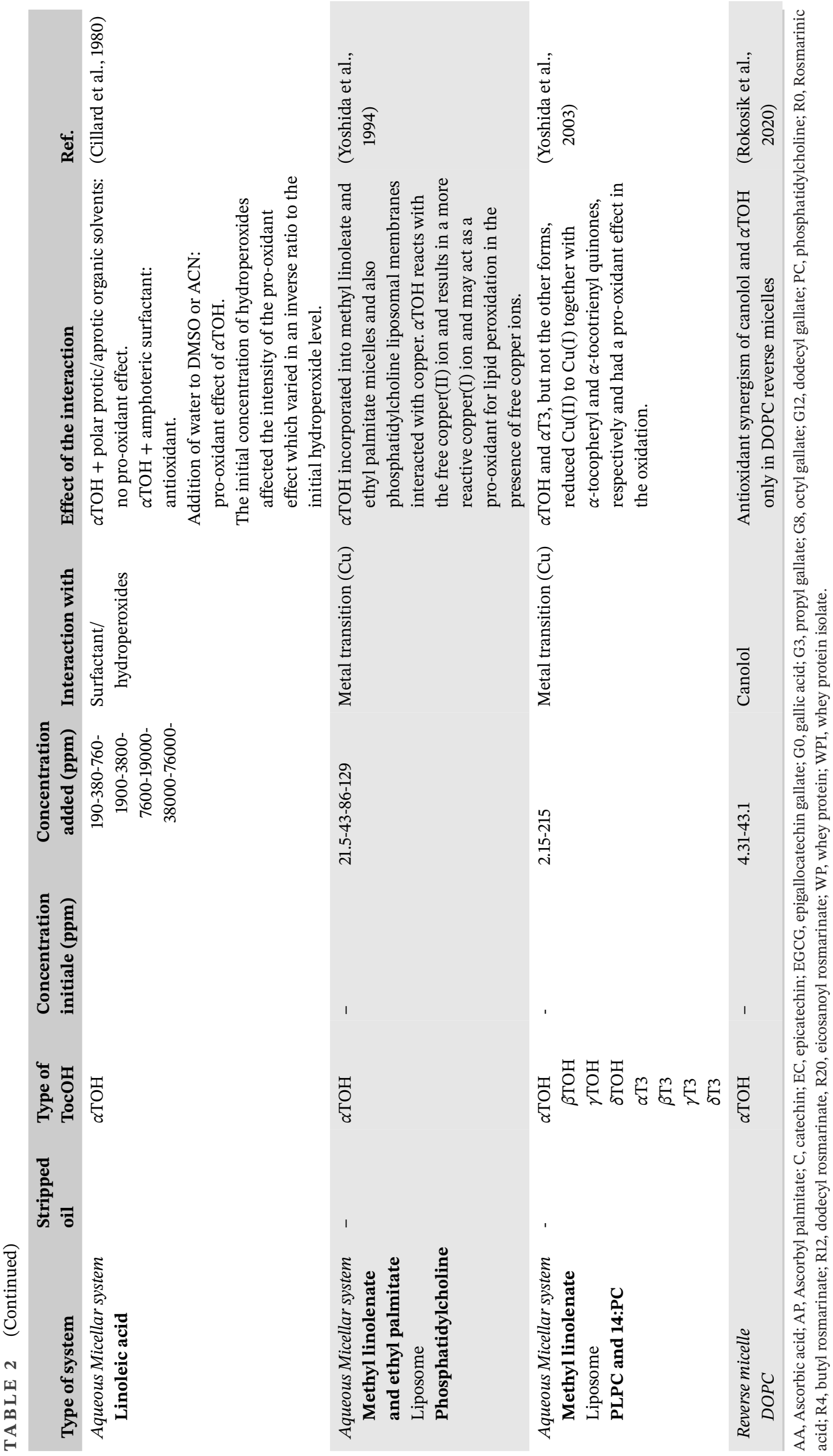


1. TocOH and radical scavengers: Intuitively, having antioxidants working with the same mechanism may not lead to a significant synergistic effect. Introducing another hydrogen donor in addition to $\mathrm{TocOH}$ may achieve the same effect as a higher concentration of $\mathrm{TocOH}$. Yet, considering that the relationship between the concentration of $\mathrm{TocOH}$ and its antioxidant effect was not predicted to be linear, one can hypothesize that a scavenging antioxidant compound introduced with $\mathrm{TocOH}$ at their optimal (low) concentration is responsible for highly efficient protection of lipids. That being said, this would not systematically produce a synergistic effect, but rather an optimal additive antioxidant effect. Considering the complexity of the chemical pathways (Figure 5) and the different factors involved, particularly the physical (micro) structure of the lipid system, this could happen when the radical scavenging ability of the antioxidants differs with the region. Thus, synergistic antioxidant actions may be obtained through the protective effect of one antioxidant by oxidizing itself (Decker, 2002; Pedrielli \& Skibsted, 2002). For example, the less effective antioxidant (or its radical produced from oxidation) traps alkyl peroxy radicals, so the best antioxidant does not oxidize, therefore extending the shelf life of products due to prolonged antioxidant activity. This process explains partially the interactions between carotenoids and $\mathrm{TocOH}$ (Haila et al., 1996; Zou \& Akoh, 2015). Moreover, mixed tocopherol analogs may enable better protection due to synergistic interactions. For instance, Fuster et al. (1998) observed such synergy between both $\alpha$-TOH and $\gamma$-TOH at a maximum concentration of $200 \mathrm{ppm}$. On the other hand, Lampi et al. (1999) reported an addition effect and no synergism with the same combination of $\mathrm{TocOH}$. The participation of phospholipids possessing a primary amine (e.g., phosphatidylethanolamine [PE] and phosphatidylserine), along with sulfur-containing amino acids (cysteine, cystine, and methionine), in radical-scavenging activity was also reported to have a sparing effect on $\mathrm{TocOH}$ and in that way may provide a synergistic effect (Judde et al., 2003; Lambelet et al., 1994).

2. Regeneration of TocOH: The mechanism is effective when $\mathrm{TocOH}$ with a substance are together. This substance is able to regenerate $\mathrm{TocOH}$ from their oxidation products, mostly the TocO radical, and hence restore their antioxidant activity. Indeed, $\mathrm{TocO} \cdot$ can be reduced through electron transfer from another antioxidant. This mechanism is all the more possible when: (i) the difference in BDE between antioxidants is high, (ii) the synergist has a lower standard reduction potential than $\mathrm{TocOH}(\mathrm{EO} \sim 0.5 \mathrm{~V})$, and (iii) when the rate constant to react with $\mathrm{TocO} \bullet$ is high and resem- bles that of the reaction constant with alkyl peroxy radicals $\left(\sim 10^{3} \mathrm{M}^{-1} \mathrm{~s}^{-1}\right.$; Figure $5, \mathrm{~A}_{5}$ or $\mathrm{A}_{6}$ ) (Amorati et al., 2002; Decker, 2002; Pedrielli \& Skibsted, 2002). Water-soluble antioxidants such as AA, gallic acid, epigallocatechin gallate, epicatechin gallate, epigallocatechin, epicatechin, quercetin, glutathione, and rosmarinic acid and its esters have already been shown to regenerate TocO in nano-emulsion systems (Niki et al., 1982; Panya et al., 2012; Pedrielli \& Skibsted, 2002; Wefers \& Sies, 1988; Zhou et al., 2005), whereas PE was found to synergize with $\alpha$-TOH by regenerating itself from $\alpha$-tocopherylquinone (Cui et al., 2015; Weng \& Gordon, 1993). TocO was reduced by antioxidants in the water phase. This phenomenon was described by some groups who worked in simple organic media and micellar systems using electron paramagnetic resonance (EPR), pulse radiolysis, or laser flash photolysis (Bisby \& Parker, 1991; Packer et al., 1979; Panya et al., 2012; Zhou et al., 2005). TocOH regeneration was also observed in membrane models and postmortem meat (Scarpa et al., 1984; Sharma \& Buettner, 1993); the same results were also described in vivo (i.e., TocO • was reduced in biological membranes). However, a lack of understanding persists because no group has succeeded direct observation of TocO $\cdot$ and aqueous phase antioxidant interaction in complex lipid dispersion systems (e.g., oil-in-water [O/W] emulsions). These observations are probably methodological challenges. We can suppose that the process of antioxidant synergy starts with the initial $\mathrm{TocOH}$ oxidation and the formation of TocO 0 (Figure $5, \mathrm{~A}_{4}$ ) becoming oriented at the oil and water interface and subsequently being reduced by the water-soluble antioxidant to regenerate TocOH. With the example of AA, its reduction of TocO • is thermodynamically favored by its low reducing potential (E0 $\sim 0.28 \mathrm{~V}$ and $0.5 \mathrm{~V}$ for TocO $\bullet$ vs. TocOH, respectively) (Becker et al., 2004), whereas the efficiency of rosmarinic acid and its esters to reduce $\alpha$-TO $\bullet$ was shown to be very low because of their higher electron reduction potential (E0 > 1.1 V) (Panya et al., 2012). The interaction between $\mathrm{TocOH}$ and carotenoids is another example of synergism. For instance, the prooxidant effect of lutein was inhibited by adding low levels of $\gamma-\mathrm{TOH}$, and the combination allowed the synergistic effect to inhibit the hydroperoxide formation of triacylglycerols (Haila et al., 1996). The benefit of a combination of a carotenoid and $\mathrm{TocOH}$ was attributed by the authors to the capacity of $\gamma$-TOH to retard the formation of degradation products of the carotenoid. The regeneration of carotenoid by $\mathrm{TocOH}$ is favored because the carotenoid radical cation has a higher potential than $\mathrm{TocO} \bullet$ (between $>0.5$ and $1 \mathrm{~V}$ vs. $\sim 0.5 \mathrm{~V}$, respectively) (Jeevarajan \& Kispert, 1996; Liu et al., 2000; Niedzwiedzki et al., 2005). Both 
the regeneration of carotenoid from its radical cation by $\mathrm{TocOH}$ and $\mathrm{TocOH}$ regeneration by the carotenoid from the TocO • radical are possible (Edge et al., 1998; Mortensen \& Skibsted, 1997a, 1997b; Mortensen et al., 1998).

Some authors proposed that such interactions occur in complex lipid dispersion, but in the absence of direct evidence for interactions between $\mathrm{TocO}$ - and water-soluble antioxidants, process of $\mathrm{TocOH}$ regeneration does not appeared like essential. Furthermore, the regeneration of the $\mathrm{TocO} \bullet$ is not systematically related to better protection of lipids. Indeed, if one molecule of antioxidant regenerates one $\mathrm{TocO} \cdot$, then the molecule of antioxidant is not free to act in oxidation of LH (i.e., reduce oxidizing species). This may be the reason why Durand et al. (2015) observed that, although AA seems to affect the global stability of $\alpha$-TOH in conventional $\mathrm{O} / \mathrm{W}$ emulsion, where, possibly, it is able to regenerate $\alpha-\mathrm{TOH}$ from $\mathrm{TO} \cdot$, the antioxidant capacity addition could be described like the combination of two separate effects. On the other hand, regeneration of TocO - may be a good way to prevent prooxidant action of $\mathrm{TocOH}$ when the latter has been oxidized or when it is located near the surface of reverse aggregates or micelles/interfaces containing attacking aqueous radicals (Figure 5, $\mathrm{P}_{1}$ ).

The complexity of the physical (micro)structure of the system is another parameter that may significantly affect this mechanism, either physically or chemically (Figure 3). For instance, the fact that $\mathrm{TocOH}$ are located in lipid droplet cores in $\mathrm{O} / \mathrm{W}$ emulsions could physically isolate TocO from the water-soluble antioxidants at the interface. Thus, lipid droplet internalization of TocOH may prevent their synergism with the antioxidants present in the aqueous phase. In addition, the composition and architecture of the interface, a region that is only a few nanometers thick composed of oil, water, and surface-active molecules, may affect this chemical regeneration. The net charge of the interface between oil and water depends on the surface-active molecules that compose and stabilize the system, which can be anionic (e.g., SDS), cationic (e.g., DTAB), nonionic (e.g., Tween), or zwitterionic (e.g., phospholipids). The thickness and the structure of molecules present in the interfacial phase (proteins, polysaccharides, etc.) along with the $\mathrm{pH}$, ionic strength, and so forth of the medium may significantly influence the penetration, diffusion, and interaction of molecules, and therefore the regeneration mechanism of $\mathrm{TocOH}$. All these conditions would explain the contradicting results of different experiments. Some studies were unable to demonstrate efficient interaction in $\mathrm{O} / \mathrm{W}$ emulsions, with no synergistic effect between the $\mathrm{TocOH}$ and various antioxidants dispersed in the aqueous phase, whereas other studies, on the contrary, found a strong influence (Kittipongpittaya, Panya, Phonsatta, et al., 2016; Sørensen et al., 2017).

3. Complementary antioxidant action: $\mathrm{TocOH}$ may provide significant synergistic effects when combined with antioxidants with metal chelating (detailed in the following paragraph) or a singlet oxygen quenching ability. This phenomenon can be explained by the presence of chelators or oxygen quenchers that reduced the effect of free radical scavengers. Metal chelators mostly interfere during the initial part of oxidation pathway, whereas $\mathrm{TocOH}$ are more active during the propagation step. Thus, TocOH showed synergistic effects with phospholipids, amino acids, peptides, and phenolic compounds, which are mainly the result of the metal-chelating activities of the latter, resulting in the production of fewer radicals to be reduced by $\mathrm{TocOH}$. (Bandarra et al., 1999; Bazin et al., 1984; Dziedzic \& Hudson, 1984; Hildebrand et al., 1984).

For instance, $\alpha-\mathrm{TOH}$ showed a synergistic effect when associated with phospholipids or quercetin, which inhibited metal-catalyzed oxidation through the formation of inactive complexes, whereas $\alpha-\mathrm{TOH}$ acts as a free radical scavenger (Hudson \& Lewis, 1983; Koidis \& Boskou, 2006; Servili \& Montedoro, 2002). The antioxidant properties of melanoidins (Maillard reaction products formed between reducing sugars and compounds containing an amino group, e.g., peptides and proteins; This Vo Kientza, 2016) also acted as synergists with $\mathrm{TocOH}$ and were partially linked to their metal-chelating properties (Namiki, 1988).

Once again, regardless of the synergistic mechanism involved and their possible interaction with $\mathrm{TocOH}$, the side effects of the complementary antioxidant molecule have to be taken into consideration, as does the nature of antioxidants and prooxidants, their chemical oxidative pathway, their concentration, and the complexity of the physical (micro)structure of the system. All these parameters may lead to different conclusions, even though the studies deal with similar compounds. For instance, synergistic interaction of rosmarinic acid (or caffeic acid) with $\alpha$-TOH was observed in stripped soybean oil in water emulsion (Panya et al., 2012), whereas other authors observed an antagonistic effect, either in rapeseed oil (in bulk or emulsion) or in an aqueous dispersion system of linoleic acid (Peyrat-Maillard et al., 2003; Samotyja \& Małecka, 2007). This consideration is even more important with antioxidant plant extracts that are rich in diverse molecules, in addition to the presence of presumably active antioxidants (e.g., phenolic compounds). For example, Wada and Fang (1992) highlighted a positive synergy between rosemary extracts and $\alpha-\mathrm{TOH}$ (500 and $200 \mathrm{ppm}$, respectively) in a 
sardine oil and in frozen-crushed fish meat, whereas other authors found an antagonist effect in rapeseed oil (stripped or raw, bulk or emulsion) (Samotyja \& Małecka, 2007).

\section{2 | Interaction with prooxidant metal transition}

Trace metal catalysts $(\mathrm{Fe}, \mathrm{Cu}, \mathrm{Ni}, \mathrm{Co}, \mathrm{Mn}$, etc.) may be present almost everywhere, including in the aqueous or buffer phase, in oils, and in some antioxidant plant extracts. The chemical action of metals on lipid oxidation in multiphasic systems follows several pathways (Schaich, 1992). State metals of higher valence can transfer an electron and result in the direct oxidation of LH; conversely, state metals of lower valence form metal oxygen transition complex and lead to autoxidation (Ingold, 1961; Uri, 1961). Preformed lipid hydroperoxides (LOOH) can get reduced or oxidized by metals. Such reactions trigger the formation of $\mathrm{LO} \cdot$ and $\mathrm{LOO}$ radicals, or decompose the hydrogen peroxide into $\mathrm{HO} \cdot$. Therefore, the global kinetics of lipid oxidation process is significantly accelerated because these radicals remove hydrogen faster from any oxidizable substrate than the initial rates of $\mathrm{L} \cdot$ formation (Kremer, 1963; Waters, 1971). Besides, metals affect not only the rate of initiation and total extent of lipid oxidation by peroxide decomposition, but also alter the nature and distribution of oxidation products and termination reactions (for instance, rearrangement of $\mathrm{LOOH}$ into epoxides can be observed) (Schaich, 2020). Transition metal ions at lower valence states, such as $\mathrm{Fe}^{2+}$ and $\mathrm{Cu}^{+}$, can decompose $\mathrm{LOOH}$ much faster than those at higher valence states, $\mathrm{Fe}^{3+}$ and $\mathrm{Cu}^{2+}$ (Schaich, 1992). This is the main explanation for why the antioxidants that reduce metal ions may, under certain circumstances, act as prooxidants (Keceli \& Gordon, 2002). Concerning TocOH, it has been shown that $\alpha$-form reduced cupric iron $\left(\mathrm{Cu}^{2+}\right)$ leading to an increase in lipid oxidation (Yoshida et al., 2003). In contrast, $\beta-, \gamma-$, and $\delta$ - analogs were not able to significantly reduce $\mathrm{Cu}^{2+}$, likely due to their higher oxidation potentials, and consequently had no prooxidant effect (Yoshida et al., 2007). In that context, metal chelators are particularly efficient in limiting lipid oxidation by preventing the various chemical pathways catalyzed by transition metals (e.g., formation of insoluble metal complexes, steric obstruction either between metals and oxidizable food components or between metals and their oxidation products). TocOH do not appear to be strong metal chelators. However, combining TocOH with efficient metal chelators could have synergistic effects (see Section 2.1). Both citric acid and EDTA are the conventional metal chelators used in foods. Yet, metal ions can also get linked up by phospholipids, flavonoids, lignans, polyphenols, AA, proteins, pep- tides (e.g., carnosine), and free amino acids (e.g., histidine) (Koidis \& Boskou, 2006; Rice-Evans et al., 1996; Riisom et al., 1980). The formation of metal/chelator complex has a double effect: (1) it impacts the electron density of the metal and thus modify its redox potential, and (2) it affects the distribution and availability of the metallic ions in the multiphasic system. By this double action, both the balance of reactants in the system and global oxidation reaction are affected. To take a precise example, the formation of EDTA/iron complex will both capture free or weakly complexed iron and will lower the $\mathrm{Fe}^{3+} / \mathrm{Fe}^{2+}$ redox potential $(0.77 \mathrm{vs} .0 .12 \mathrm{~V})$. This lowering of potential will induce a faster reduction of lipid hydroperoxides (Mahoney et al., 1986; Schaich, 1992).

\section{3 | Physical interactions to drive chemical pathways (e.g., lipid hydroperoxides and phospholipids)}

The chemical reactivity between molecules lies in their capacity to interact, so they have to be in each other's vicinity. In multiphasic systems, in which some surface-active molecules can get aggregated and define specific phases or substructures, the relative distribution of molecules acting in the oxidation process is difficult. For instance, lipid hydroperoxides $(\mathrm{LOOH})$ or phospholipids trigger the formation of microstructures (e.g., reversed micelles in bulk oils) that change the partition and interactions between molecules. Altogether, these modulations of distribution alter the global oxidation process of the system (Huang, Hopia, et al., 1996). Antioxidants such as TocOH may alter the distribution of oxidation products. Indeed, TocOH can influence the relative abundance of the oxidative products, for example, in the qualitative and quantitative variation in the proportion of $\mathrm{LOOH}$ isomers, and their subsequent secondary decomposition products (Coxon et al., 1984; Frankel \& Gardner, 1989; Peers \& Coxon, 1983; Peers et al., 1981; Terao \& Matsushita, 1986; Yamagata et al., 1983). These results suggest that (i) TocOH interact with $\mathrm{LOOH}$, perhaps through hydrogen bonding assisted by van der Waals interactions, and (ii) lipid oxidation products are affected by the capacity of antioxidants (e.g., $\mathrm{TocOH}$ ) to interact, or self-assemble, with primary oxidation products. Similarly, phospholipids are known to influence the antioxidant behavior of $\mathrm{TocOH}$ through a physically assisted mechanism that affects their distribution and consequently their antioxidant effect (Koga \& Terao, 1995). Phospholipids, in addition to the water level found in commercial refined oil, can self-assemble in bulk oils to form microstructures such as reverse micelles that can incorporate antioxidant compounds (e.g., TocOH) (Chen et al., 2010), and consequently influence the microenvironment 
where lipid oxidation chemistry occurs. For instance, association colloids formed by dioleoylphosphatidylcholine (DOPC) in stripped soybean oil had a prooxidant effect, and DOPC reverse micelles improved the antioxidant activity of low concentrations $(10 \mu \mathrm{M})$ of $\alpha-\mathrm{TOH}$ or Trolox, whereas the opposite effect was found at a higher concentration $(100 \mu \mathrm{M})$ (Chen et al., 2011), likely due to competition between antioxidant (free radical scavenging) and prooxidant (reduction of transition metals) activities. Interestingly, the dioleoylphosphatidylethanolamine (DOPE) reverse micelle did not catch $\alpha$-TOH in contrast to the DOPC reverse micelles. Thus, the physical location of $\alpha-\mathrm{TOH}$ did not change in DOPE reverse micelles. However, the regeneration of $\alpha$-TOH quinone by DOPE primary amine head group likely via an ionic mechanism increased the antioxidant capacity (Cui et al., 2015). Trolox that is polar than $\alpha$-TOH was also more antioxidant in the presence of both DOPC and DOPE reverse micelles because it got segregated into the aqueous-phase microenvironment of reverse aggregates, closer to the oil-water interface than $\alpha$-TOH (Cui et al., 2015) (Figure 2c). In conclusion, TocOH interactions with surface-active molecules may alter their physical location, which in turn would alter the overall impact on lipid oxidation.

\section{4 | THE PHYSICAL DISTRIBUTION OF TOCOPHEROLS IN SYSTEMS MODULATES THEIR ANTIOXIDANT EFFECT}

Understanding the location (distance from the interface, lateral distribution), orientation, and mobility of TocOH in heterogeneous systems and bilayers of phospholipids representative of biological membrane is a key aspect of their antioxidant role. TocOH may in turn impact membrane fluidity and the molecular mobility of reactive components in the vicinity of membranes. Recent experimentation, modeling, and theoretical studies have elucidated the molecular mechanisms underlying cooperation between membrane components and several phenolic compounds including $\mathrm{TocOH}$, vitamin $\mathrm{C}$, and polyphenols. These antioxidants form a noncovalent association with the lipid bilayer close to the membrane/internal part of the assembly interface. Such a supramolecular association and location is hypothesized to favor antioxidants regeneration (Fabre et al., 2015). More generally, the distribution of $\mathrm{TocOH}$ in heterogeneous systems can be seen as a dynamic picture influenced by the present amphiphiles, their state of association, phase, and charge, and the presence of other synergetic antioxidants.

\section{1 | Specificity of interactions with phospholipids}

Among the pioneer works, Hildebrand et al. (1984) demonstrated that combining phospholipids (PL) and $\mathrm{TocOH}$ enhanced their antioxidant effect on stabilizing refined bulk oils. The work of these authors was based on the empirical observation that crude oil containing phospholipids at concentrations of $0 \%-1 \%$ was more stable than refined oil. They tested a factorial combination of three levels of soybean TocOH (blend of three isomers and $\alpha, \delta$, and $\gamma$ at respective levels of $5.4 \%, 44.9 \%$, and $49.8 \%$; tocopherol at levels of $0,1.2$, and $4-5 \mathrm{mg} / \mathrm{g}$ oil) and two levels of PL ( 0 and $5 \mathrm{mg} / \mathrm{g}$ oil phosphatidylcholine [PC] and PE, and 0 and $2.5 \mathrm{mg} / \mathrm{g}$ oil phosphatidic acid (PA) and phosphatidylinositol [PI]). The efficacy of such combinations was determined by measuring the induction period in days before refined soybean oil incubated at $110^{\circ} \mathrm{C}$ reached a $\mathrm{PV}$ value of $100 \mathrm{meq} / \mathrm{kg}$. The most effective stabilization was reached by adding either all PL at highest levels, plus TocOH at intermediate to high levels (1.2-4 mg/g oil), or the highest levels of PC and PE (5 mg/g oil), and a similar amount of TocOH. Alone, neither TocOH nor PL were as effective. Among the PL, the same authors concluded that PE and PI were the most effective in increasing oil stability, although proof of real higher efficacy of PI in this experiment can be questioned. Concerning the mechanism behind PL protection and synergy with $\mathrm{TocOH}$, the authors excluded simple prooxidant metal chelation by PL (citric acid added as a control to test this hypothesis) and rather proposed the hypothesis that PL could increase $\mathrm{TocOH}$ capacity of free radical termination. Indeed, they hypothesized that some reactive PL groups (amine for PE and PC, reducing sugar for PI) could facilitate $\mathrm{H}$ or electron transfer to $\mathrm{TocOH}$ and their regeneration.

Following this thread, Judde et al. (2003) tested the addition of standard lecithins at $1 \% \mathrm{w} / \mathrm{w}$ concentration in various oils with given FA and TocOH composition. Overall, the addition had a protective effect against oxidation. However, protection depended not only on the phospholipid profile of the tested lecithin (lecithins containing high amounts of PC and PE were more efficient), but also on the FA profile in the tested oil. Lastly, the type of $\mathrm{TocOH}$ present in the oil also influenced antioxidant capacity (strong synergetic effect was evidenced for mixtures of $\gamma$ - and $\delta$-tocopherols with lecithin but no effect was evidenced for $\alpha$-tocopherol). In terms of the FA profile of the oil, the authors established that the addition of lecithin $(1 \% \mathrm{w} / \mathrm{w})$ was effective in stabilizing linoleic oils that contain a natural blend of $\gamma / \delta$-tocopherols, but not PUFA oils that naturally contain mainly $\alpha$-tocopherols. To further test this hypothesis and to untangle the effects of 
(a)

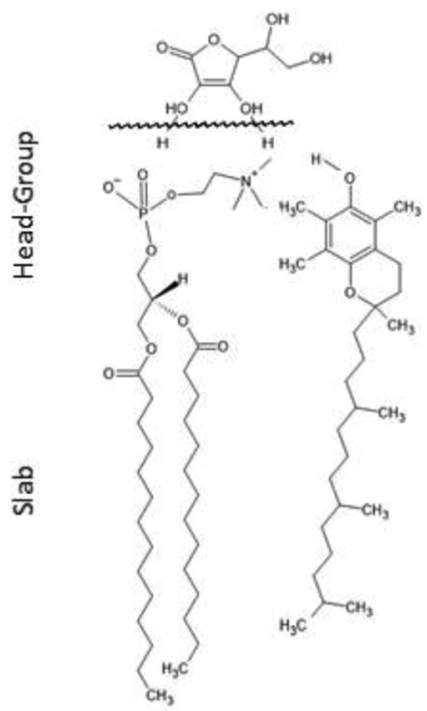

(b)

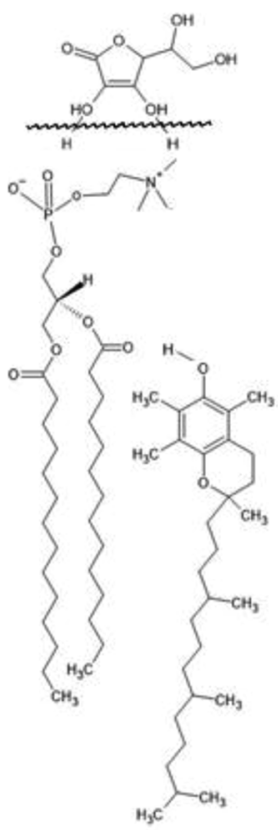

(c)

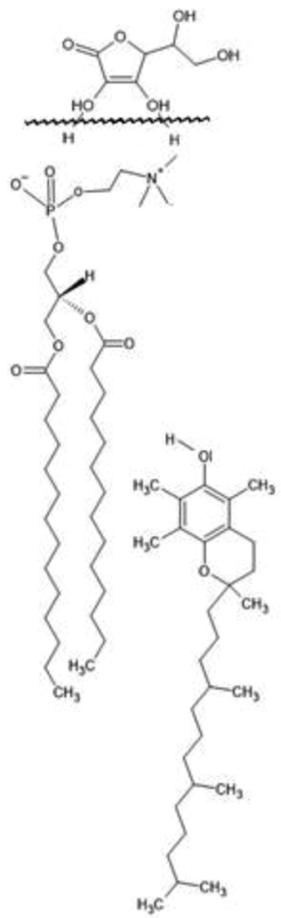

F I G U R E 8 Schematic models of the location of tocopherol in the lipid bilayer. Adapted from Afri et al. (2004)

TocOH isoforms and the FA profile, they assessed the stability of methyl esters blended with various $\mathrm{TocOH}$ and in the presence of $1 \% \mathrm{w} / \mathrm{w}$ lecithin. The addition of $\alpha$ or $\delta$-tocopherol resulted in slower oxidation kinetics for all methyl esters. Particularly for linoleate and linolenate, these results confirmed the greater antioxidant efficiency of the $\gamma$-/ $\delta$-tocopherol mixture compared to $\alpha$-tocopherol alone. Concerning PUFA methyl esters, the addition of lecithin improved the efficiency of the tocopherols, particularly $\gamma$-/ $\delta$-tocopherols. The model with methyl esters thus confirmed the previous observations concerning linoleic or linolenic oils rich in $\gamma$ - or $\delta$-tocopherols such as rapeseed, soy, and walnut.

In the 1990s, the physical interaction between $\mathrm{TocOH}$ and phospholipids was introduced for a better understanding of their chemical synergy (Salgado et al., 1993). Combining nuclear magnetic resonance (NMR) (31P), Fourier-transform infrared spetroscopy (FTIR). and light microscopy, these authors demonstrated that $\alpha$-TocOH tends to stabilize bilayers of PC instead of micelle.

Since then, several experimental and modeling studies have proven that the location and association of $\mathrm{TocOH}$ within membrane glycerophospholipids enhances their efficiency. For example, the vertical location of $\mathrm{TocOH}$ in phospholipid membrane was investigated in depth. The three hypotheses summarized in Figure 8 were initially proposed (Fukuzawa et al., 1993). Experimental evaluation of $\mathrm{TocOH}$ analogs in the liposomal bilayer of dimyris- toylphosphatidylcholine (DMPC) was conducted using the 13C NMR chemical-shift/polarity correlation technique to shed light on the physical framework favoring "lipidactive antioxidant" recycling by hydrophilic AA (Afri et al., 2004). Using a quite high load of TocOH (TocOH/DMPC ratio of 1:5, i.e., $17 \mathrm{~mol} \%$ ), these authors established that the tocopherol chromanol hydroxyl C6 group lies very close to water interface between location A and B (Figure 8) where it can abstract $\mathrm{H}$ from $\mathrm{AA}$ (Figure 8c).

The vertical distribution of $\alpha$-tocopherol, that is, with the chromanol ring located in the upper part of the hydrophobic bilayer and the tail chain parallel to the PC acyl chains, was proven more recently in saturated PC (DMPC, DPPC) by coupling physical characterization (small- and wide-angle X-ray diffraction, fluorescence quenching, and $1 \mathrm{H}$ nuclear Overhauser enhancement spectroscopy [NOESY] magic-angle spinning [MAS]NMR spectroscopy (Ausili et al., 2018).

There is now quite a consensus that $\alpha-\mathrm{TOH}$ location close to lipid-water interface is universal and has been checked experimentally in various model bilayers (1palmitoyl-2-oleoyl-sn-glycero-3-phosphoethanolamine, 1-palmitoyl-2-oleoyl-sn-glycero-3-phospho-L-serine, and sphingomyelin bilayers) by Marquardt et al. (2015). However, one exception was reported by same authors (Marquardt et al., 2014) in artificial DMPC bilayers.

Molecular dynamic simulations can predict the location of $\mathrm{TocOH}$ in membrane. A simulation in a lipid bilayer 
comprising DOPC molecules indicated that $\mathrm{TocOH}$ are generally inserted below the membrane/water interface but reach the bilayer center (Fabre, 2015). More precisely, simulation but also experimental data (Marquardt et al., 2013) evidenced that the extremity of C5-methyl group of $\mathrm{TocOH}$ is located $1.5-1.7 \mathrm{~nm}$ from the center of the bilayer. $\alpha-\mathrm{TOH}$ insertion in the bilayer is hypothesized to favor the location of the $\mathrm{OH}$ group close to the lipid polar head group, that is, close to the interface where it promotes lipid oxidation. Fabre et al. (2015) stated that the $\mathrm{OH}$ group of $\mathrm{TocOH}$, which is responsible for free radical scavenging by hydrogen atom transfer, was mainly located close to the lipid polar head groups, that is, at the lipid/water interface, suggesting inhibition of both the initiation and propagation steps of lipid oxidation. In addition to the vertical location, the lateral distribution of $\mathrm{TocOH}$ within a liposomal bilayer can be questioned, as this distribution is also dependent on the composition and heterogeneity of the bilayer. It was hypothesized that $\alpha$-TOH have more affinity for PUFA and thus get segregated in the fluid zone of heterogeneous membrane (Atkinson et al., 2010) and reduce fluid-gel membrane transitions (Paz Sánchez-Migallón et al., 1996). In addition, and as can be inferred from chemical mobility, $\alpha$-tocopherol is oxidized faster in liquid phase than in gel phase (Fukuzawa, 2008).

Another important point to address is the vertical and lateral mobility of $\mathrm{TocOH}$ within the bilayer, which is not yet settled and is highly influenced by the chemical composition of the bilayer. It was suggested very early that $\alpha$-tocopherol lateral diffusion coefficient was 100 times higher than that of PC (egg yolk) $\left(4.8 \times 10^{-6} \mathrm{~cm}^{2} \mathrm{~s}^{-1}\right.$ at $25^{\circ} \mathrm{C}$ vs. $0.9-1.8 \times 10^{-8} \mathrm{~cm}^{2} \mathrm{~s}^{-1}$ at $20^{\circ} \mathrm{C}$, respectively) favoring its action as a mobile antioxidant barrier (Fukuzawa et al., 1992).

Boonnoy et al. (2017) investigated the dynamic distribution of $\alpha$-tocopherol in oxidized bilayers using molecular dynamic simulations. The authors showed that the addition of $\alpha$-tocopherol in bilayers of 1 palmitoyl-2-linoleoyl-sn-3-phosphocholine and the two aldehydes deriving from it (1-palmitoyl-2-(9-oxononanoyl)-sn-3-phosphocholine and 1-palmitoyl-2-(12oxo-cis-9-dodecenoyl)-sn-3-phosphocholine) at a ratio of 1:1 tended to reduce or even inhibit pore formation within the bilayer at high $\alpha-\mathrm{TOH}$ concentrations. Such pores result from the tendency of oxidized lipids to aggregate, a phenomenon that subtends the formation of a water pore across the bilayer. A mechanism of protection has been proposed, suggesting that $\alpha$-tocopherol traps the polar group of the oxidized lipids at the membrane interface.

Still using molecular dynamic simulations (Boonnoy et al., 2018) confirmed that $\alpha$-tocopherol remained buried in the lipid bilayer containing oxidized lipids and with the hydroxyl group in contact with the interface.
Model bilayers were based on 1-palmitoyl-2-lauroylsn-glycero-3-phosphocholine (PLPC). Oxidation was modeled using 1:1 binary mixtures of PLPC and one of its four main oxidative derivative products (either hydroperoxides [1-palmitoyl-2-(9-hydroperoxytrans-10, cis-12-octadecadienoyl)-sn-glycero-3-phosphocholine,

9-tc and 1-palmitoyl-2-(13-hydroperoxy-trans-11,cis-9octadecadienoyl)-sn-glycero-3-phosphocholine, 13-tc] or aldehydes [1-palmitoyl-2-(9-oxo-nonanoyl)-sn-glycero3-phosphocholine, 9-al and 1-stearoyl-2-(12-oxo-cis-9dodecenoyl)-snglycero-3-phosphocholine]). Inter-bilayer flip-flop was observed and enhanced (higher frequency) in the aldehyde lipid bilayer. These authors demonstrated that flip-flop rates hinge on the type of oxidized species present in the bilayer. $\alpha-\mathrm{TOH}$ were initially studied at concentrations ranging from $0 \%$ to $11.1 \%$ but higher concentrations-5.9\% and $11.1 \%$-led to much slower passive penetration into the bilayer (over several microseconds, whereas 100 - to 1000 -fold faster penetration occurred at lower concentrations). Such high initial concentrations could even lead to pore formation in the bilayer.

Accordingly, the strong physical interactions of phospholipids with $\mathrm{TocOH}$ will eventually modify the antioxidant effect of the latter. For example, Koga and Terao (1995) evaluated the effect of phospholipids on the radicalscavenging activity of TocOH using methyl esters as oxidizable substrate. These authors observed that phospholipids boosted the action of $\mathrm{TocOH}$ when oxidation was triggered by a water-soluble radical initiator but that $\mathrm{TocOH}$ had no significant effect when a lipid-soluble radical initiator was used. According to the authors, these results imply that phospholipids enhance the accessibility of TocOH toward the chain-initiating radicals in an aqueous microenvironment. To explain such an effect, they hypothesized that TocOH is positioned in the aggregation form of phospholipids (reverse micelles) with the phenolic head group located near the polar region where aqueous peroxyl radicals are generated (Rokosik et al., 2020).

\section{2 | Specificity of interactions with surfactants in emulsions and resulting antioxidant activity}

Small amphiphilic molecules, also known as surfactants, can also modify antioxidant activity especially in biphasic systems ( $\mathrm{O} / \mathrm{W}$ or $\mathrm{W} / \mathrm{O}$ emulsions) by modulating the physical location of the antioxidant. For example, concerning TocOH, Lopez-Martinez and Rocha-Uribe (2018) evaluated the efficiency of $\alpha$-TOH for the protection of an oil-in-water model emulsion stabilized either by Tween 65 or Tween 80 emulsifier and compared the antioxidant efficacy to its 
partitioning in the emulsion. They showed that $\alpha$-TOH was not efficient as an antioxidant when Tween 80 was used and was only slightly prooxidant when Tween 65 was used. The same authors calculated that more than $98 \%$ of $\alpha-\mathrm{TOH}$ present were located in the oily phase, therefore limiting its capacity to act as an antioxidant at the interface. Moreover, they considered that the diffusion of $\alpha$-TOH from one lipid droplet to another by their micellization with surfactants molecule was improbable due to the low affinity of $\mathrm{TocOH}$ for the aqueous phase. These results partially contradict the results obtained by Kiralan et al. (2014) who observed $\mathrm{TocOH}$ micellization with surfactants. These authors investigated the effect of increasing concentrations $(0.1 \%$, $0.5 \%$, and $1 \%$ ) of a nonionic surfactant (polyoxyethylene sorbitol ester) on the partitioning behavior and antioxidant activity of various TocOH isoforms $(\alpha, \gamma$, and $\delta$; 10-100 $\mu \mathrm{M})$ in an $\mathrm{O} / \mathrm{W}$ stripped soybean oil/phosphate buffer ( $\mathrm{pH}$ 7.0) system. Whatever the concentration, the addition of surfactant increased the concentration of $\mathrm{TocOH}$ in the aqueous phase due to the formation of mixed micelles but without modifying the order of increasing solubility of the tocopherol isoform, that is, $\delta->\gamma->\alpha-\mathrm{TOH}$. The addition of surfactants enhanced the antioxidant activity of the two isoforms $\delta$ (tested at 10 $\mu \mathrm{M}$ ) and $\alpha$ (tested at $35 \mu \mathrm{M}$ ) but the effect on the $\delta$ isoform was stronger. The concentration effect of surfactant was correlated with the increase in the concentration of tocopherol in the subphase. These authors hypothesized that surfactant micelles help dissolving TocOH out of the lipid droplet. In addition, they hypothesized that the combination of surfactants and $\mathrm{TocOH}$ micelles plays the double role of "vehicles" and also of "reservoir" to restore oxidized $\mathrm{TocOH}$ at the interface (Figure 9).

The discrepancies between the results obtained by Kiralan et al. (2014) and Lopez-Martinez and Rocha-Uribe (2018) could be due not only to the different nature of the emulsifiers used in the two studies but also to the difference in the type of the emulsion tested, as one study worked with a $10 \%$ oil/water emulsion, whereas the other used much more oil (around $80 \%$ ). Such parameters could favor (or not) the transport of $\mathrm{TocOH}$ through the micellization effect. In that context, one can cite the study by Losada-Barreiro et al. (2013), who evaluated the effects of the hydrophile-lipophile balance (HLB) and of the concentration of emulsifier on the distribution of $\alpha-\mathrm{TOH}$ (among other studied antioxidants) in emulsions. They used an emulsion composed of stripped corn oil stabilized by a mixture of various nonionic surfactants including Tween 20, 40, and 80 and Span 20 to fix the global HLB value, and evaluated the partitioning of the antioxidant molecule between the oil, aqueous, or interfacial regions. They showed that increasing the concentration of the emulsifier (surfactant volume fractions of 0.04) led to the presence of more than $50 \%$ of $\alpha-\mathrm{TOH}$ at the interface and that this incorporation was favored in the case of lower HLB of surfactants. Although not actually studied in the work by Losada-Barreiro et al., cited here, their results emphasize the fact that the efficiency of $\mathrm{TocOH}$ as antioxidants in emulsion can be influenced by their interaction with surfactants, and that these interactions depend on the type of surfactant. Similarly, Panya et al. (2012) observed that Tween 20 micelles could modify TocOH partitioning in emulsions and drag them to the aqueous phase where their synergistic effect with water-soluble antioxidant (in that case, rosmarinic acid) was optimized, resulting in enhanced antioxidant protection.

Other authors have also described the influence of the nature of the emulsifier on the partitioning of $\mathrm{TocOH}$ in emulsion and $\mathrm{TocOH}$ activity. For example, using a stripped fish oil emulsion with either whey proteins or Tween 80 as emulsifiers, Pernin et al. (2019) studied the efficiency of $\alpha-\mathrm{TOH}$ and found that $\alpha-\mathrm{TOH}$ were efficient in the presence of whey proteins, but not in the presence of Tween 80. As an explanation, they suggested that the more compact organization of Tween 80 at the interface compared to that of whey proteins would limit the accessibility of $\alpha-\mathrm{TOH}$ to the interface in the presence of Tween 80 and thus hinder the potential activity of $\alpha-\mathrm{TOH}$. Similarly, Yi et al. (2018) evaluated the behavior of $\alpha$-TOH in corn oil-in-water emulsions containing anionic (SDS), neutral (Tween 20), and cationic (CTAB) charged emulsifiers and studied different types of lipid oxidation using riboflavin photosensitization, photooxidation, or autoxidation. Their results showed that, whatever the type of induced oxidation, $\alpha-\mathrm{TOH}$ were efficient antioxidants in the presence of a cationic emulsifier. With a neutral emulsifier, the same molecule acted as an antioxidant with riboflavin photosensitization, whereas it showed a prooxidant effect at photooxidation. Concerning anionic emulsifier, $\alpha-\mathrm{TOH}$ activity differed with the concentration and types of oxidative stress. Finally, one can also cite Schwarz et al. (2000), who compared the behavior of $\alpha-\mathrm{TOH}$ in homogenous or emulsified systems (oil-in-water or water-in-oil emulsions) and evaluated their interaction with emulsifiers. In their study, these authors used different types of emulsion: $\mathrm{o} / \mathrm{w}$ emulsion containing cetheareth-15 and glyceryl stearate (HLB value $=12.1), \mathrm{o} / \mathrm{w}$ emulsion containing polyglyceryl glucose methyl distearate (HLB value $=11.5$ ), $\mathrm{w} / \mathrm{o}$ emulsion containing polysiloxane polyalcohol polyether copolymer $(\mathrm{HLB}$ value $=5.1)$, and w/o emulsion contained polyglyceryl-3 oleate (HLB value $=5.1$ ). In contrast to the other antioxidants tested (gallic acid and its propyl ester, Trolox, carnosic acid and its methyl ester), $\alpha-\mathrm{TOH}$ inhibited hydroperoxide formation in polysiloxane polyalcohol polyether copolymer W/O emulsion and polyglyceryl glucose methyl distearate $\mathrm{O} / \mathrm{W}$ emulsion to the same 


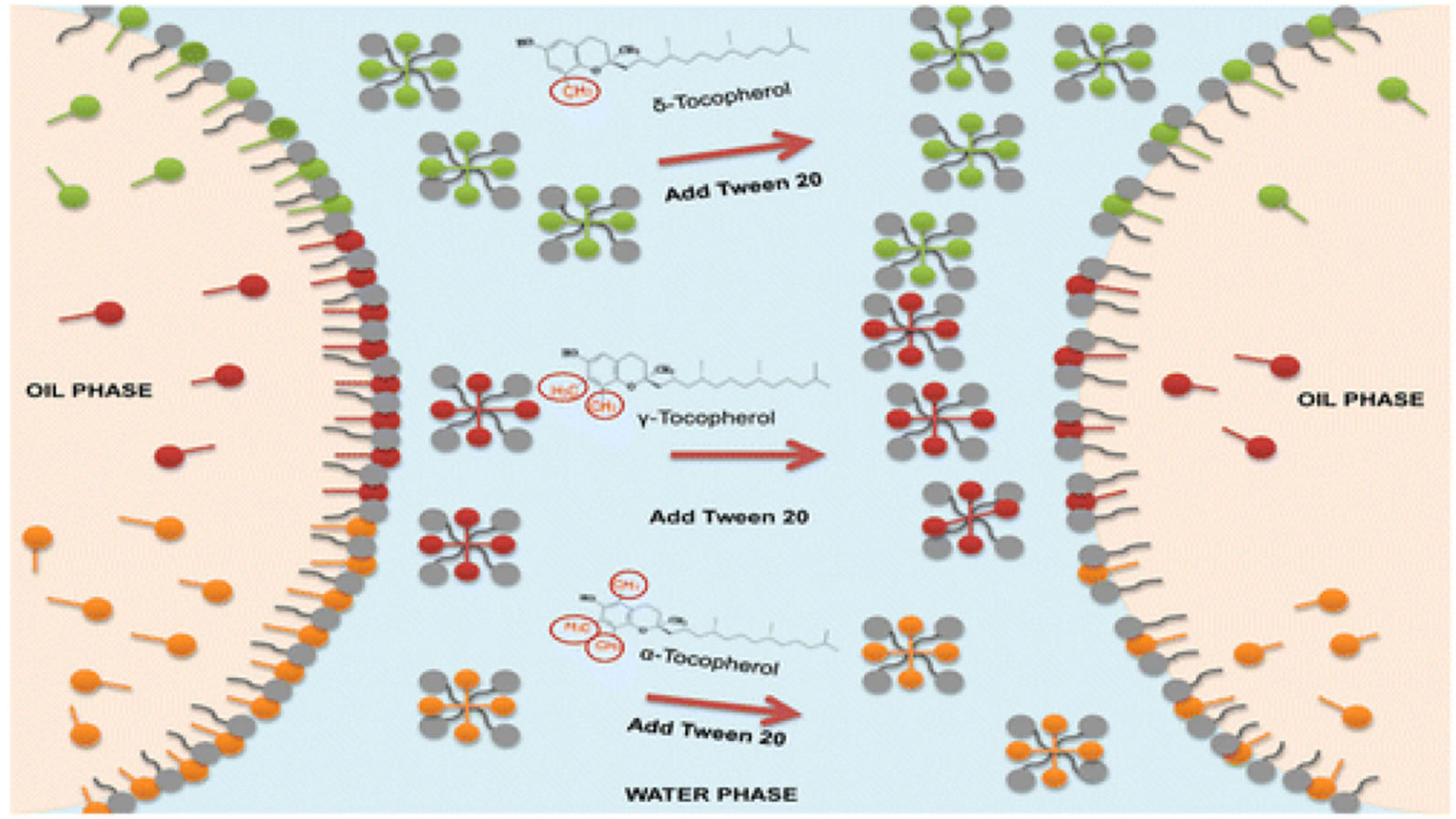

F I G U R E 9 Reprinted with permission from Kiralan et al. (2014).Copyright 2014 American Chemical Society

extent as in bulk oil. However, the inhibition of oxidation by $\alpha$-TOH was much less pronounced in cetheareth-15 and glyceryl stearate $\mathrm{O} / \mathrm{W}$ emulsion and in polyglyceryl3 oleate $\mathrm{W} / \mathrm{O}$ emulsion. In the homogenous system, the authors used a bulk oil containing emulsifiers with the same emulsifier/oil ratio as in the previous emulsions. They observed that mixtures of cetheareth-15/glyceryl stearate and polyglyceryl glucose methyl/distearate emulsifiers increased $\alpha-\mathrm{TOH}$ activity, whereas polyglyceryl-3 oleate strongly reduced $\alpha$-TOH activity. To explain their results, the authors postulated that the emulsifiers they tested were capable of solubilizing a portion of $\alpha-\mathrm{TOH}$ and of bringing it to the interfacial area to express optimized activity and that this capacity of the emulsifier was of course influenced by its type. However, to the best of our knowledge, there is a lack of rational studies that evaluate the molecular interactions between $\mathrm{TocOH}$ and emulsifiers, and how the type of $\mathrm{TocOH}$ and the nature of the emulsifiers can affect such interactions and participate in the relocation of $\mathrm{TocOH}$ in the interfacial area of emulsions or bulk oils (associate colloids). However, one can cite the work by Pastoriza-Gallego et al. (2009) who used a "combined linear sweep voltammetry (LSV)/pseudophase kinetic model" to determine the transfer entropies of $\alpha$ $\mathrm{TOH}$ between the oil and interface in an emulsion. With this model, these authors were able to estimate the most appropriate concentration of surfactant to obtain an optimized $\alpha-\mathrm{TOH}$ concentration at the interface. The same research group (Sanchez-Paz et al, 2008) used the same pseudophase kinetic model to estimate the constants that describe $\alpha$-TOH partitioning between the oil/interfacial and water/interfacial regions of tributyrin/Brij 30/water emulsions. Here again, they were able to determine the concentration of surfactant that produced the best distribution of the antioxidant in the interfacial region.

The example above illustrates the potential advantage of using physicochemical interactions to regulate $\mathrm{TocOH}$ partitioning in heterogenous systems, and hence optimize their resulting antioxidant efficiency. In that sense, Schröeder et al. (2020) conceived an innovative approach to optimize the antioxidant effects of $\mathrm{TocOH}$ in emulsions by formulating them in Pickering particles that would act as both emulsion stabilizers and as reservoirs of antioxidants that would locate in the interfacial area. These authors observed that the systems based on Pickering particles formulation allow $\mathrm{TocOH}$ to reside for a substantial period at the interface during the initiation step of lipid oxidation. The extended location of the antioxidant at the site of oxidation would favor its effect and limit oxidation diffusion from one lipid droplet to another.

\section{3 | Interactions of TocOH with association colloids in bulk oils and resulting antioxidant activity}

In the case of bulk oil systems, as mentioned previously, the presence and nature of association colloids strongly influence the activity and efficiency of TocOH. These reverse micelles are stabilized by minor surface-active 
components (fatty acids, partial glycerides, phospholipids, sterols) that are not completely removed during the oil refining processes and can form reverse micelles in the presence of small quantities of water (around $300 \mathrm{ppm}$ ) (Chaiyasit et al., 2007; Xenakis et al., 2010). Amphiphilic substances such as lipid hydroperoxides and prooxidant metals concentrate colloids within these associations and favor the production of free radicals from $\mathrm{LOOH}$. Koga and Terao (1995) were pioneers to set the hypothesis that "oil-water interface resulting from residual traces of water in the system" was the main site of oxidation in bulk oil systems (Koga \& Terao, 1995). Indeed, they showed that the antioxidant capacity of $\alpha-\mathrm{TOH}$ in a bulk oil containing $1 \%(\mathrm{v} / \mathrm{v})$ of water was increased by phospholipids. With a water-soluble azo compound (AAPH) releasing free radicals in the water phase, increasing the concentrations of phospholipids decreased the concentration of $\alpha-\mathrm{TOH}$. They hypothesized that $\alpha-\mathrm{TOH}$ are located in the association colloids in bulk oils and that phospholipids increase the exposure of $\alpha-\mathrm{TOH}$ to the water phase. The same kind of observation was made by Chen et al. (2011) who used a stripped soybean oil to determine the activity of $\alpha-\mathrm{TOH}$ and its polar counterpart (Trolox) in the presence or absence of 1,2-dioleoyl-sn-glycero-3-phosphocholine (DOPC) micelles (Chen et al., 2011). At low concentrations $(10 \mu \mathrm{M})$, these authors showed that the activities of both $\alpha$-TOH and Trolox were enhanced, whereas at higher concentrations $(100 \mu \mathrm{M})$, they decreased. They highlighted that the concentration of Trolox increased in the reverse micelles, so it could explain why it was more efficient than $\alpha$-TOH.

In the context of the presence of association colloids in bulk oils, some authors tried to evaluate the effect of relative humidity $(\mathrm{RH})$ on the antioxidant properties of TocOH. For instance, Kim et al. (2015) evaluated the effect of $\mathrm{RH}$ with different concentrations of $\alpha-\mathrm{TOH}$ in stripped corn oil. The same concentration of $\alpha-\mathrm{TOH}$ showed different levels of oxidative stability under different $\mathrm{RH}$ conditions. Generally, lower RH was associated with higher oxidative stability. In addition, a high concentration of a-tocopherol (84 ppm) had more prooxidative properties than a low concentration $(10 \mathrm{ppm})$. These results suggest that both the concentration and moisture content play an important role in the antioxidant properties of $\mathrm{TocOH}$ in bulk oils. The authors concluded that at low RH, different forces drive oxidation compared to high $\mathrm{RH}$, and attributed their result to the number of association colloids present in the system. Unfortunately, colloids depending on the RH values were not quantified in their study. In a comparable work, the same research group studied the stability of $\alpha$-TOH in stripped corn oils with or without added $\gamma$-TOH quantified under different levels of RH (0\%-93\%) (Jung et al., 2016). These authors have shown that the moisture acts on the stability of both $\alpha$ - and $\gamma$-TOH but also on the oxidative stability of the oil. Moisture, the presence of $\gamma-\mathrm{TOH}$, and the concentration of $\alpha$-TOH affect significantly the stability of $\alpha$-TOH. $\alpha-\mathrm{TOH}$ at a concentration of up to $100 \mathrm{ppm}$ was the least stable at $75 \% \mathrm{RH}$; the best stability of $\alpha-\mathrm{TOH}$ was obtained at $93 \%$ $\mathrm{RH}$ and with concentration of $200 \mathrm{ppm}$, whereas the worst stability of $\alpha-\mathrm{TOH}$ was obtained under $0 \% \mathrm{RH}$ with the presence of $\gamma-\mathrm{TOH}$. Although, here again, the presence of association colloids was not correlated with $\mathrm{RH}$, the authors suggested that $\gamma$-TOH, with only few lipophilic properties in the chromane ring moiety, may be the best candidate for the inside positioning into association colloids. Therefore, $\gamma$-TOH may not be properly located on the interface of oils and water. This fact would imply that more $\gamma$-TOH can be retained than $\alpha$-TOH. Accordingly, $\gamma$-TOH in lower moisture content environment may more likely get in the vicinity of prooxidative factors, thereby reducing their oxidative stability. However, contradictory results were obtained by Kittipongpittaya, Panya, and Decker (2016). They used stripped corn oils that were supplemented with either 400 or $1000 \mathrm{ppm}$ of water and evaluated the oil's resistance to oxidation. The lag time of lipid oxidation did not depend significantly on water content. In presence of water, the lag time of hydroperoxides decreased and hexanal concentration increased in bulk oil containing oleic acid, stigmasterol, and Trolox. On the other hand, the antioxidant capacity of $\alpha-\mathrm{TOH}$ did not change significantly with $1000 \mathrm{ppm}$ of water. The authors hypothesized that, because this antioxidant was not measured as surface active, it may present in the oil media and water could not act on the oxidative stability. Moreover, the same team (Kittipongpittaya et al., 2014) showed that minor oil surface-active components such as DOPC, DOPE, stigmasterol, oleic acid, and DAG were able to get adsorbed at the oil-water interface and therefore induced a reduction of interfacial tension. In addition, DOPC and DOPE could aggregate at the critical micelle concentration (CMC) of 40 and $200 \mu \mathrm{mol} / \mathrm{kg}$ oil, respectively (Kittipongpittaya et al., 2014). Association colloids appeared with CMC as low as $20 \mu \mathrm{mol} / \mathrm{kg}$ oil due to a blend with other minor molecules. However, the authors observed that these physical structures did not affect the antioxidative efficiency of TocOH at 10 and 50 $\mu \mathrm{mol} / \mathrm{kg}$ oil. More recently, several studies reported that the performance of $\mathrm{TocOH}$ in bulk oils was correlated with their interactions with association colloids. Kim et al. (2019) studied the effect of added lecithin (300-3000 ppm) on the oxidative stability of nonstripped or stripped corn oil. The effectiveness of $\mathrm{TocOH}$ as antioxidant in nonstripped oil was highest when lecithin was present near or above and above CMC (1288 ppm). In this situation, lecithins with moisture formed association colloids in 
the bulk oil and these colloids were able to incorporate lipophilic $\mathrm{TocOH}$ in their structure, thus making them efficient antioxidants and resulting in high oxidative stability. In parallel, more residual $\mathrm{TocOH}$ were observed when the concentration of lecithin was higher than CMC. Rokosik et al. (2020) investigated the interaction of canolol (4-vinylsyringol) and $\alpha-\mathrm{TOH}$ in rapeseed oil in the presence of association colloids (reverse micelles) made of DOPC (Rokosik et al., 2020). Using fluorescence measurements, the authors were able to show that canolol was incorporated into the structure of DOPC reverse micelles, whereas no interactions between $\alpha-\mathrm{TOH}$ and association colloids were demonstrated. Still, the presence of association colloids was shown to affect the antioxidant efficiency of both compounds. In the absence of DPOC micelles, an antioxidant action of $\alpha$-TOH was observed at 10 and $100 \mu \mathrm{mol}$ amounts when hexanal concentrations were measured. Interestingly, the authors reported that at high concentrations of $\alpha-\mathrm{TOH}(100 \mu \mathrm{mol})$ a prooxidant effect was rapidly observed. They attributed this phenomenon to the possible association of amphiphilic lipid oxidation products (hydroperoxides, aldehydes) with $\alpha-\mathrm{TOH}$ to form reverse micelles that would decrease the antioxidant efficiency. This hypothesis was corroborated by the fact that reverse micelles formed with $\alpha-\mathrm{TOH}$ were observed by the fluorescence measurements of the N-(7-Nitrobenz-2-oxa-1,3-diazol-4-yl)-1,2-dihexadecanoylsnglycero-3-phosphoethanolamine, triethylammonium salt (NBD-PE) probe and this formation is influenced by the concentration of $\alpha-\mathrm{TOH}$. In the presence of DOPOC micelles, when primary oxidation compounds were measured, $\alpha$-TOH at $10 \mu \mathrm{mol}$ showed a significant prooxidant effect. The same observation was made at higher amounts (100 $\mu \mathrm{mol})$ but the effect was less pronounced. Here again, a change in the composition of DOPC reverse micelles was confirmed with NBD-PE probes resulting in a modification of the efficiency of the antioxidant. These results are in accordance with the results obtained by Cui et al (2015) who also reported that reverse micelles with a combination of DOPC and $\alpha$-TOH may have prooxidant capacity (Cui et al., 2015).

\section{5 | CONCLUSION}

For many years now, antioxidants have been used to combat lipid oxidation in food, cosmetics, and pharmaceutical products. Among these additives, tocopherols, either as natural extracts or in synthetic pure form (mainly as $\alpha$ $\mathrm{TOH}$ ), are probably the most widely used. Although their efficiency in protecting unsaturated lipids from oxidative degradation is recognized, their mechanism of action has still not been completely characterized and depends on many factors especially in complex systems such as real products. In such products, the efficiency of a given antioxidant is driven not only by its chemical reactivity but also by its physical behavior (i.e., its distribution within the product) and its interactions with other substances present in the product. The abundant literature on tocopherols as antioxidants is sometimes contradictory but nevertheless underlines the fact that it is strongly system dependent. In terms of chemical reactivity, the antioxidant activity of tocopherols is principally due to their ability to donate their phenolic hydrogen and can theoretically be predicted based on the structure of the four tocopherol isomers $(\alpha, \beta, \gamma$, and $\delta$-TocOH). However, the results of many published studies show that prediction is impossible and that in practice, the effectiveness of each tocopherol isomer in lipid dispersion systems or in bulk oil is unpredictable as it depends on many side reactions involving neighboring molecules. The fate of TocO $\bullet$ radicals will depend on various parameters leading to different chemical pathways, and consequently, to different degrees of efficiency of tocopherols as antioxidants depending on the product in which they are used. In certain cases, especially when used at high concentrations, tocopherols may also be involved in oxidation routes and contribute to lipid degradation by complex chemical pathways. Nevertheless, the most effective dose of tocopherols beyond which their antioxidant activity will switch to prooxidant is still not clear. However, the PCA we performed on several research articles focused on this topic tends to show that up to a value of about $200 \mathrm{ppm}$, TocOH exhibited only antioxidant activity, whereas beyond that value, $\mathrm{TocOH}$ activity very often switched to prooxidant, except for very low level of oil oxidation. The effects of the interaction of tocopherols with other antioxidant molecules are also crucial to guarantee an effective antioxidant system. However, here again, the results reported in the literature vary between synergistic or antagonist effects and the chemical interactions involved are complex. When all the antioxidant molecules are in contact within the final product, such interactions are difficult to predict. Finally, the complexity of the physical (micro)structure of the system may also significantly affect the efficiency of tocopherols as antioxidants. In particular, the physical distribution of tocopherols between the different phases of the systems will influence their activity. Although considerable data exist regarding the interactions between tocopherols and phospholipids (mainly in biological membranes), in emulsions, some recent literatures underline the importance of the micellization phenomena of surfactants and tocopherols that affect the partitioning of the tocopherols and increase or alter their antioxidant effect. Here again, some results are contradictory meaning more research is required to elucidate the specific 
mechanisms. Yet, these results suggest that the conception of new antioxidant systems involving interactions between tocopherols and surfactants could be promising in emulsified systems. Similarly, a better understanding of how tocopherols interact with association colloids present in bulk oils should also help to optimize activity against lipid oxidation.

\section{ACKNOWLEDGMENT}

This research did not receive any specific grant from funding agencies in the public, commercial, or not-for-profit sectors.

\section{AUTHOR CONTRIBUTIONS}

Nathalie Barouh: Conceptualization; data curation; formal analysis; investigation; methodology; writingoriginal draft; writing-review and editing. Claire Bourlieu-Lacanal: Conceptualization; formal analysis; methodology; writing-review and editing. Erwann Durand: Conceptualization; visualization; Writingreview \& editing and Pierre Villeneuve: Conceptualization; methodology; visualization; Writing—review \& editing. Maria-Cruz Figueroa-Espinoza: Visualization; Writing-review \& editing conceptualized the idea of the study. Nathalie Barouh, Claire Bourlieu-Lacanal, and Pierre Villeneuve performed methodology. Nathalie Barouh performed investigation, curated the data, and prepared the original draft. Nathalie Barouh and Claire Bourlieu-Lacanal performed formal analysis. Nathalie Barouh, Erwann Durand, and Maria Figueroa-Espinoza performed visualization. All authors wrote, reviewed, and edited the manuscript.

\section{CONFLICT OF INTEREST}

The authors declare no conflict of interest.

\section{O R C I D}

Pierre Villeneuve (1) https://orcid.org/0000-0003-1685-1494

\section{RE F E RE N C ES}

Afri, M., Ehrenberg, B., Talmon, Y., Schmidt, J., Cohen, Y., \& Frimer, A. A. (2004). Active oxygen chemistry within the liposomal bilayer: Part III: Locating Vitamin E, ubiquinol and ubiquinone and their derivatives in the lipid bilayer. Chemistry and Physics of Lipids, 131(1), 107-121. https://doi.org/10.1016/j.chemphyslip.2004. 04.007

Alamed, J., Chaiyasit, W., McClements, D. J., \& Decker, E. A. (2009). Relationships between free radical scavenging and antioxidant activity in foods. Journal of Agricultural and Food Chemistry, 57(7), 2969-2976. https://doi.org/10.1021/jf803436c

Aliaga, C., López de Arbina, A., \& Rezende, M. C. (2016). Cut-off” effect of antioxidants and/or probes of variable lipophilicity in microheterogeneous media. Food Chemistry, 206, 119-123. https: //doi.org/10.1016/j.foodchem.2016.03.024
Amorati, R., Ferroni, F., Lucarini, M., Pedulli, G. F., \& Valgimigli, L. (2002). A quantitative approach to the recycling of $\alpha$-tocopherol by coantioxidants. The Journal of Organic Chemistry, 67(26), 92959303. https://doi.org/10.1021/jo026501f

Atkinson, J., Harroun, T., Wassall, S. R., Stillwell, W., \& Katsaras, J. (2010). The location and behavior of alpha-tocopherol in membranes. Molecular Nutrition \& Food Research, 54(5), 641-651. https: //doi.org/10.1002/mnfr.200900439

Ausili, A., Torrecillas, A., de Godos, A. M., Corbalán-García, S., \& Gómez-Fernández, J. C. (2018). Phenolic group of $\alpha$-tocopherol anchors at the lipid-Water Interface of fully saturated membranes. Langmuir, 34(10), 3336-3348. https://doi.org/10.1021/acs. langmuir.7b04142

Azizkhani, M., \& Zandi, P. (2009). Effects of some natural antioxidants mixtures on margarine stability. International Journal of Biological, Biomolecular, Agricultural and Biotechnological Engineering, 3(1), 53-56.

Azzi, A. (2018). Many tocopherols, one vitamin E. Molecular Aspects of Medicine, 61, 92-103. https://doi.org/10.1016/j.mam.2017.06.004

Bakır, T., Yıldoğan Beker, B., Sönmezoğlu, İ., İmer, F., \& Apak, R. (2013). Antioxidant and prooxidant effects of $\alpha$-tocopherol in a linoleic acid-copper(II)-ascorbate system. European Journal of Lipid Science and Technology, 115(3), 372-376. https://doi.org/10. 1002/ejlt.201200124

Bandarra, N. M., Campos, R. M., Batista, I., Nunes, M. L., \& Empis, J. M. (1999). Antioxidant synergy of $\alpha$-tocopherol and phospholipids. Journal of the American Oil Chemists' Society, 76(8), 905-913. https: //doi.org/10.1007/s11746-999-0105-4

Banias, C., Oreopoulou, V., \& Thomopoulos, C. D. (1992). The effect of primary antioxidants and synergists on the activity of plant extracts in lard. Journal of the American Oil Chemists Society, 69(6), 520-524. https://doi.org/10.1007/BF02636101

Barden, L., \& Decker, E. A. (2016). Lipid oxidation in low-moisture food: A review. Critical Reviews in Food Science and Nutrition, 56(15), 2467-2482. https://doi.org/10.1080/10408398.2013.848833

Bayrasy, C., Chabi, B., Laguerre, M., Lecomte, J., Jublanc, É., Villeneuve, P., Wrutniak-Cabello, C., \& Cabello, G. (2013). Boosting antioxidants by lipophilization: A strategy to increase cell uptake and target mitochondria. Pharmaceutical Research, 30(8), 19791989. https://doi.org/10.1007/s11095-013-1041-4

Bazin, B., Cillard, J., Koskas, J.-P., \& Cillard, P. (1984). Arachidonic acid autoxidation in an aqueous media effect of $\alpha$-tocopherol, cysteine and nucleic acids. Journal of the American Oil Chemists Society, 61(7), 1212-1215. https://doi.org/10.1007/BF02636254

Becker, E. M., Nissen, L. R., \& Skibsted, L. H. (2004). Antioxidant evaluation protocols: Food quality or health effects. European Food Research and Technology, 219(6), 561-571. https://doi.org/10. 1007/s00217-004-1012-4

Becker, E. M., Ntouma, G., \& Skibsted, L. H. (2007). Synergism and antagonism between quercetin and other chain-breaking antioxidants in lipid systems of increasing structural organisation. Food Chemistry, 103(4), 1288-1296. https://doi.org/10.1016/j.foodchem. 2006.10.034

Beddows, C. G., Jagait, C., \& Kelly, M. J. (2001). Effect of ascorbyl palmitate on the preservation of $\alpha$-tocopherol in sunflower oil, alone and with herbs and spices. Food Chemistry, 73(3), 255-261. https://doi.org/10.1016/S0308-8146(00)00295-8

Berton-Carabin, C. C., Ropers, M.-H., \& Genot, C. (2014). Lipid oxidation in oil-in-water emulsions: Involvement of the interfacial layer. 
Comprehensive Reviews in Food Science and Food Safety, 13(5), 945977. https://doi.org/10.1111/1541-4337.12097

Berton-Carabin, C. C., Sagis, L., \& Schroën, K. (2018). Formation, structure, and functionality of interfacial layers in food emulsions. Annual Review of Food Science and Technology, 9(1), 551-587. https: //doi.org/10.1146/annurev-food-030117-012405

Bisby, R. H., \& Parker, A. W. (1991). Reactions of the $\alpha$-tocopheroxyl radical in micellar solutions studied by nanosecond laser flash photolysis. FEBS Letters, 290(1-2), 205-208. https://doi.org/10. 1016/0014-5793(91)81260-f

Blekas, G., Tsimidou, M., \& Boskou, D. (1995). Contribution of $\alpha$ tocopherol to olive oil stability. Food Chemistry, 52(3), 289-294. https://doi.org/10.1016/0308-8146(95)92826-6

Boonnoy, P., Karttunen, M., \& Wong-ekkabut, J. (2017). Alphatocopherol inhibits pore formation in oxidized bilayers. Physical Chemistry Chemical Physics, 19(8), 5699-5704. https://doi.org/10. 1039/C6CP08051K

Boonnoy, P., Karttunen, M., \& Wong-ekkabut, J. (2018). Does $\alpha$ tocopherol flip-flop help to protect membranes against oxidation? The Journal of Physical Chemistry B, 122(45), 10362-10370. https: //doi.org/10.1021/acs.jpcb.8b09064

Bowry, V. W., \& Stocker, R. (1993). Tocopherol-mediated peroxidation. The prooxidant effect of vitamin $\mathrm{E}$ on the radical-initiated oxidation of human low-density lipoprotein. Journal of the American Chemical Society, 115(14), 6029-6044. https://doi.org/10.1021/ ja00067a019

Budilarto, E. S., \& Kamal-Eldin, A. (2015a). Stabilization of cod liver oil with a quaternary combination of $\alpha$-tocopherol and synergists: Method of assessment. European Journal of Lipid Science and Technology, 117(10), 1598-1606. https://doi.org/10.1002/ ej1t.201400637

Budilarto, E. S., \& Kamal-Eldin, A. (2015b). The supramolecular chemistry of lipid oxidation and antioxidation in bulk oils. European Journal of Lipid Science and Technology, 117(8), 1095-1137. https://doi.org/10.1002/ejlt.201400200

Burton, G. W., \& Ingold, K. U. (1981). Autoxidation of biological molecules. 1. Antioxidant activity of vitamin $\mathrm{E}$ and related chainbreaking phenolic antioxidants in vitro. Journal of the American Chemical Society, 103(21), 6472-6477. https://doi.org/10.1021/ ja00411a035

Carelli, A. A., Franco, I. C., \& Crapiste, G. H. (2005). Effectiveness of added natural antioxidants in sunflower oil. Grasas y Aceites, 56(4), 303-310. https://doi.org/10.3989/gya.2005.v56.i4.97

Carlotti, M. E., Gallarate, M., Gasco, M. R., Morel, S., Serafino, A., \& Ugazio, E. (1997). Synergistic action of vitamin C and amino acids on vitamin $\mathrm{E}$ in inhibition of the lipoperoxidation of linoleic acid in disperse systems. International Journal of Pharmaceutics, 155(2), 251-261. https://doi.org/10.1016/S0378-5173(97)00168-3

Castle, L., \& Perkins, M. J. (1986). Inhibition kinetics of chainbreaking phenolic antioxidants in SDS micelles. Evidence that intermicellar diffusion rates may be rate-limiting for hydrophobic inhibitors such as .alpha.-tocopherol. Journal of the American Chemical Society, 108(20), 6381-6382. https://doi.org/10.1021/ ja00280a041

Chaiyasit, W., Elias, R. J., McClements, D. J., \& Decker, E. A. (2007). Role of physical structures in bulk oils on lipid oxidation. Critical Reviews in Food Science and Nutrition, 47, 299-317. https://doi.org/ 10.1080/10408390600754248

Chaiyasit, W., McClements, D. J., \& Decker, E. A. (2005). The relationship between the physicochemical properties of antioxidants and their ability to inhibit lipid oxidation in bulk oil and oilin-water emulsions. Journal of Agricultural and Food Chemistry, 53(12), 4982-4988. https://doi.org/10.1021/jf0501239

Chapman, T. M., Kim, H. J., \& Min, D. B. (2009). Prooxidant activity of oxidized $\alpha$-tocopherol in vegetable oils. Journal of Food Science, 74(7), C536-C542. https://doi.org/10.1111/j.1750-3841.2009.01262.x

Chen, B., Han, A., Laguerre, M., McClements, D. J., \& Decker, E. A. (2011). Role of reverse micelles on lipid oxidation in bulk oils: Impact of phospholipids on antioxidant activity of $\alpha$-tocopherol and Trolox. Food \& Function, 2(6), 302-309. https://doi.org/10. 1039/c1fo10046g

Chen, B., Han, A., McClements, D. J., \& Decker, E. A. (2010). Physical structures in soybean oil and their impact on lipid oxidation. Journal of Agricultural and Food Chemistry, 58(22), 11993-11999. https://doi.org/10.1021/jf102763p

Chen, B., McClements, D. J., \& Decker, E. A. (2013). Oxidation in different food matrices: How physical structure impacts lipid oxidation in oil-in-water emulsions and bulk oils. In A. Logan, U. Nienaber, \& X. Pan (Eds.), Lipid oxidation (pp. 129-154). AOCS Press. https://doi.org/10.1016/B978-0-9830791-6-3.50006-0

Chen, B., Rao, J., Ding, Y., McClements, D. J., \& Decker, E. A. (2016). Lipid oxidation in base algae oil and water-in-algae oil emulsion: Impact of natural antioxidants and emulsifiers. Food Research International, 85, 162-169. https://doi.org/10.1016/j.foodres.2016. 04.038

Chen, H., Lee, D. J., \& Schanus, E. G. (1992). The inhibitory effect of water on the $\mathrm{Co} 2+$ and $\mathrm{Cu} 2+$ catalyzed decomposition of methyl linoleate hydroperoxides. Lipids, 27(3), 234-239. https://doi.org/ 10.1007/BF02536184

Chow, C. K., \& Draper, H. H. (1970). Isolation of $\gamma$-tocotrienol dimers from Hevea latex. Biochemistry, 9(2), 445-450. https://doi.org/10. 1021/bi00804a036

Cillard, J., \& Cillard, P. (1980). Behavior of alpha, gamma, and delta tocopherols with linoleic acid in aqueous media. Journal of the American Oil Chemists' Society, 57(1), 39-42. https://doi.org/10. 1007/bf02675523

Cillard, J., Cillard, P., \& Cormier, M. (1980). Effect of experimental factors on the prooxidant behavior of $\alpha$-tocopherol. Journal of the American Oil Chemists' Society, 57(8), 255-261. https://doi.org/10. 1007/bf02668255

Clough, R. L., Yee, B. G., \& Foote, C. S. (1979). Chemistry of singlet oxygen. 30. The unstable primary product of tocopherol photooxidation. Journal of the American Chemical Society, 101(3), 683-686. https://doi.org/10.1021/ja00497a033

Coxon, D. T., Peers, K. E., \& Rigby, N. M. (1984). Selective formation of dihydroperoxides in the $\alpha$-tocopherol inhibited autoxidation of methyl linolenate. Journal of the Chemical Society, Chemical Communications. https://doi.org/10.1039/C39840000067

Cui, L., McClements, D. J., \& Decker, E. A. (2015). Impact of phosphatidylethanolamine on the antioxidant activity of $\alpha$-tocopherol and trolox in bulk oil. Journal of Agricultural and Food Chemistry, 63(12), 3288-3294. https://doi.org/10.1021/acs.jafc.5b00243

Decker, E. A. (2002). Antioxidant mechanisms. In C. C. Akoh \& D. B. Min (Eds.), Food lipids (2nd ed., pp. 517-542). Marcel Dekker Inc.

Decker, E. A., McClements, D. J., Bourlieu-Lacanal, C., Durand, E., Figueroa-Espinoza, M. C., Lecomte, J., \& Villeneuve, P. (2017). Hurdles in predicting antioxidant efficacy in oil-in-water emulsions. Trends in Food Science \& Technology, 67, 183-194. https: //doi.org/10.1016/j.tifs.2017.07.001 
DellaPenna, D. (2005). A decade of progress in understanding vitamin E synthesis in plants. Journal of Plant Physiology, 162(7), 729737. https://doi.org/10.1016/j.jplph.2005.04.004

Dolde, D., \& Wang, T. (2011). Oxidation of corn oils with spiked tocols. Journal of the American Oil Chemists' Society, 88(11), 1759-1765. https://doi.org/10.1007/s11746-011-1853-5

Drach, M., Narkiewicz-Michałek, J., Sienkiewicz, A., Szymula, M., \& Bravo-Díaz, C. (2011). Antioxidative properties of vitamins C and E in micellar systems and in microemulsions. Colloids and Surfaces A: Physicochemical and Engineering Aspects, 379(1), 79-85. https: //doi.org/10.1016/j.colsurfa.2010.11.073

Durand, E., Zhao, Y., Coupland, J. N., \& Elias, R. J. (2015). Assessing interactions between lipophilic and hydrophilic antioxidants in food emulsions. Journal of Agricultural and Food Chemistry, 63(49), 10655-10661. https://doi.org/10.1021/acs.jafc.5b04152

Dziedzic, S. Z., \& Hudson, B. J. F. (1984). Phosphatidyl ethanolamine as a synergist for primary antioxidants in edible oils. Journal of the American Oil Chemists Society, 61(6), 1042-1045. https://doi.org/ 10.1007/BF02636214

Edge, R., Land, E. J., McGarvey, D., Mulroy, L., \& Truscott, T. G. (1998). Relative one-electron reduction potentials of carotenoid radical cations and the interactions of carotenoids with the vitamin E radical cation. Journal of the American Chemical Society, 120(17), 4087-4090. https://doi.org/10.1021/ja974191q

Elisia, I., Young, J. W., Yuan, Y. V., \& Kitts, D. D. (2013). Association between tocopherol isoform composition and lipid oxidation in selected multiple edible oils. Food Research International, 52(2), 508-514. https://doi.org/10.1016/j.foodres.2013.02.013

Emerson, O. H. (1938). The structure of $\beta$ - and $\gamma$-tocopherols. Journal of the American Chemical Society, 60(8), 1741-1742.

Evans, H. M., \& Bishop, K. S. (1922). On the existence of a hitherto unrecognized dietary factor essential for reproduction. Science, 56(1458), 650-651. https://doi.org/10.1126/science.56.1458.650

Evans, H. M., Emerson, O. H., \& Emerson, G. A. (1936). The isolation from wheat germ oil of an alcohol, $\alpha$ tocopherol, having the properties of vitamin E. Journal of Biological Chemistry, 113(1), 319-332.

Fabre, G. (2015). Molecular interaction of natural compounds with lipid bilayer membranes: Towards a better understanding of their biological and pharmaceutical actions ( $\mathrm{PhD}$ thesis). Université de Limoges.

Fabre, G., Bayach, I., Berka, K., Paloncýová, M., Starok, M., Rossi, C., Duroux, J.-L., Otyepka, M., \& Trouillas, P. (2015). Synergism of antioxidant action of vitamins $\mathrm{E}, \mathrm{C}$ and quercetin is related to formation of molecular associations in biomembranes. Chemical Communications, 51(36), 7713-7716. https://doi.org/10.1039/ $\mathrm{C} 5 \mathrm{CC} 00636 \mathrm{H}$

Frankel, E. N. (1996). Antioxidants in lipid foods and their impact on food quality. Food Chemistry, 57(1), 51-55. https://doi.org/10.1016/ 0308-8146(96)00067-2

Frankel, E. N. (2005). Lipid oxidation (2nd ed.). PJ Barnes and Associates.

Frankel, E. N., Cooney, P. M., Moser, H. A., Cowan, J. C., \& Evans, C. D. (1959). Effect of antioxidants and metal inactivators in tocopherol-free soybean oil. Fette, Seifen, Anstrichmittel, 61(10), 1036-1039. https://doi.org/10.1002/lipi.19590611046

Frankel, E. N., \& Gardner, H. W. (1989). Effect of $\alpha$-tocopherol on the volatile thermal decomposition products of methyl linoleate hydroperoxides. Lipids, 24(7), 603-608. https://doi.org/10.1007/ BF02535076

Frankel, E. N., Huang, S. W., Kanner, J., \& German, J. B. (1994). Interfacial phenomena in the evaluation of antioxidants: Bulk oils vs emulsions. Journal of Agricultural and Food Chemistry, 42(5), 1054-1059.

Frankel, E. N., Satué-Gracia, T., Meyer, A. S., \& German, J. B. (2002). Oxidative stability of fish and algae oils containing long-chain polyunsaturated fatty acids in bulk and in oil-in-water emulsions. Journal of Agricultural and Food Chemistry, 50(7), 2094-2099. https://doi.org/10.1021/jf0111458

Fukuzawa, K. (2008). Dynamics of lipid peroxidation and antioxidion of alpha-tocopherol in membranes. Journal of Nutritional Science and Vitaminology, 54(4), 273-285. https://doi.org/10.3177/jnsv.54. 273

Fukuzawa, K., Ikebata, W., Shibata, A., Kumadaki, I., Sakanaka, T., \& Urano, S. (1992). Location and dynamics of $\alpha$-tocopherol in model phospholipid membranes with different charges. Chemistry and Physics of Lipids, 63(1), 69-75. https://doi.org/10.1016/ 0009-3084(92)90024-J

Fukuzawa, K., Ikebata, W., \& Sohmi, K. (1993). Location, antioxidant and recycling dynamics of alpha-tocopherol in liposome membranes. Journal of Nutritional Science and Vitaminology, 39(Suppl), S9-S22. https://doi.org/10.3177/jnsv.39.supplement_s9

Fuster, M. D., Lampi, A.-M., Hopia, A., \& Kamal-Eldin, A. (1998). Effects of $\alpha$ - and $\gamma$-tocopherols on the autooxidation of purified sunflower triacylglycerols. Lipids, 33(7), 715-722. https://doi.org/ 10.1007/s11745-998-0261-3

Ghorbani Gorji, S., Calingacion, M., Smyth, H. E., \& Fitzgerald, M. (2019). Effect of natural antioxidants on lipid oxidation in mayonnaise compared with BHA, the industry standard. Metabolomics, 15(8), 106. https://doi.org/10.1007/s11306-019-1568-4

Górnaś, P., Soliven, A., \& Segliṇa, D. (2015). Seed oils recovered from industrial fruit by-products are a rich source of tocopherols and tocotrienols: Rapid separation of $\alpha / \beta / \gamma / \delta$ homologues by RPHPLC/FLD. European Journal of Lipid Science and Technology, 117(6), 773-777. https://doi.org/10.1002/ej1t.201400566

Green, J., Marcinkiewicz, S., \& Watt, P. R. (1955). The determination of tocopherols by paper chromatography. Journal of the Science of Food and Agriculture, 6(5), 274-282. https://doi.org/10.1002/jsfa. 2740060506

Haila, K. M., Lievonen, S. M., \& Heinonen, M. I. (1996). Effects of lutein, lycopene, annatto, and gamma-tocopherol on autoxidation of triglycerides. Journal of Agricultural and Food Chemistry, 44(8), 2096-2100. https://doi.org/10.1021/jf9504935

Hamilton, R. J., Kalu, C., McNeill, G. P., Padley, F. B., \& Pierce, J. H. (1998). Effects of tocopherols, ascorbyl palmitate, and lecithin on autoxidation of fish oil. Journal of the American Oil Chemists' Society, 75(7), 813-822. https://doi.org/10.1007/s11746-998-0231-4

Han, D., Yi, O.-S., \& Shin, H.-K. (1991). Solubilization of vitamin C in fish oil and synergistic effect with vitamin $\mathrm{E}$ in retarding oxidation. Journal of the American Oil Chemists Society, 68(10), 740-743. https://doi.org/10.1007/bf02662163

Hicks, M., \& Gebicki, J. M. (1981). Inhibition of peroxidation in linoleic acid membranes by nitroxide radicals, butylated hydroxytoluene, and $\alpha$-tocopherol. Archives of Biochemistry and Biophysics, 210(1), 56-63. https://doi.org/10.1016/0003-9861(81) 90163-6 
Hildebrand, D. H., Terao, J., \& Kito, M. (1984). Phospholipids plus tocopherols increase soybean oil stability. Journal of the American Oil Chemists' Society, 61(3), 552-555. https://doi.org/10.1007/ BF02677029

Hopia, A. I., Huang, S.-W., Schwarz, K., German, J. B., \& Frankel, E. N. (1996). Effect of different lipid systems on antioxidant activity of rosemary constituents carnosol and carnosic acid with and without $\alpha$-tocopherol. Journal of Agricultural and Food Chemistry, 44(8), 2030-2036. https://doi.org/10.1021/jf950777p

Horn, A. F., Nielsen, N. S., \& Jacobsen, C. (2009). Additions of caffeic acid, ascorbyl palmitate or $\gamma$-tocopherol to fish oil-enriched energy bars affect lipid oxidation differently. Food Chemistry, 112(2), 412420. https://doi.org/10.1016/j.foodchem.2008.05.094

Horvath, G., Wessjohann, L., Bigirimana, J., Jansen, M., Guisez, Y., Caubergs, R., \& Horemans, N. (2006). Differential distribution of tocopherols and tocotrienols in photosynthetic and nonphotosynthetic tissues. Phytochemistry, 67(12), 1185-1195. https:// doi.org/10.1016/j.phytochem.2006.04.004

Hraš, A. R., Hadolin, M., Knez, Ž., \& Bauman, D. (2000). Comparison of antioxidative and synergistic effects of rosemary extract with $\alpha$-tocopherol, ascorbyl palmitate and citric acid in sunflower oil. Food Chemistry, 71(2), 229-233. https://doi.org/10.1016/ S0308-8146(00)00161-8

Huang, S.-W., Frankel, E. N., \& German, J. B. (1995). Effects of individual tocopherols and tocopherol mixtures on the oxidative stability of corn oil triglycerides. Journal of Agricultural and Food Chemistry, 43(9), 2345-2350. https://doi.org/10.1021/jf00057a006

Huang, S.-W., Frankel, E. N., Schwarz, K., \& German, J. B. (1996). Effect of $\mathrm{pH}$ on antioxidant activity of $\alpha$-tocopherol and trolox in oil-in-water emulsions. Journal of Agricultural and Food Chemistry, 44(9), 2496-2502. https://doi.org/10.1021/jf960262d

Huang, S.-W., Hopia, A., Schwarz, K., Frankel, E. N., \& German, J. B. (1996). Antioxidant activity of $\alpha$-tocopherol and trolox in different lipid substrates: Bulk oils vs oil-in-water emulsions. Journal of Agricultural and Food Chemistry, 44(2), 444-452. https://doi.org/ 10.1021/jf9505685

Huang, S. W., Frankel, E. N., \& German, J. B. (1994). Antioxidant activity of $\alpha$ - and $\gamma$-tocopherols in bulk oils and in oil-in-water emulsions. Journal of Agricultural and Food Chemistry, 42(10), 2108-2114. https://doi.org/10.1021/jf00046a007

Hudson, B. J. F., \& Lewis, J. I. (1983). Polyhydroxy flavonoid antioxidants for edible oils. structural criteria for activity. Food Chemistry, 10(1), 47-55. https://doi.org/10.1016/S0308-8146(83)80001-6

Ingold, K. U. (1961). Inhibition of the autoxidation of organic substances in the liquid phase. Chemical Reviews, 61(6), 563-589. https: //doi.org/10.1021/cr60214a002

Isnardy, B., Wagner, K.-H., \& Elmadfa, I. (2003). Effects of $\alpha-, \gamma$, and $\delta$-tocopherols on the autoxidation of purified rapeseed oil triacylglycerols in a system containing low oxygen. Journal of Agricultural and Food Chemistry, 51(26), 7775-7780. https://doi.org/10. 1021/jf0348525

Iwatsuki, M., Tsuchiya, J., Komuro, E., Yamamoto, Y., \& Niki, E. (1994). Effects of solvents and media on the antioxidant activity of $\alpha$-tocopherol. Biochimica et Biophysica Acta (BBA) - General Subjects, 1200(1), 19-26. https://doi.org/10.1016/0304-4165(94)90022-1

Jacobsen, C., Hartvigsen, K., Lund, P., Adler-Nissen, J., Hølmer, G., $\&$ Meyer, A. S. (2000). Oxidation in fish-oil-enriched mayonnaise. European Food Research and Technology, 210(4), 242-257. https:// doi.org/10.1007/s002179900070
Jacobsen, C., Hartvigsen, K., Lund, P., Thomsen, M. K., Skibsted, L. H., Hølmer, G., Adler-Nissen, J., \& Meyer, A. S. (2001). Oxidation in fish oil-enriched mayonnaise: 4 . Effect of tocopherol concentration on oxidative deterioration. European Food Research and Technology, 212(3), 308-318. https://doi.org/10.1007/s002170000251

Jayasinghe, C., Gotoh, N., \& Wada, S. (2013). Pro-oxidant/antioxidant behaviours of ascorbic acid, tocopherol, and plant extracts in $\mathrm{n}$ 3 highly unsaturated fatty acid rich oil-in-water emulsions. Food Chemistry, 141(3), 3077-3084. https://doi.org/10.1016/j.foodchem. 2013.05.143

Jeevarajan, J. A., \& Kispert, L. D. (1996). Electrochemical oxidation of carotenoids containing donor/acceptor substituents. Journal of Electroanalytical Chemistry, 411(1), 57-66. https://doi.org/10.1016/ 0022-0728(96)04572-X

Judde, A., Villeneuve, P., Rossignol-Castera, A., \& Le Guillou, A. (2003). Antioxidant effect of soy lecithins on vegetable oil stability and their synergism with tocopherols. Journal of the American Oil Chemists' Society, 80(12), 1209-1215. https://doi.org/10.1007/ s11746-003-0844-4

Jung, J., Gim, S. Y., Lee, C., Kim, M.-J., \& Lee, J. (2016). Effects of moisture content and presence of $\gamma$-tocopherol on the stability of $\alpha$-tocopherol in stripped corn oils. European Journal of Lipid Science and Technology, 118(12), 1926-1934. https://doi.org/10.1002/ ejlt.201500554

Jung, J., Yi, B., Kim, M.-J., \& Lee, J. (2018). Influence of different moisture contents on the stability of tocochromanols in bulk oils at $25^{\circ} \mathrm{C}$ storage. Journal of the American Oil Chemists' Society, 95(2), 197-207. https://doi.org/10.1002/aocs.12001

Jung, M. Y., \& Min, D. B. (1990). Effects of $\alpha$-, $\gamma$-, and $\delta$-tocopherols on oxidative stability of soybean oil. Journal of Food Science, 55(5), 1464-1465. https://doi.org/10.1111/j.1365-2621.1990.tb03960.x

Jung, M. Y., \& Min, D. B. (1992). Effects of oxidized $\alpha$-, $\gamma$ - and $\delta$ tocopherols on the oxidative stability of purified soybean oil. Food Chemistry, 45(3), 183-187. https://doi.org/10.1016/0308-8146(92) 90112-F

Kaiser, S., Di Mascio, P., Murphy, M. E., \& Sies, H. (1990). Physical and chemical scavenging of singlet molecular oxygen by tocopherols. Archives of Biochemistry and Biophysics, 277(1), 101-108. https://doi.org/10.1016/0003-9861(90)90556-E

Kamal-Eldin, A., \& Appelqvist, L.-Å. (1996). The chemistry and antioxidant properties of tocopherols and tocotrienols. Lipids, 31(7), 671-701. https://doi.org/10.1007/BF02522884

Kancheva, V. D., Slavova-Kazakova, A. K., Angelova, S. E., Kumar, P., Malhotra, S., Singh, B. K., Saso, L., Prasad, A. K., \& Parmar, V. S. (2018). Protective effects of new antioxidant compositions of 4-methylcoumarins and related compounds with dl- $\alpha$-tocopherol and 1-ascorbic acid. Journal of the Science of Food and Agriculture, 98(10), 3784-3794. https://doi.org/10.1002/jsfa.8892

Karabulut, I. (2010). Effects of $\alpha$-tocopherol, $\beta$-carotene and ascorbyl palmitate on oxidative stability of butter oil triacylglycerols. Food Chemistry, 123(3), 622-627. https://doi.org/10.1016/j. foodchem.2010.04.080

Keceli, T., \& Gordon, M. H. (2002). Ferric ions reduce the antioxidant activity of the phenolic fraction of virgin olive oil. Journal of Food Science, 67(3), 943-947. https://doi.org/10.1111/j.1365-2621. 2002.tb09432.x

Kim, H. J. (2014). Effect of $\alpha$-, $\beta$-, $\gamma$-, and $\delta$-tocotrienol on the oxidative stability of lard. Journal of the American Oil Chemists' Society, 91(5), 777-782. https://doi.org/10.1007/s11746-014-2423-4 
Kim, H. J., Lee, H. O., \& Min, D. B. (2007). Effects and prooxidant mechanisms of oxidized $\alpha$-tocopherol on the oxidative stability of soybean oil. Journal of Food Science, 72(4), C223-C230. https://doi. org/10.1111/j.1750-3841.2007.00339.x

Kim, J., \& Choe, E. (2019). Interaction effect of tocopherol homologs with peppermint extract on the iron-catalyzed oxidation of soybean oil-in-water emulsion. Food Science and Biotechnology, 28(6), 1679-1685. https://doi.org/10.1007/s10068-019-00613-9

Kim, J., Woo, Y., Ryu, J., Kim, M.-J., \& Lee, J. (2019). Lecithin near its critical micelle concentration increases oxidative stability of nonstripped corn oil but not stripped corn oil. European Journal of Lipid Science and Technology, 121(1), 1800219. https://doi.org/10. 1002/ejlt.201800219

Kim, J. Y., Kim, M.-J., Yi, B., Oh, S., \& Lee, J. (2015). Effects of relative humidity on the antioxidant properties of $\alpha$-tocopherol in stripped corn oil. Food Chemistry, 167, 191-196. https://doi.org/10. 1016/j.foodchem.2014.06.108

Kinen, M. M., Kamal-Eldin, A., Lampi, A.-M., \& Hopia, A. (2000). Effects of $\alpha$ - and $\gamma$-tocopherols on formation of hydroperoxides and two decomposition products from methyl linoleate. Journal of the American Oil Chemists' Society, 77(8), 801-806. https://doi.org/10. 1007/s11746-000-0128-z

Kiralan, S. S., Doğu-Baykut, E., Kittipongpittaya, K., McClements, D. J., \& Decker, E. A. (2014). Increased antioxidant efficacy of tocopherols by surfactant solubilization in oil-in-water emulsions. Journal of Agricultural and Food Chemistry, 62(43), 10561-10566. https://doi.org/10.1021/jf503115j

Kittipongpittaya, K., Panya, A., Cui, L., McClements, D. J., \& Decker, E. A. (2014). Association colloids formed by multiple surface active minor components and their effect on lipid oxidation in bulk oil. Journal of the American Oil Chemists' Society, 91(11), 1955-1965. https://doi.org/10.1007/s11746-014-2541-z

Kittipongpittaya, K., Panya, A., \& Decker, E. A. (2016). Role of water and selected minor components on association colloid formation and lipid oxidation in bulk oil. Journal of the American Oil Chemists' Society, 93(1), 83-91. https://doi.org/10.1007/ s11746-015-2752-y

Kittipongpittaya, K., Panya, A., Phonsatta, N., \& Decker, E. A. (2016). Effects of environmental $\mathrm{pH}$ on antioxidant interactions between rosmarinic acid and $\alpha$-tocopherol in oil-in-water $(\mathrm{O} / \mathrm{W})$ emulsions. Journal of Agricultural and Food Chemistry, 64(34), 65756583. https://doi.org/10.1021/acs.jafc.6b02700

Koga, T., \& Terao, J. (1995). Phospholipids increase radicalscavenging activity of vitamin $\mathrm{E}$ in a bulk oil model system. Journal of Agricultural and Food Chemistry, 43(6), 1450-1454. https: //doi.org/10.1021/jf00054a007

Koidis, A., \& Boskou, D. (2006). The contents of proteins and phospholipids in cloudy (veiled) virgin olive oils. European Journal of Lipid Science and Technology, 108(4), 323-328. https://doi.org/10. 1002/ejlt.200500319

Kremer, M. L. (1963). Oxidation reduction step in catalytic decomposition of hydrogen peroxide by ferric ions. Transactions of the Faraday Society, 59, 2535-2542. https://doi.org/10.1039/TF9635902535

Kulås, E., \& Ackman, R. G. (2001). Properties of $\alpha-, \gamma$-, and $\delta$ tocopherol in purified fish oil triacylglycerols. Journal of the American Oil Chemists' Society, 78(4), 361-367. https://doi.org/10.1007/ s11746-001-0269-0

Kulås, E., Olsen, E., \& Ackman, R. G. (2002). Effect of $\alpha-, \gamma$-, and $\delta$-tocopherol on the distribution of volatile secondary oxidation products in fish oil. European Journal of Lipid Science and Tech- nology, 104(8), 520-529. https://doi.org/10.1002/1438-9312(200208) 104:8<520::AID-EJLT520〉3.0.CO;2-H

Laguerre, M., Bayrasy, C., Panya, A., Weiss, J., McClements, D. J., Lecomte, J., Decker, E. A., \& Villeneuve, P. (2015). What makes good antioxidants in lipid-based systems? The next theories beyond the polar paradox. Critical Reviews in Food Science and Nutrition, 55(2), 183-201. https://doi.org/10.1080/10408398. 2011.650335

Laguerre, M., Bily, A., Roller, M., \& Birtić, S. (2017). Mass transport phenomena in lipid oxidation and antioxidation. Annual Review of Food Science and Technology, 8(1), 391-411. https://doi.org/10.1146/ annurev-food-030216-025812

Laguerre, M., López Giraldo, L. J., Lecomte, J., Figueroa-Espinoza, M.-C., Baréa, B., Weiss, J., Decker, E. A., \& Villeneuve, P. (2009). Chain length affects antioxidant properties of chlorogenate esters in emulsion: The cutoff theory behind the polar paradox. Journal of Agricultural and Food Chemistry, 57(23), 11335-11342. https: //doi.org/10.1021/jf9026266

Laguerre, M., López Giraldo, L. J., Lecomte, J., Figueroa-Espinoza, M.-C., Baréa, B., Weiss, J., Decker, E. A., \& Villeneuve, P. (2010). Relationship between hydrophobicity and antioxidant ability of "Phenolipids" in emulsion: A parabolic effect of the chain length of rosmarinate esters. Journal of Agricultural and Food Chemistry, 58(5), 2869-2876. https://doi.org/10.1021/jf904119v

Laguerre, M., Tenon, M., Bily, A., \& Birtić, S. (2020). Toward a spatiotemporal model of oxidation in lipid dispersions: A hypothesisdriven review. European Journal of Lipid Science and Technology, 122(3), 1900209. https://doi.org/10.1002/ejlt.201900209

Lambelet, P., Saucy, F., \& Löliger, J. (1994). Radical exchange reactions between vitamin $\mathrm{E}$, vitamin $\mathrm{C}$ and phospholipids in autoxidizing polyunsaturated lipids. Free Radical Research, 20(1), 1-10. https://doi.org/10.3109/10715769409145621

Lampi, A.-M., Kataja, L., Kamal-Eldin, A., \& Vieno, P. (1999). Antioxidant activities of $\alpha$ - and $\gamma$-tocopherols in the oxidation of rapeseed oil triacylglycerols. Journal of the American Oil Chemists' Society, 76(6), 749-755. https://doi.org/10.1007/s11746-999-0171-7

Lea, C. H. (1960). On the antioxidant activities of the tocopherols II.Influence of substrate, temperature and level of oxidation. Journal of the Science of Food and Agriculture, 11(4), 212-218. https://doi. org/10.1002/jsfa.2740110407

Lea, C. H., \& Ward, R. J. (1959). Relative antioxidant activities of the seven tocopherols. J. Sci. Food Agric., 10, 537-548. https://doi.org/ 10.1002/jsfa.2740101007

Let, M. B., Jacobsen, C., \& Meyer, A. S. (2007). Ascorbyl palmitate, $\gamma$-tocopherol, and EDTA affect lipid oxidation in fish oil enriched salad dressing differently. Journal of Agricultural and Food Chemistry, 55(6), 2369-2375. https://doi.org/10.1021/jf062675c

Let, M. B., Jacobsen, C., Pham, K. A., \& Meyer, A. S. (2005). Protection against oxidation of fish-oil-enriched milk emulsions through addition of rapeseed oil or antioxidants. Journal of Agricultural and Food Chemistry, 53(13), 5429-5437. https://doi.org/10.1021/ jf047960f

Li, P., McClements, D. J., \& Decker, E. A. (2020). Application of flow cytometry as novel technology in studying lipid oxidation and mass transport phenomena in oil-in-water emulsions. Food Chemistry, 315, 126225. https://doi.org/10.1016/j.foodchem.2020.126225

Liu, D., Gao, Y., \& Kispert, L. D. (2000). Electrochemical properties of natural carotenoids. Journal of Electroanalytical Chemistry, 488(2), 140-150. https://doi.org/10.1016/S0022-0728(00)00205-9 
López-Martínez, A., \& Rocha-Uribe, A. (2018). Antioxidant hydrophobicity and emulsifier type influences the partitioning of antioxidants in the interface improving oxidative stability in $\mathrm{O} / \mathrm{W}$ emulsions rich in n-3 fatty acids. European Journal of Lipid Science and Technology, 120(1), 1700277. https://doi.org/10.1002/ejlt.201700277

Losada-Barreiro, S., Sánchez-Paz, V., \& Bravo-Díaz, C. (2013). Effects of emulsifier hydrophile-lipophile balance and emulsifier concentration on the distributions of gallic acid, propyl gallate, and $\alpha$ tocopherol in corn oil emulsions. Journal of Colloid and Interface Science, 389(1), 1-9. https://doi.org/10.1016/j.jcis.2012.07.036

Lucarini, M., Pedulli, G. F., \& Cipollone, M. (1994). Bond dissociation enthalpy of .alpha.-tocopherol and other phenolic antioxidants. The Journal of Organic Chemistry, 59(17), 5063-5070. https: //doi.org/10.1021/jo00096a061

Mahoney, J., JOHN, R., \& GRAF, E. (1986). Role of alpha-tocopherol, ascorbic acid, citric acid and EDTA as oxidants in model systems. Journal of Food Science, 51(5), 1293-1296. https://doi.org/10.1111/j. 1365-2621.1986.tb13108.x

Mallet, J. F., Cerrati, C., Ucciani, E., Gamisans, J., \& Gruber, M. (1994). Antioxidant activity of plant leaves in relation to their alphatocopherol content. Food Chemistry, 49(1), 61-65. https://doi.org/ 10.1016/0308-8146(94)90233-X

Marinova, E. M., \& Yanishlieva, N. V. (1992). Effect of temperature on the antioxidative action of inhibitors in lipid autoxidation. Journal of the Science of Food and Agriculture, 60(3), 313-318. https://doi. org/10.1002/jsfa.2740600307

Marquardt, D., Kučerka, N., Katsaras, J., \& Harroun, T. A. (2015). $\alpha$ Tocopherol's location in membranes is not affected by their composition. Langmuir, 31(15), 4464-4472. https://doi.org/10.1021/ la502605c

Marquardt, D., Williams, J. A., Kinnun, J. J., Kučerka, N., Atkinson, J., Wassall, S. R., Katsaras, J., \& Harroun, T. A. (2014). Dimyristoyl phosphatidylcholine: A remarkable exception to $\alpha$-tocopherol's membrane presence. Journal of the American Chemical Society, 136(1), 203-210. https://doi.org/10.1021/ja408288f

Marquardt, D., Williams, J. A., Kučerka, N., Atkinson, J., Wassall, S. R., Katsaras, J., \& Harroun, T. A. (2013). Tocopherol activity correlates with its location in a membrane: A new perspective on the antioxidant vitamin E. Journal of the American Chemical Society, 135(20), 7523-7533. https://doi.org/10.1021/ja312665r

Martin-Rubio, A. S., Sopelana, P., \& Guillen, M. D. (2018). A thorough insight into the complex effect of gamma-tocopherol on the oxidation process of soybean oil by means of $\mathrm{H}-1$ Nuclear Magnetic Resonance. Comparison with alpha-tocopherol. Food Research International, 114, 230-239. https://doi.org/10.1016/j.foodres.2018. 07.064

Martin-Rubio, A. S., Sopelana, P., Ibargoitia, M. L., \& Guillén, M. D. (2018). Prooxidant effect of $\alpha$-tocopherol on soybean oil. Global monitoring of its oxidation process under accelerated storage conditions by $1 \mathrm{H}$ nuclear magnetic resonance. Food Chemistry, 245, 312-323. https://doi.org/10.1016/j.foodchem.2017.10.098

Martínez-Yusta, A., \& Guillén, M. D. (2019). Enrichment of sunflower oil with $\gamma$-tocopherol. Study by $1 \mathrm{H}$ NMR of its effect under accelerated storage conditions. European Journal of Lipid Science and Technology, 121(6), 1800457. https://doi.org/10.1002/ejlt.201800457

Mène-Saffrané, L. (2018). Vitamin $\mathrm{E}$ biosynthesis and its regulation in plants. Antioxidants, 7(1), 2. https://doi.org/10.3390/ antiox7010002
Mohanan, A., Nickerson, M. T., \& Ghosh, S. (2018). Oxidative stability of flaxseed oil: Effect of hydrophilic, hydrophobic and intermediate polarity antioxidants. Food Chemistry, 266, 524-533. https: //doi.org/10.1016/j.foodchem.2018.05.117

Mortensen, A., \& Skibsted, L. H. (1997a). Importance of carotenoid structure in radical-scavenging reactions. Journal of Agricultural and Food Chemistry, 45(8), 2970-2977. https://doi.org/10.1021/ jf970010s

Mortensen, A., \& Skibsted, L. H. (1997b). Relative stability of carotenoid radical cations and homologue tocopheroxyl radicals. A real time kinetic study of antioxidant hierarchy. FEBS Letters, 417(3), 261-266. https://doi.org/10.1016/S0014-5793(97)01297-0

Mortensen, A., Skibsted, L. H., Willnow, A., \& Everett, S. A. (1998). Re-appraisal of the tocopheroxyl radical reaction with $\beta$-carotene: Evidence for oxidation of vitamin $\mathrm{E}$ by the $\beta$-Carotene radical cation. Free Radical Research, 28(1), 69-80. https://doi.org/10. 3109/10715769809097877

Moure, A., Cruz, J. M., Franco, D., Domıńguez, J. M., Sineiro, J., Domıńguez, H., José Núñez, M., \& Parajó, J. C. (2001). Natural antioxidants from residual sources. Food Chemistry, 72(2), 145-171. https://doi.org/10.1016/S0308-8146(00)00223-5

Mukai, K., Daifuku, K., Okabe, K., Tanigaki, T., \& Inoue, K. (1991). Structure-activity relationship in the quenching reaction of singlet oxygen by tocopherol (vitamin E) derivatives and related phenols. Finding of linear correlation between the rates of quenching of singlet oxygen and scavenging of peroxyl and phenoxyl radicals in solution. The Journal of Organic Chemistry, 56(13), 4188-4192. https://doi.org/10.1021/jo00013a021

Mukai, K., Sawada, K., Kohno, Y., \& Terao, J. (1993). Kinetic study of the prooxidant effect of tocopherol. Hydrogen abstraction from lipid hydroperoxides by tocopheroxyls in solution. Lipids, 28(8), 747-752. https://doi.org/10.1007/BF02535998

Namiki, M. (1988). Chemistry of Maillard reactions: Recent studies on the browning reaction mechanism and the development of antioxidants and mutagens. Advances in Food Research, 32, 115184. https://doi.org/10.1016/S0065-2628(08)60287-6

Neely, W. C., Martin, J. M., \& Barker, S. A. (1988). Products and relative reaction rates of the oxidation of tocopherols with singlet molecular oxygen. Photochemistry and Photobiology, 48(4), 423428. https://doi.org/10.1111/j.1751-1097.1988.tb02840.x

Niedzwiedzki, D., Rusling, J. F., \& Frank, H. A. (2005). Voltammetric redox potentials of carotenoids associated with the xanthophyll cycle in photosynthesis. Chemical Physics Letters, 415(4), 308-312. https://doi.org/10.1016/j.cplett.2005.09.010

Niki, E., Tsuchiya, J., Tanimura, R., \& Kamiya, Y.(1982). Regeneration of vitamin e from $\alpha$-chromanoxyl radical by glutathione and vitamin C. Chemistry Letters, 11(6), 789-792. https://doi.org/10.1246/cl. 1982.789

O’Brien, P. J. (1969). Intracellular mechanisms for the decomposition of a lipid peroxide. I. Decomposition of a lipid peroxide by metal ions, heme compounds, and nucleophiles. Canadian Journal of Biochemistry, 47(5), 485-492. https://doi.org/10.1139/069-076

Olsen, E., Vogt, G., Saarem, K., Greibrokk, T., \& Nilsson, A. (2005). Autoxidation of cod liver oil with tocopherol and ascorbyl palmitate. Journal of the American Oil Chemists' Society, 82(2), 97-103. https://doi.org/10.1007/s11746-005-1049-6

Osborn-Barnes, H. T., \& Akoh, C. C. (2003a). Copper-catalyzed oxidation of a structured lipid-based emulsion containing $\alpha$ tocopherol and citric acid: Influence of $\mathrm{pH}$ and $\mathrm{NaCl}$. Journal of 
Agricultural and Food Chemistry, 51(23), 6851-6855. https://doi. org/10.1021/jf0261553

Osborn-Barnes, H. T., \& Akoh, C. C. (2003b). Effects of $\alpha$-tocopherol, $\beta$-carotene, and soy isoflavones on lipid oxidation of structured lipid-based emulsions. Journal of Agricultural and Food Chemistry, 51(23), 6856-6860. https://doi.org/10.1021/jf026212s

Packer, J. E., Slater, T. F., \& Willson, R. L. (1979). Direct observation of a free radical interaction between vitamin $\mathrm{E}$ and vitamin C. Nature, 278(5706), 737-738. https://doi.org/10.1038/ $278737 \mathrm{a} 0$

Panya, A., Kittipongpittaya, K., Laguerre, M., Bayrasy, C., Lecomte, J., Villeneuve, P., McClements, D. J., \& Decker, E. A. (2012). Interactions between $\alpha$-tocopherol and rosmarinic acid and its alkyl esters in emulsions: Synergistic, additive, or antagonistic effect? Journal of Agricultural and Food Chemistry, 60(41), 10320-10330. https://doi.org/10.1021/jf302673j

Pastoriza-Gallego, M. J., Sánchez-Paz, V., Losada-Barreiro, S., BravoDíaz, C., Gunaseelan, K., \& Romsted, L. S. (2009). Effects of temperature and emulsifier concentration on $\alpha$-tocopherol distribution in a stirred, fluid, emulsion. Thermodynamics of $\alpha$-tocopherol transfer between the oil and interfacial regions. Langmuir, 25(5), 2646-2653. https://doi.org/10.1021/la803224j

Paz Sánchez-Migallón, M., Aranda, F. J., \& Gómez-Fernández, J. C. (1996). Interaction between $\alpha$-tocopherol and heteroacid phosphatidylcholines with different amounts of unsaturation. Biochimica et Biophysica Acta (BBA) - Biomembranes, 1279(2), 251-258. https://doi.org/10.1016/0005-2736(95)00276-6

Pedrielli, P., \& Skibsted, L. H. (2002). Antioxidant synergy and regeneration effect of quercetin, (-)-epicatechin, and (+)-catechin on $\alpha$-tocopherol in homogeneous solutions of peroxidating methyl linoleate. Journal of Agricultural and Food Chemistry, 50(24), 71387144. https://doi.org/10.1021/jf0204371

Peers, K. E., \& Coxon, D. T. (1983). Controlled synthesis of monohydroperoxides by $\alpha$-tocopherol inhibited autoxidation of polyunsaturated lipids. Chemistry and Physics of Lipids, 32(1), 49-56. https: //doi.org/10.1016/0009-3084(83)90069-5

Peers, K. E., Coxon, D. T., \& Chan, H. W.-S. (1981). Autoxidation of methyl linolenate and methyl linoleate: The effect of $\alpha$-tocopherol. Journal of the Science of Food and Agriculture, 32(9), 898-904. https://doi.org/10.1002/jsfa.2740320908

Pennock, J. F., Hemming, F. W., \& Kerr, J. D. (1964). A reassessment of tocopherol chemistry. Biochemical and Biophysical Research Communications, 17(5), 542-548. https://doi.org/10.1016/ 0006-291X(64)90062-2

Pernin, A., Bosc, V., Soto, P., Le Roux, E., \& Maillard, M. N. (2019). Lipid oxidation in oil-in-water emulsions rich in omega-3: Effect of aqueous phase viscosity, emulsifiers, and antioxidants. European Journal of Lipid Science and Technology, 121(9), 1800462. https:// doi.org/10.1002/ejlt.201800462

Peyrat-Maillard, M. N., Cuvelier, M. E., \& Berset, C. (2003). Antioxidant activity of phenolic compounds in 2,2'-azobis (2amidinopropane) dihydrochloride (AAPH)-induced oxidation: Synergistic and antagonistic effects. Journal of the American Oil Chemists' Society, 80(10), 1007. https://doi.org/10.1007/ s11746-003-0812-Z

Player, M. E., Kim, H. J., Lee, H. O., \& Min, D. B. (2006). Stability of $\alpha$-, $\gamma$-, or $\delta$-tocopherol during soybean oil oxidation. Journal of Food Science, 71(8), C456-C460. https://doi.org/10.1111/j.1750-3841. 2006.00153.x
Porter, W. L. (1993). Paradoxical behavior of antioxidants in food and biological systems. Toxicology and Industrial Health, 9(1-2), 93-122. https://doi.org/10.1177/0748233793009001-209

Porter, W. L., Black, E. D., \& Drolet, A. M. (1989). Use of polyamide oxidative fluorescence test on lipid emulsions: Contrast in relative effectiveness of antioxidants in bulk versus dispersed systems. Journal of Agricultural and Food Chemistry, 37(3), 615-624. https://doi.org/10.1021/jf00087a009

Poyato, C., Navarro-Blasco, I., Calvo, M. I., Cavero, R. Y., Astiasarán, I., \& Ansorena, D. (2013). Oxidative stability of O/W and W/O/W emulsions: Effect of lipid composition and antioxidant polarity. Food Research International, 51(1), 132-140. https://doi. org/10.1016/j.foodres.2012.11.032

Rao, M. K. G., \& Achaya, K. T. (1967). Role of tocopherol as an antioxidant in safflower oil. Fette, Seifen, Anstrichmittel, 69(10), 711-714. https://doi.org/10.1002/lipi.19670691003

Rice-Evans, C. A., Miller, N. J., \& Paganga, G. (1996). Structureantioxidant activity relationships of flavonoids and phenolic acids. Free Radical Biology and Medicine, 20(7), 933-956. https://doi.org/ 10.1016/0891-5849(95)02227-9

Riisom, T., Sims, R. J., \& Fioriti, J. A. (1980). Effect of amino acids on the autoxidation of safflower oil in emulsions. Journal of the American Oil Chemists Society, 57(10), 354-359. https://doi.org/10. 1007/BF02662057

Rokosik, E., Siger, A., Rudzińska, M., \& Dwiecki, K. (2020). Antioxidant activity and synergism of canolol and $\alpha$-tocopherol in rapeseed oil is affected by the presence of phospholipid association colloids. LWT - Food Science and Technology, 133, 110095. https: //doi.org/10.1016/j.lwt.2020.110095

Salgado, J., Villalain, J., \& Gomezfernandez, J. C. (1993). $\alpha-$ tocopherol interacts with natural micelle-forming single-chain phospholipids stabilizing the bilayer phase. Archives of Biochemistry and Biophysics, 306(2), 368-376. https://doi.org/10.1006/ abbi.1993.1525

Samotyja, U., \& Małecka, M. (2007). Effects of blackcurrant seeds and rosemary extracts on oxidative stability of bulk and emulsified lipid substrates. Food Chemistry, 104(1), 317-323. https://doi. org/10.1016/j.foodchem.2006.11.046

Sánchez-Paz, V., Pastoriza-Gallego, M. J., Losada-Barreiro, S., BravoDíaz, C., Gunaseelan, K., \& Romsted, L. S. (2008). Quantitative determination of $\alpha$-tocopherol distribution in a tributyrin/Brij 30/water model food emulsion. Journal of Colloid and Interface Science, 320(1), 1-8. https://doi.org/10.1016/j.jcis.2007.12.018

Scarpa, M., Rigo, A., Maiorino, M., Ursini, F., \& Gregolin, C. (1984). Formation of $\alpha$-tocopherol radical and recycling of $\alpha$-tocopherol by ascorbate during peroxidation of phosphatidylcholine liposomes: An electron paramagnetic resonance study. Biochimica et Biophysica Acta (BBA) - General Subjects, 801(2), 215-219. https://doi.org/ 10.1016/0304-4165(84)90070-9

Schaich, K. M. (1992). Metals and lipid oxidation. Contemporary issues. Lipids, 27(3), 209-218. https://doi.org/10.1007/bf02536181

Schaich, K. M. (2005). Lipid oxidation: Theoretical aspects. In F. Shahidi (Ed.), Bailey's industrial oil and fat products (pp. 269-355). John Wiley \& Sons, Inc.

Schaich, K. M. (2012). Thinking outside the classical chain reaction box of lipid oxidation. Lipid Technology, 24(3), 55-58. https://doi. org/10.1002/lite.201200170

Schaich, K. M. (2020). Lipid oxidation: New perspectives on an old reaction. In F. Shahidi (Ed.), Bailey's industrial oil and fat 
products (pp. 1-72). John Wiley \& Sons, Inc. https://doi.org/10. 1002/047167849X.bio067.pub2

Schaich, K. M., Xie, J., \& Bogusz, B. A. (2017). Thinking outside the classical chain reaction box of lipid oxidation: Evidence for alternate pathways and the importance of epoxides. Lipid Technology, 29(9-10), 91-96. https://doi.org/10.1002/lite.201700025

Schröder, A., Laguerre, M., Sprakel, J., Schroën, K., \& BertonCarabin, C. C. (2020). Pickering particles as interfacial reservoirs of antioxidants. Journal of Colloid and Interface Science, 575, 489498. https://doi.org/10.1016/j.jcis.2020.04.069

Schwarz, K., Huang, S.-W., German, J. B., Tiersch, B., Hartmann, J., \& Frankel, E. N. (2000). Activities of antioxidants are affected by colloidal properties of oil-in-water and water-in-oil emulsions and bulk oils. Journal of Agricultural and Food Chemistry, 48(10), 48744882. https://doi.org/10.1021/jf991289a

Selmi, S., Limam, Z., Batista, I., Bandarra, N. M., \& Nunes, M. L. (2011). Effects of storage temperature and $\alpha$-tocopherol on oil recovered from sardine mince. International Journal of Refrigeration, 34(5), 1315-1322. https://doi.org/10.1016/j.ijrefrig.2010.08.018

Sen, C. K., Khanna, S., \& Roy, S. (2006). Tocotrienols: Vitamin E beyond tocopherols. Life Sciences, 78(18), 2088-2098. https://doi. org/10.1016/j.lfs.2005.12.001

Servili, M., \& Montedoro, G. (2002). Contribution of phenolic compounds to virgin olive oil quality. European Journal of Lipid Science and Technology, 104(9-10), 602-613. https://doi.org/10.1002/ 1438-9312(200210)104:9/10<602::aid-ejlt602〉3.0.co;2-X

Shahidi, F., \& Ambigaipalan, P. (2015). Phenolics and polyphenolics in foods, beverages and spices: Antioxidant activity and health effects - A review. Journal of Functional Foods, 18, 820-897. https: //doi.org/10.1016/j.jff.2015.06.018

Sharma, M. K., \& Buettner, G. R. (1993). Interaction of vitamin C and vitamin $\mathrm{E}$ during free radical stress in plasma: An ESR study. Free Radical Biology and Medicine, 14(6), 649-653. https://doi.org/10. 1016/0891-5849(93)90146-1

Siqueira Melo, P., de Oliveira Rodrigues Arrivetti, L., Matias de Alencar, S., \& Skibsted, L. H. (2016). Antioxidative and prooxidative effects in food lipids and synergism with $\alpha$-tocopherol of açaí seed extracts and grape rachis extracts. Food Chemistry, 213, 440-449. https://doi.org/10.1016/j.foodchem.2016.06.101

Slavova-Kazakova, A., \& Kancheva, V. D. (2017). Synergism between DL-alpha-tocopherol and ascorbyl palmitate at various ratios in binary antioxidant compositions. La Risvesta Italiana Delle Sostanze Grasse, 95, 75-88.

Soll, J., Kemmerling, M., \& Schultz, G. (1980). Tocopherol and plastoquinone synthesis in spinach chloroplasts subfractions. Archives of Biochemistry and Biophysics, 204(2), 544-550. https://doi.org/10. 1016/0003-9861(80)90066-1

Sørensen, A.-D. M., Durand, E., Laguerre, M., Bayrasy, C., Lecomte, J., Villeneuve, P., \& Jacobsen, C. (2014). Antioxidant properties and efficacies of synthesized alkyl caffeates, ferulates, and coumarates. Journal of Agricultural and Food Chemistry, 62(52), 12553-12562. https://doi.org/10.1021/jf500588s

Sørensen, A.-D. M., Villeneuve, P., \& Jacobsen, C. (2017). Alkyl caffeates as antioxidants in $\mathrm{O} / \mathrm{W}$ emulsions: Impact of emulsifier type and endogenous tocopherols. European Journal of Lipid Science and Technology, 119(6), 1600276. https://doi.org/10.1002/ejlt. 201600276

Stern, M. H., Robeson, C. D., Weisler, L., \& Baxter, J. G. (1947). $\delta$ Tocopherol. I. Isolation from soybean oil and properties. Journal of the American Chemical Society, 69(4), 869-874. https://doi.org/ 10.1021/ja01196a041

Sumarno, M., Atkinson, E., Suarna, C., Saunders, J. K., Cole, E. R., \& Southwell-Keely, P. T. (1987). Solvent influence on model oxidations of alpha-tocopherol. Biochimica Et Biophysica Acta, 920(3), 247-250. https://doi.org/10.1016/0005-2760(87)90101-9

Sure, B. (1924). Diatery requirements for reproduction II. The existence of a specific vitamin for reproduction. Journal of Biological Chemistry, 58, 693-709.

Terao, J., \& Matsushita, S. (1980). The isomeric compositions of monohydroperoxides produced by oxidation of unsaturated fatty acid esters with singlet oxygen. Journal of Food Processing and Preservation, 3(4), 329-337. https://doi.org/10.1111/j.1745-4549. 1980.tb00590.x

Terao, J., \& Matsushita, S. (1986). The peroxidizing effect of $\alpha$ tocopherol on autoxidation of methyl linoleate in bulk phase. Lipids, 21(4), 255-260. https://doi.org/10.1007/BF02536407

This Vo Kientza, H. (2016). "Maillard products" and "Maillard reactions" are much discussed in food science and technology, but do such products and reactions deserve their name? Academic Notes from the French Academy of Agriculture, 3, 1-10.

Thomas, M. J., \& Foote, C. S. (1978). Chemistry of singlet oxygenXXVI. Photooxygenation of phenols. Photochemistry and Photobiology, 27(6), 683-693. https://doi.org/10.1111/j.1751-1097.1978. tb07665.x

Uri, N. (1961). Mechanism of antioxidant. In W. O. Lundberg (Ed.), Autoxidation and antioxidants (Vol. 1, p. 133-169). Interscience.

Valenzuela, A., Sanhueza, J., \& Nieto, S. (2002). Differential inhibitory effect of alpha-, beta-, gamma-, and delta-tocopherols on the metal-induced oxidation of cholesterol in unilamellar phospholipid-cholesterol liposomes. Journal of Food Science, 67(6), 2051-2055. https://doi.org/10.1111/j.1365-2621.2002.tb09499.x

Wada, S., \& Fang, X. (1992). The synergistic antioxidant effect of rosemary extract and $\alpha$-tocopherol in sardine oil model system and frozen-crushed fish meat. Journal of Food Processing and Preservation, 16(4), 263-274. https://doi.org/10.1111/j.17454549.1992.tb00207.x

Wagner, K.-H., Wotruba, F., \& Elmadfa, I. (2001). Antioxidative potential of tocotrienols and tocopherols in coconut fat at different oxidation temperatures. European Journal of Lipid Science and Technology, 103(11), 746-751. https://doi.org/10.1002/ 1438-9312(200111)103:11<746::AID-EJLT746〉3.0.CO;2-P

Wagner, K., Isnardy, B., \& Elmadfa, I. (2004). $\gamma$ - and $\delta$-tocopherols are more effective than $\alpha$-tocopherol on the autoxidation of a $10 \%$ rapeseed oil triacylglycerol-in-water emulsion with and without a radical initiator. European Journal of Lipid Science and Technology, 106, 44-51.

Wang, X., Zhu, C., Peng, T., Zhang, W., Zhang, J., Liu, H., Wu, C., Pan, X., \& Wu, C. (2018). Enhanced stability of an emulsion enriched in unsaturated fatty acids by dual natural antioxidants fortified in both the aqueous and oil phases. Food Hydrocolloids, 82, 322-328. https://doi.org/10.1016/j.foodhyd.2018.02.012

Wang, Y., Wu, C., Zhou, X., Zhang, M., Chen, Y., Nie, S., \& Xie, M. (2020). Combined application of gallate ester and $\alpha$-tocopherol in oil-in-water emulsion: Their distribution and antioxidant efficiency. Journal of Dispersion Science and Technology, 41(6), 909917. https://doi.org/10.1080/01932691.2019.1614033 
Waraho, T., McClements, D. J., \& Decker, E. A. (2011). Mechanisms of lipid oxidation in food dispersions. Trends in Food Science \& Technology, 22(1), 3-13. https://doi.org/10.1016/j.tifs.2010.11.003

Warner, K. (2005). Effects on the flavor and oxidative stability of stripped soybean and sunflower oils with added pure tocopherols. Journal of Agricultural and Food Chemistry, 53(26), 9906-9910. https://doi.org/10.1021/jf0517593

Waters, W. A. (1971). The kinetics and mechanism of metal-catalyzed autoxidation. Journal of the American Oil Chemists' Society, 48(9), 427-433. https://doi.org/10.1007/BF02544654

Wefers, H., \& Sies, H. (1988). The protection by ascorbate and glutathione against microsomal lipid peroxidation is dependent on vitamin E. European Journal of Biochemistry, 174(2), 353-357. https: //doi.org/10.1111/j.1432-1033.1988.tb14105.x

Weng, X. C., \& Gordon, M. H. (1993). Antioxidant synergy between phosphatidyl ethanolamine and $\alpha$-tocopherylquinone. Food Chemistry, 48(2), 165-168. https://doi.org/10.1016/0308-8146(93) 90051-G

Whittle, K. J., Dunphy, P. J., \& Pennock, J. F. (1966). The isolation and properties of $\delta$-tocotrienol from Hevea latex. Biochemical Journal, 100(1), 138-145. https://doi.org/10.1042/bj1000138

Wood, P. M. (1988). The potential diagram for oxygen at $\mathrm{pH} 7$. The Biochemical Journal, 253(1), 287-289. https://doi.org/10.1042/ bj 2530287

Xenakis, A., Papadimitriou, V., \& Sotiroudis, T. G. (2010). Colloidal structures in natural oils. Current Opinion in Colloid \& Interface Science, 15(1), 55-60. https://doi.org/10.1016/j.cocis.2009.11.007

Yamagata, S., Murakami, H., Terao, J., \& Matsushita, S. (1983). Nonenzymatic oxidation products of methyl arachidonate. Agricultural and Biological Chemistry, 47(12), 2791-2799. https://doi. org/10.1080/00021369.1983.10866033

Yamaoka, M., Tanaka, A., \& Kato, A. (1985). Antioxidative activity of tocotrienols. Journal of Japan Oil Chemists' Society, 34(2), 120-121. https://doi.org/10.5650/jos1956.34.120

Yamauchi, R., \& Matsushita, S. (1977). Quenching effect of tocopherols on the methyl linoleate photooxidation and their oxidation products. Agricultural and Biological Chemistry, 41(8), 1425-1430. https://doi.org/10.1080/00021369.1977.10862693

Yang, W., Cahoon, R. E., Hunter, S. C., Zhang, C., Han, J., Borgschulte, T., \& Cahoon, E. B. (2010). Vitamin E biosynthesis: Functional characterization of the monocot homogentisate geranylgeranyl transferase. The Plant Journal, 65(2), 206-217. https: //doi.org/10.1111/j.1365-313X.2010.04417.x

Yanishlieva, N. V., Kamal-Eldin, A., Marinova, E. M., \& Toneva, A. G. (2002). Kinetics of antioxidant action of $\alpha$ - and $\gamma$-toco-pherols in sunflower and soybean triacylglycerols. European Journal of Lipid Science and Technology, 104(5), 262-270. https://doi.org/10.1002/ 1438-9312(200205)104:5〈262::aid-ejlt262〉3.0.co;2-b

Yi, B., Kim, M. J., \& Lee, J. (2018). Oxidative stability of oil-inwater emulsions with -tocopherol, charged emulsifier, and different oxidative stress. Food Science and Biotechnology, 27(6), 15711578. https://doi.org/10.1007/s10068-018-0407-0

Yi, J., Andersen, M. L., \& Skibsted, L. H. (2011). Interactions between tocopherols, tocotrienols and carotenoids during autoxidation of mixed palm olein and fish oil. Food Chemistry, 127(4), 1792-1797. https://doi.org/10.1016/j.foodchem.2011.02.061

Yi, J., Dong, W., Zhu, Z., Liu, N., Ding, Y., McClements, D. J., \& Decker, E. A. (2015). Surfactant concentration, antioxidants, and chelators influencing oxidative stability of water-in-walnut oil emulsions. Journal of the American Oil Chemists' Society, 92(8), 1093-1102. https://doi.org/10.1007/s11746-015-2675-7

Yi, O.-S., Han, D., \& Shin, H.-K. (1991). Synergistic antioxidative effects of tocopherol and ascorbic acid in fish oil/lecithin/water system. Journal of the American Oil Chemists Society, 68(11), 881883. https://doi.org/10.1007/bf02660606

Yin, J., Becker, E. M., Andersen, M. L., \& Skibsted, L. H. (2012). Green tea extract as food antioxidant. Synergism and antagonism with $\alpha$-tocopherol in vegetable oils and their colloidal systems. Food Chemistry, 135(4), 2195-2202. https://doi.org/10.1016/j.foodchem. 2012.07.025

Yoshida, Y., Niki, E., \& Noguchi, N. (2003). Comparative study on the action of tocopherols and tocotrienols as antioxidant: Chemical and physical effects. Chemistry and Physics of Lipids, 123(1), 63-75. https://doi.org/10.1016/S0009-3084(02)00164-0

Yoshida, Y., Saito, Y., Jones, L. S., \& Shigeri, Y. (2007). Chemical reactivities and physical effects in comparison between tocopherols and tocotrienols: Physiological significance and prospects as antioxidants. Journal of Bioscience and Bioengineering, 104(6), 439-445. https://doi.org/10.1263/jbb.104.439

Yoshida, Y., Tsuchiya, J., \& Niki, E. (1994). Interaction of $\alpha$-tocopherol with copper and its effect on lipid peroxidation. Biochimica et Biophysica Acta (BBA) - General Subjects, 1200(2), 85-92. https://doi. org/10.1016/0304-4165(94)90121-X

Zaunschirm, M., Pignitter, M., Kienesberger, J., Hernler, N., Riegger, C., Eggersdorfer, M., \& Somoza, V. (2018). Contribution of the ratio of tocopherol homologs to the oxidative stability of commercial vegetable oils. Molecules, 23(1), 206. https://doi.org/10.3390/ molecules23010206

Zeng, M., Heine, N., \& Wilson, K. R. (2020). Evidence that Criegee intermediates drive autoxidation in unsaturated lipids. Proceedings of the National Academy of Sciences, 117(9), 4486-4490. https: //doi.org/10.1073/pnas.1920765117

Zhong, Y., \& Shahidi, F. (2012). Antioxidant behavior in bulk oil: Limitations of polar paradox theory. Journal of Agricultural and Food Chemistry, 60(1), 4-6. https://doi.org/10.1021/jf204165g

Zhou, B., Wu, L.-M., Yang, L., \& Liu, Z.-L. (2005). Evidence for $\alpha$ tocopherol regeneration reaction of green tea polyphenols in SDS micelles. Free Radical Biology and Medicine, 38(1), 78-84. https:// doi.org/10.1016/j.freeradbiomed.2004.09.023

Zou, L., \& Akoh, C. C. (2015). Oxidative stability of structured lipidbased infant formula emulsion: Effect of antioxidants. Food Chemistry, 178, 1-9. https://doi.org/10.1016/j.foodchem.2015.01.073

Zuta, P. C., Simpson, B. K., Zhao, X., \& Leclerc, L. (2007). The effect of $\alpha$-tocopherol on the oxidation of mackerel oil. Food Chemistry, 100(2), 800-807. https://doi.org/10.1016/j.foodchem.2005.11.003

How to cite this article: Barouh, N., Bourlieu-Lacanal, C., Figueroa-Espinoza, M. C., Durand, E., \& Villeneuve, P. (2021). Tocopherols as antioxidants in lipid-based systems: The combination of chemical and physicochemical interactions determines their efficiency. Compr Rev Food Sci Food Saf. 1-47.

https://doi.org/10.1111/1541-4337.12867 